Aus der Poliklinik für Präventive Zahnmedizin, Parodontologie und Kariologie

(Prof. Dr. med. dent. A. Wiegand)

im Zentrum der Zahn-, Mund- und Kieferheilkunde

der Medizinischen Fakultät der Universität Göttingen

\title{
Einfluss verschiedener Präparationstechniken \\ bei geraden und gekrümmten Wurzelkanälen auf die Entstehung von Mikrorissen im Dentin
}

\section{Eine Mikro-Computertomografie-Studie}

\author{
INAUGURAL-DISSERTATION \\ zur Erlangung des Doktorgrades \\ für Zahnmedizin \\ der Medizinischen Fakultät \\ der Georg-August-Universität zu Göttingen \\ vorgelegt von \\ Juliane Krämer \\ aus \\ Jena
}

Göttingen 2021 
Dekan:

Betreuungsausschuss

Betreuer/in:

Ko-Betreuer/in:

\section{Prüfungskommission}

Referent/in:

Ko-Referent/in:

Drittreferent/in:
Prof. Dr. med. W. Brück

Prof. Dr. med. dent. T. Rödig

PD Dr. med. dent. W. Hahn
Prof. Dr. med. dent. T. Rödig

PD Dr. med. dent. W. Hahn

Prof. Dr. med. T. Meyer

Datum der mündlichen Prüfung: 27.01.2022 
Hiermit erkläre ich, die Dissertation mit dem Titel „Einfluss verschiedener Präparationstechniken bei geraden und gekrümmten Wurzelkanälen auf die Entstehung von Mikrorissen im Dentin: Eine Mikro-Computertomografie-Studie“ eigenständig angefertigt und keine anderen als die von mir angegebenen Quellen und Hilfsmittel verwendet zu haben.

Göttingen, den 25.05.2021

Juliane Krämer 
Die vorliegende Promotionsschrift war die Grundlage für folgende Veröffentlichung:

Rödig T, Krämer J, Müller C, Wiegand, Haupt F, Rizk M (2019):

Incidence of microcracks after preparation of straight and curved root canals with three different NiTi instrumentation techniques assessed by micro-CT. Aust Endod $\mathrm{J} \underline{45}, 394-399$ 


\section{Inhaltsverzeichnis}

Abbildungsverzeichnis ..............................................................................

Tabellenverzeichnis .................................................................................... IV

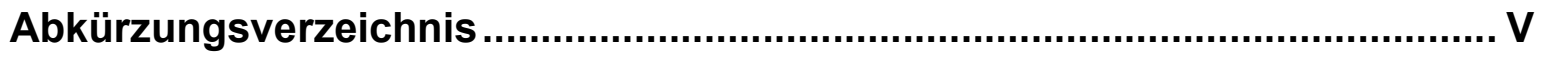

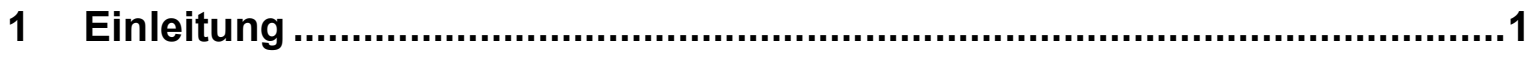

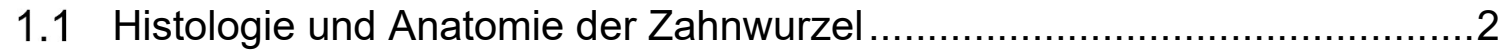

1.2 Pathogenese endodontischer Erkrankungen...........................................

1.3 Das Ziel einer Wurzelkanalbehandlung und ihre Prognose .........................5

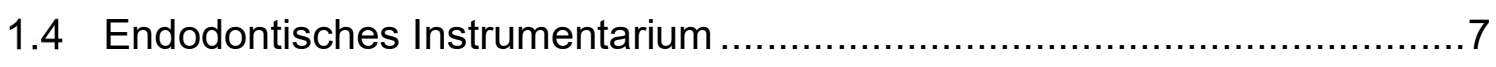

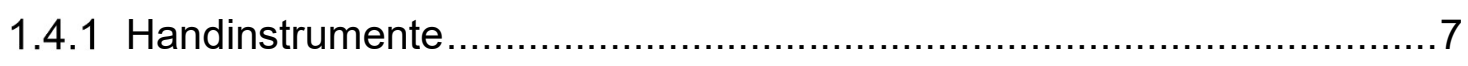

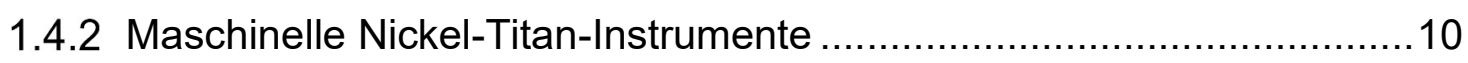

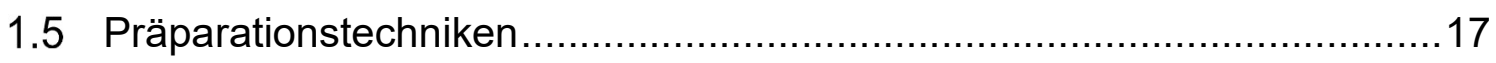

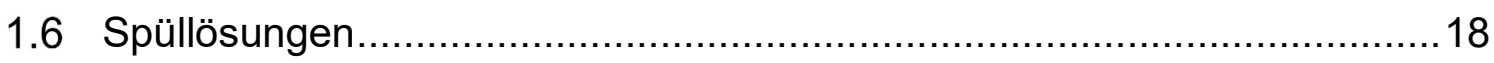

1.7 Bedeutung der Mikrorisse und Frakturen im Wurzeldentin......................20

1.7.1 Definition von Riss und Fraktur .................................................20

1.7.2 Die Ausbreitung von Rissen im Dentin ..........................................20

1.7.3 Klassifikation vertikaler Zahnfrakturen ..........................................21

1.7.4 Klinische Relevanz der Wurzelrisse und -frakturen ..........................22

1.8 Methoden zur Beurteilung von Mikrorissen im Wurzeldentin ...................23

1.8.1 Stereomikroskopische Untersuchung von Sägeschnitten ...................23

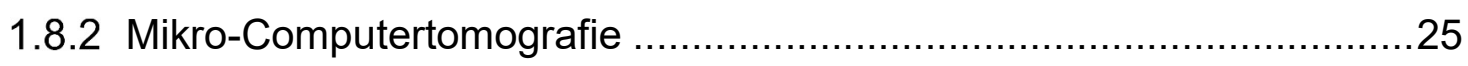

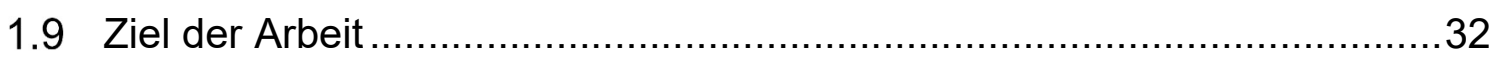

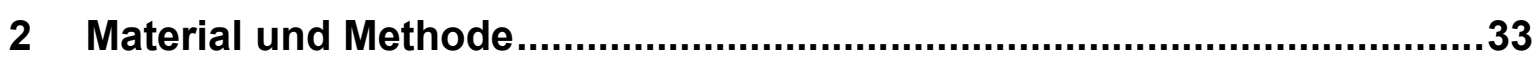

2.1 Zahnauswahl und Vorbereitung der Proben ..........................................33

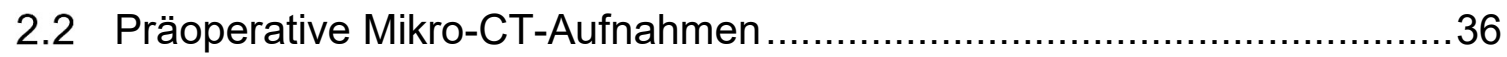

2.3 Rekonstruktion der präoperativen Mikro-CT-Aufnahmen .........................38

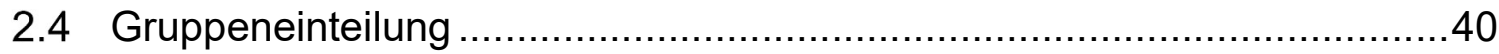




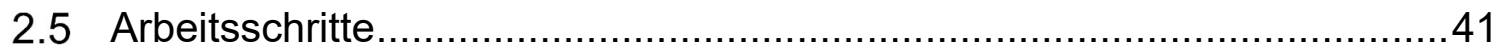

2.5.1 Herstellung des parodontalen Ligamentes ................................41

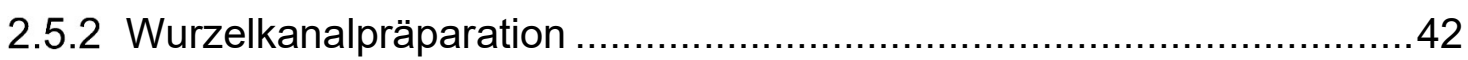

2.6 Postoperative Mikro-CT-Aufnahmen .......................................... 44

2.7 Rekonstruktion der postoperativen Mikro-CT-Aufnahmen und 3D-

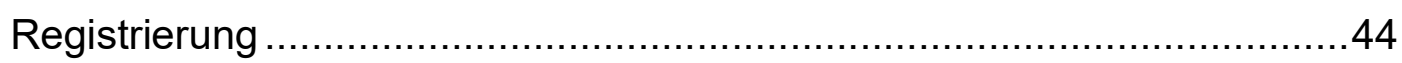

2.8 Auswahl der Schnittbilder und Analyse ...................................... 45

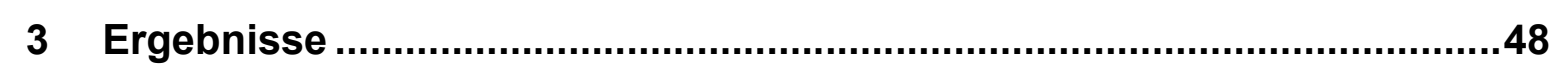

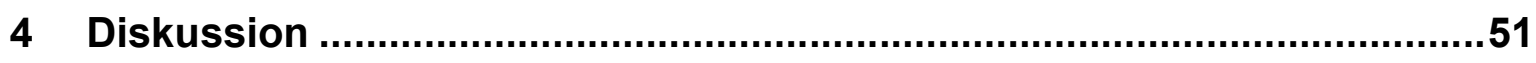

4.1 Diskussion von Material und Methode ......................................... 51

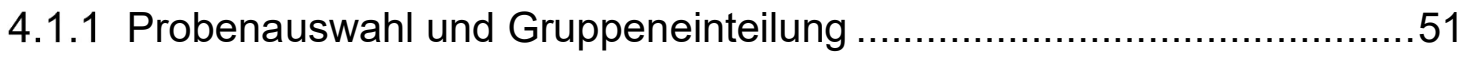

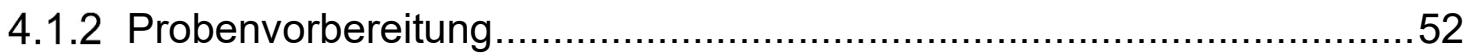

4.1.3 Instrumentenauswahl und Präparation.....................................53

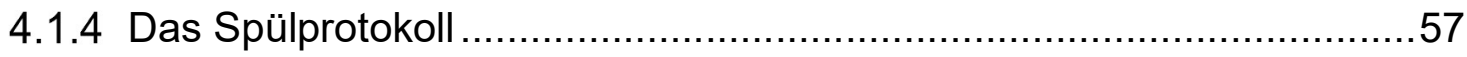

4.1.5 Darstellung der Mikrorisse und Bildbewertung ..............................58

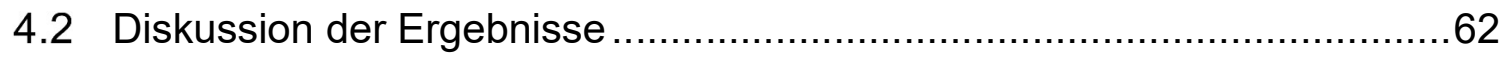

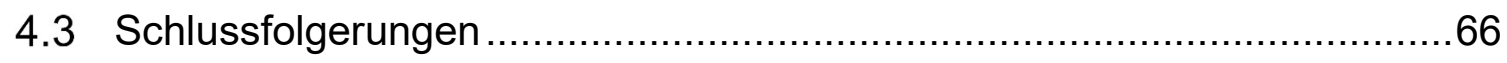

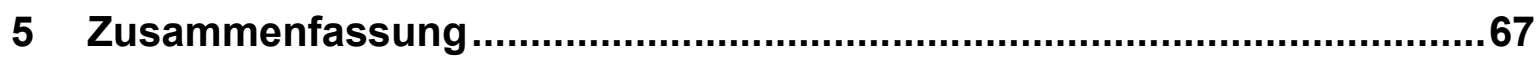

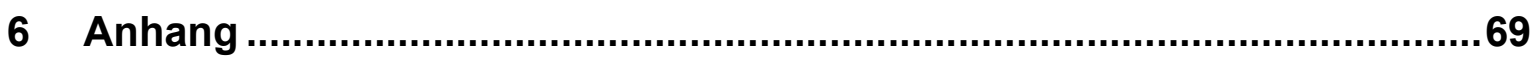

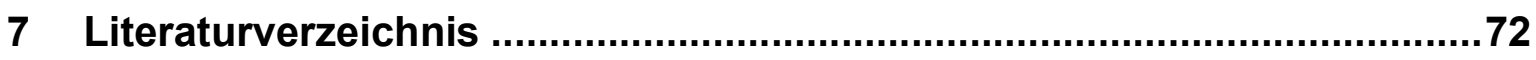




\section{Abbildungsverzeichnis}

Abbildung 1-1: Schematischer Aufbau eines ISO-normierten

Handinstrumentes.

Abbildung 1-2: Instrumentenquerschnitte von Reamern, K-Feilen und

Hedström-Feilen.

Abbildung 1-3: Zip und Elbow. 10

Abbildung 1-4: Reciproc-Instrument R25. .14

Abbildung 1-5: OneShape-Instrument 15

Abbildung 1-6: ProTaper NEXT-Instrument. 16

Abbildung 1-7: Schematische Darstellung des Rissverlaufs zwischen den Dentintubuli. .20

Abbildung 1-8: Schematische Darstellung von Frakturverläufen. 21

Abbildung 1-9: Schematischer Aufbau eines Mikro-CTs. 26

Abbildung 1-10: Beam-Hardening Correction.... .28

Abbildung 1-11: Ring Artefact Correction. .29

Abbildung 1-12: Post-Alignment Correction. .29

Abbildung 2-1: Bestimmung des Krümmungswinkels nach Schneider et al. (1971). .35

Abbildung 2-2: Positionierung der Probe im Trägerröhrchen (links) und Mikro-CT (rechts).

Abbildung 2-3: Metallische Artefakte im Wurzelkanal und der Außenfläche. 39

Abbildung 2-4: Herstellung des PDLs.

Abbildung 2-5: 3D-Registrierung.

Abbildung 2-6: Querschnittaufnahme mit einem positiv gewerteten Mikroriss. 46

Abbildung 2-7: Querschnittaufnahmen mit nicht als Mikroriss gewerteten Defekten.

Abbildung 3-1: Querschnittbilder vor und nach der Präparation mit RP,

OS und PTN an geraden Kanälen im Vergleich.

Abbildung 3-2: Querschnittbilder vor und nach der Präparation mit RP, OS und PTN an gekrümmten Kanälen im Vergleich. .50 


\section{Tabellenverzeichnis}

Tabelle 1-1: ISO-Farbkodierung und zugehöriger

Instrumentendurchmesser an der Feilenspitze.

.8

Tabelle 1-2: $\quad$ Übersicht über die verschiedenen Instrumente des Mehr-Feilen-Systems ProTaper NEXT. 16

Tabelle 2-1: Ein- und Ausschlusskriterien der Proben..................................33

Tabelle 2-2: Einstellungsparameter des Scans. ...................................... 37

Tabelle 2-3: Homogene Verteilung der Proben hinsichtlich ihrer

Wurzelkanalkrümmungswinkel. .40

Tabelle 2-4: Homogene Verteilung der Proben hinsichtlich ihrer Wurzelkanalradien. .40

Tabelle A-1: $\quad$ Liste verwendeter Materialien und Geräte. .69 


\section{Abkürzungsverzeichnis}

$\mathrm{AL}$

Arbeitslänge

Aqua dest.

Destilliertes Wasser

CCD

Charge-Coupled-Device

CT

Computertomografie

EDTA

Ethylendiamintetraessigsäure

HB

Härte Brinell

ISO

Internationale Organisation für Normung

LED

Licht emittierende Diode

MB

Megabyte

Mikro-CT

Mikro-Computertomografie

$\mathrm{NaOCl}$

Natriumhypochlorit

$\mathrm{NiTi}$

Nickel-Titan

OS

OneShape

PDL

Parodontales Ligament

PNG

Portable Network Graphics

PTN

ProTaper NEXT

$\mathrm{RP}$

Reciproc

TIFF

Tagged Image File Format 


\section{$1 \quad$ Einleitung}

Im klinischen Alltag der Zahnärzte nehmen die Zahnerhaltung und Prophylaxe parodontaler Erkrankungen einen großen Stellenwert ein. Extraktionen nicht erhaltungswürdiger Zähne und damit verbundener Zahnersatz sollen dabei so lange wie möglich vermieden werden. Der Erhalt von Zähnen mit einer langfristig guten Prognose ist daher von großer Bedeutung. Treten zum Beispiel in Folge von kariösen Läsionen oder traumatischen Verletzungen irreversible Schädigungen der Pulpa auf, kann eine Wurzelkanalbehandlung den Erhalt des Zahnes sowie zur Wiederherstellung gesunder Verhältnisse der periradikulären Gewebe ermöglichen.

Als ältestes Fachgebiet der Zahnheilkunde beschäftigt sich die Endodontologie neben der Anatomie und Funktion der Pulpa sowie der angrenzenden periradikulären Gewebe mit deren Erkrankungen, Diagnostik und Therapie. Innerhalb eines Zahnes bilden die Wurzelkanäle ein komplex verzweigtes System aus Haupt- und Seitenkanälen mit verschiedenen Krümmungen. Diese komplexe Anatomie stellt besondere Anforderungen an die Präparationsinstrumente, die verwendete Präparationstechnik, Desinfektion und Obturation des Hohlraumsystems.

Aufgrund der Materialeigenschaften der endodontischen Instrumente und Präparationstechniken beschränkte sich die Behandlung lange Zeit auf einwurzelige Zähne. Besonders durch die Weiterentwicklung der Legierungen und die Einführung von Nickel-Titan-Instrumenten wurde die Reinigung und Formgebung der Kanalsysteme erleichtert (Shen et al. 2013; Cassimiro et al. 2017). Im Gegensatz zu konventionellen Handinstrumenten aus Edelstahl zeichnen sich Nickel-TitanInstrumente durch ihre hohe Flexibilität aus und ermöglichen eine suffiziente Präparation gekrümmter Kanäle, wobei deren ursprünglicher Verlauf beinahe vollständig erhalten bleibt (Capar et al. 2014a). Inzwischen findet sich eine Vielzahl von Präparationssystemen auf dem Markt, die sich hinsichtlich der Instrumentengeometrie, Legierung, Kinematik und Anwendungssequenz unterscheiden. Der Einfluss dieser verschiedenen Parameter auf die Entstehung von Defekten im Wurzeldentin und daraus möglicherweise resultierenden Wurzellängsfrakturen steht seit einigen Jahren im Zentrum der endodontischen Forschung (Bier et al. 2009; Liu et al. 2013; Capar et al. 2014b; Karataş et al. 2015; Zuolo et al. 2017; Aksoy et al. 2019; Vieira et al. 2020). Derzeit liegen nur wenige Mikro-CT-Studien 
zur Entstehung von Mikrorissen im Dentin durch die Wurzelkanalpräparation bei ausschließlich geraden oder gekrümmten Kanälen mit vergleichbarer methodischer Versuchsdurchführung vor (De-Deus et al. 2014; 2015; 2016; Jamleh et al. 2015; Bayram et al. 2017b; Cassimiro et al. 2017; Li et al. 2017).

In der vorliegenden In-vitro-Untersuchung wurden drei maschinelle Präparationssysteme aus Nickel-Titan mit unterschiedlicher Instrumentenzahl und Kinematik unter standardisierten Bedingungen an geraden und gekrümmten Kanälen miteinander verglichen. Mit Hilfe prä- und postoperativer Mikro-CT-Aufnahmen wurde die Entstehung von Mikrorissen im Wurzeldentin beurteilt.

\subsection{Histologie und Anatomie der Zahnwurzel}

Für den Erfolg einer endodontischen Behandlung sind gute Kenntnisse über die Zahnanatomie und -histologie entscheidend. Den größten Masseanteil nimmt das Dentin ein. Koronal wird es vom Zahnschmelz überzogen, welches die klinische Krone formt. Das Wurzelzement bedeckt den Zahn am Wurzelanteil. Von hier aus ziehen vorwiegend kollagene Fasern (parodontales Ligament) als Verankerungselement des Zahnes zum Alveolarknochen.

Der Pulpahohlraum wird von Odontoblasten ausgekleidet, welche das Dentin mit ihren Zellfortsätzen (Tomes-Fasern) in leicht geschwungenen Kanälchen senkrecht bis zur Schmelz-Dentin-Grenze durchziehen. Diese Zellen sind für die Bildung des Dentins verantwortlich, wobei diese Substanz zeitlebens gebildet wird. Humanes Dentin besteht vorwiegend aus anorganischem Material $70 \mathrm{Gew} .-\%$, vor allem Apatit), zu 20 Gew.-\% aus anorganischer Matrix und zu 10 Gew.-\% aus Wasser (Deller 2018). Die Brinellhärte von Dentin beträgt 60-70 HB. Nach der Bildung von Primärdentin während der Zahnentwicklung sezernieren die Odontoblasten zeitlebens Sekundärdentin (Ricucci et al. 2018a). Nach Ricucci et al. (2018a) wird atubuläres tertiäres Dentin als Reaktion auf einen Reiz gebildet und die ursprüngliche Anzahl der Odontoblasten nimmt ab. Dabei scheint die radikuläre Pulpa früher und stärker von dieser Reduktion betroffen zu sein als die koronale Pulpa (Ricucci et al. 2018a). Des Weiteren befinden sich in der Pulpa Fibroblasten, freie Zellen der Immunabwehr sowie Blut- und Lymphgefäße. Ein dünn myelinisiertes Geflecht aus marklosen Nervenfasern (Raschkow-Plexus) liegt 
unterhalb der Odontoblasten. Ihre Axone ziehen mindestens $2 \mu \mathrm{m}$ weit in die Dentinkanälchen hinein (Deller 2018).

Die vom Pulpakammerboden beginnenden Wurzelkanäle durchziehen die Wurzeln vom Wurzelkanaleingang bis zum Foramen apicale. Dabei befindet sich mindestens ein Hauptkanal in einer Wurzel. Die Wurzelkanäle können dabei verschiedene Querschnittsformen annehmen, wie z. B. wie oval oder C-förmig. Zusätzlich können senkrechte oder schräg verlaufende Seitenkanäle vorhanden sein. Darüber hinaus sind weitere Foramina im Furkationsbereich, lateral zur Zahnachse verlaufend oder im apikalen Delta möglich. Neben diesen verschiedenen anatomischen Kanalausprägungen variieren die Wurzeln auch in Bezug auf die unterschiedlichen Ausprägungen der Wurzelkanalkrümmung. Eine erste Klassifikation, basierend auf einer mathematischen Betrachtung, stammt von Schneider (1971) und gilt bis heute. Wurzelkanäle mit eine Kanalkrümmung von $\leq 5^{\circ}$ gelten als gerade, eine Krümmung von $10-20^{\circ}$ als moderat und $25-70^{\circ}$ als stark gekrümmte Wurzelkanäle.

Die Bestimmung des Winkels erfolgt durch eine Röntgenbildanalyse, wobei die zweidimensionale Darstellung des Wurzelkanals beachtet werden muss. Die Methode zur Bestimmung der Wurzelkanalkrümmung wird an späterer Stelle erläutert (Kap. 2.1).

\subsection{Pathogenese endodontischer Erkrankungen}

Die Endodontologie beschäftigt sich als Teilbereich der Zahnmedizin mit der Anatomie, Funktion und Gesundheit, Verletzungen und Erkrankungen der Zahnpulpa sowie der periradikulären Region (European Society of Endodontology 2006), stets mit dem Ziel, einen Zahn und dessen umliegendes Gewebe langfristig und beschwerdefrei erhalten zu können. Dabei sollen je nach Symptom und Verlauf die vitale Pulpa erhalten bleiben, Schmerzen durch pulpale Entzündungen beseitigt, zerfallenes Pulpagewebe bei Nekrosen entfernt und die Resorption des Alveolarknochens und Wurzelzementes bei apikaler Parodontitis aufgehalten und die Wiederherstellung der periradikulären Gewebe bewirkt werden.

Neben profunden und in die Pulpa penetrierenden kariösen Läsionen können auch traumatische Verletzungen die bakterielle Infiltration des Pulpagewebes begünstigen (Kakehashi et al. 1965; Ricucci et al. 2018b). Die bakteriellen 
Endotoxine gelangen über freiliegende Dentintubuli zur Pulpa und können hier zu Entzündungsreaktionen führen (Nair 2006). Das Endodont bietet einen selektiven Lebensraum für die Anreicherung einer gemischten, vorwiegend anaeroben bakteriellen Flora (Nair 2004). Nach Takahama et al. (2018) wird eine nekrotische Pulpa von anaeroben Bakterien, wie Actinobakterien, Streptococcusspezien, Fusobakterien, Parvimonas micra und Porphyromonas endodontalis, dominiert.

In einer initialen zellulären Phase kommt es zur vermehrten Anwesenheit von Fibroblasten und undifferenzierten Zellen. Später finden sich zunehmend neutrophile Granulozyten, mononukleare Leukozyten, Lymphozyten, Makrophagen und Plasmazellen im Pulpagewebe. Im Rahmen der sich anschließenden vaskulären Phase wird die Durchblutung durch eine erhöhte Entstehungsrate an Kapillaren gesteigert (reaktive Hyperämie) (Cooper und Smith 2013). Die entstandene Entzündungsreaktion betrifft anfänglich lokale, sich an der Dentintubuligrenze befindliche Pulpaareale. Eine Ausschaltung des bakteriellen Reizes ermöglicht in diesem Stadium der Pulpitis eine erhöhte Kollagensynthese durch die Odontoblasten und die Bildung von Tertiärdentin, wodurch eine vollständige Regeneration der Pulpa möglich ist (reversible Pulpitis) (Staquet et al. 2011; Cooper und Smith 2013). Wird der kariöse Reiz nicht entfernt bzw. die Dentinwunde nicht abgedeckt, kommt es zur deutlichen Infiltration von Leukozyten und Granulozyten im Entzündungsbereich. Bedingt durch eine Degeneration der Odontoblasten verlieren sie ihre Fähigkeit, tertiäres Dentin zu bilden. Dabei treten partielle Gewebenekrosen der Pulpa auf, an dessen Grenze zur gesunden Pulpa eine erhöhte Phagozytose stattfindet. Durch eine nicht mehr ausreichende Immunantwort des Pulpagewebes findet eine fortschreitende Gewebszerstörung mit immer größeren Arealen von Nekrosen und Mikroabszessen (irreversible Pulpitis) bis hin zur vollständigen Pulpanekrose statt. In der Folge wird das nekrotische Pulpagewebe von Mikroorganismen besiedelt, deren Endotoxine zu entzündlichen Veränderungen der periradikulären Gewebe (apikale Parodontitis) führen (Ricucci und Siqueira 2010).

Unbehandelte Infektionen der Pulpa führen immer zu Entzündungen des periradikulären Gewebes und der Wurzelhaut mit Entstehung von Granulationsgewebe (Nair 2004). Während dieser periradikulären Entzündung können, je nach Bakterienspektrum, Entzündungsmediatoren, entzündungsfördernde Zytokine sowie Wachstumsfaktoren freigesetzt werden (Márton und Kiss 2014). Dieser 
Prozess führt im weiteren Verlauf der Erkrankung zur Gewebeeinschmelzung und Eiterbildung mit Abszedierung. Nach einer subperiostalen und submukösen Phase findet ein Abszess durch spontane Entleerung in das umliegende Weichgewebe oder durch intra- oder extraorale Fisteln Entlastung (Siqueira und Rocas 2013a). Des Weiteren kann eine partielle Entzündung oder lokale Nekrose der Pulpa zu internen Resorptionen der Wurzel führen (Gabor et al. 2012), welche ohne Therapie in perforierenden Defekten des Wurzeldentins resultieren können (Gabor et al. 2012). Radiologisch erkennbare, interradikuläre und laterale Läsionen weisen ebenfalls auf eine bakterielle Besiedelung des Wurzelkanalsystems hin. Auch Kronenfrakturen bei denen Bakterien in die Dentintubuli eindringen können oder etablierte Längs-frakturen im Wurzeldentin, welche einen Kontakt des periradikulären Gewebes mit der Pulpa ermöglichen, bieten Eintrittspforten für Mikroorganismen (Nair 2004; Rivera und Walton 2007).

Neben bakteriell bedingten Entzündungen des Pulpagewebes können auch iatrogene Ursachen ohne Beteiligung von Mikroorganismen eine irreversible Pulpitis verursachen. Sowohl präparative als auch prothetische Maßnahmen können sich negativ auf die Vitalität der Pulpa auswirken. Beispielsweise können durch eine ungenügende Wasserkühlung, zu starken Anpressdruck der Diamantbohrer oder eine zu starke Austrocknung des Dentins während einer Kavitäten- oder Kronenpräparation eine Entzündungsreaktion der Pulpa bis hin zur Nekrose begünstigen.

Ist das Stadium einer irreversiblen Pulpitis erreicht und der Zahn erhaltungswürdig, ist die vollständige Entfernung des Pulpagewebes im Rahmen einer Wurzelkanalbehandlung die Therapie der Wahl.

\subsection{Das Ziel einer Wurzelkanalbehandlung und ihre Prognose}

Das Ziel einer endodontischen Therapie ist es, die mikrobielle Belastung des Wurzelkanalsystems wesentlich zu reduzieren, vitales und nekrotisches Pulpagewebe vollständig zu entfernen und eine erneute Infektion durch eine Wurzelkanalfüllung und suffiziente koronale Restauration zu verhindern (Fuss et al. 1999; Nair 2006). Dies bildet die Voraussetzung, Entzündungen der periapikalen Gewebe zu verhindern bzw. ihre Ausheilung zu fördern. 
Das Wurzelkanalsystem wird durch die mechanische Wirkung endodontischer Präparationsinstrumente und die chemische Wirksamkeit von Spüllösungen, welche geeignete Voraussetzungen für die anschließende Füllung des Wurzelkanalsystems bieten, vorbereitet (Sousa-Neto et al. 2018). Während der Präparation soll die ursprüngliche Kanalkrümmung beibehalten und ein gleichmäßiger zirkulärer Substanzabtrag gewährleistet werden. Gleichzeitig soll die Wurzel durch die Instrumentierung nicht unnötig geschwächt werden (Capar et al. 2014a).

Das beste Behandlungsergebnis durch eine Wurzelkanalbehandlung wird erreicht, wenn die Wurzelkanalinfektion verhindert, beseitigt oder auf ein zur Heilung führendes Maß reduziert wird, welche mit einer Wiederherstellung der periradikulären Gewebe kompatibel ist. Der anatomische Verlauf der Wurzelkanäle, inre mikrobielle Belastung und die Konstitution der periapikalen Gewebe beeinflussen den Erfolg einer endodontischen Therapie.

Eine Behandlung gilt als erfolgreich, wenn Schmerzen langfristig beseitigt sowie Schwellungen und Fistelgänge geheilt sind. Ebenso sollte die röntgenologische Kontrolle des behandelten Wurzelsystems auch vier Jahre nach der Therapie keine entzündlichen Veränderungen an der Wurzelspitze und im periradikulären Bereich aufweisen. Die Definition und Interpretation des endodontischen Erfolges variieren zwischen den verschiedenen Studien. Unterschiede in der Länge der Beobachtungszeit, die für die Bewertung des Erfolgs verwendet wird, können zu Schwankungen der Erfolgs- oder Misserfolgsraten führen (Bender et al. 1966a, b). Mit einer Überlebensrate von $97 \%$ innerhalb von acht Jahren zeigt die endodontische Therapie eine gute Prognose (Salehrabi und Rotstein 2004). Ng et al. (2007) stellten in einer Metaanalyse fest, dass das Behandlungsergebnis neben einer hohlraumfreien, bis zum röntgenologischen Apex reichenden Wurzelkanalfüllung auch von einer suffizienten koronalen Restauration signifikant beeinflusst wird. Etwa 3\% der endodontisch behandelten Zähne erfordern jedoch innerhalb von drei Jahren nach der Wurzelkanalbehandlung eine weiterführende Therapie, wie Revision oder Wurzelspitzenresektion, einschließlich der Extraktion des Zahnes (Salehrabi und Rotstein 2004). 


\subsection{Endodontisches Instrumentarium}

Die Bearbeitung und Präparation des Wurzelkanals erfolgt mit Handinstrumenten und/oder maschinellen Instrumenten aus unterschiedlichen korrosionsfreien Legierungen. Um die Wände des Wurzelkanals während der Behandlung optimal zu bearbeiten, werden verschiedene Instrumententypen benötigt.

\subsubsection{Handinstrumente}

Um die Handinstrumente für die Wurzelkanalpräparation zu standardisieren, werden diese in der ISO-Norm 3630-1 beschrieben (International Organization for Standardization 2019). Durch die Norm werden Instrumenteneigenschaften, wie Durchmesser, Längen, Formen, Profile, Farbcodes, Symbolcodes oder mechanische Belastbarkeit definiert. Handinstrumente haben einen Griff mit anschließendem Schaft und schneidendem Arbeitsteil (Abbildung 1-1). Dieses Arbeitsteil unterliegt einer ISO-genormten Länge (ISO-Norm $16 \mathrm{~mm}$ ) (ISO 2019). Der Durchmesser D1 wird als theoretischer Durchmesser des zur Spitze verlängerten Kegels des Arbeitsteils definiert und in ISO-Stärke 1/100 mm angegeben (ISO 2019), z. B. ISO $15=0,15 \mathrm{~mm}$, ISO $20=0,20 \mathrm{~mm}$. Der Durchmesser D16 markiert bei ISO-genormten Instrumenten das Ende des Arbeitsteils. Die Durchmesserdifferenz von D1 und D16 beträgt 0,32 mm (ISO 2019).

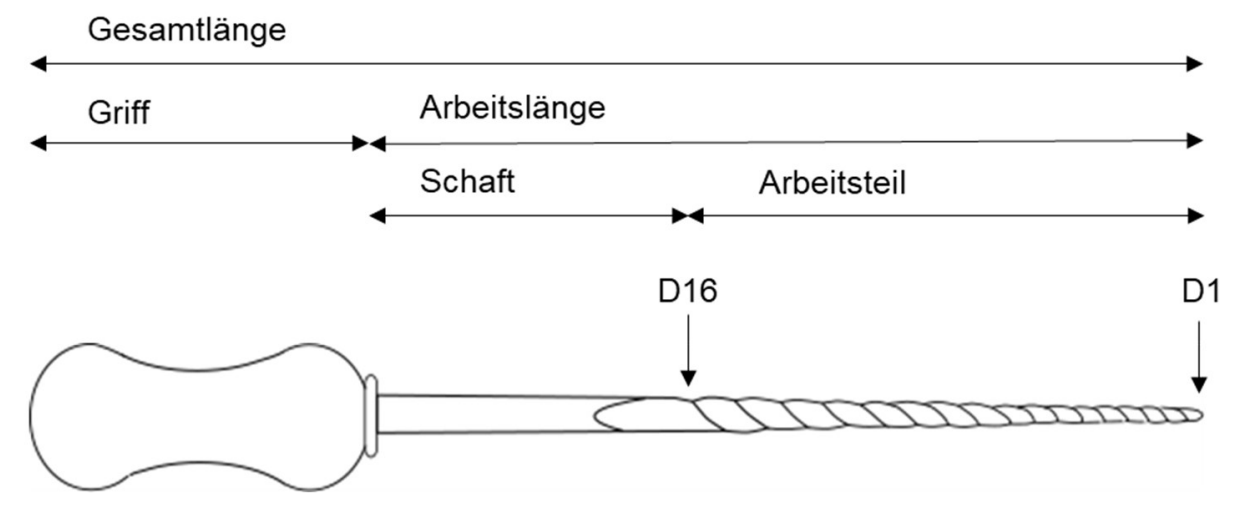

Abbildung 1-1: Schematischer Aufbau eines ISO-normierten Handinstrumentes.

D1 ist der theoretische Durchmesser des zur Spitze verlängerten Kegels des Arbeitsteils, D16 stellt den Durchmesser am Ende des Arbeitsteils dar, basierend auf Hellwig et al. (2003), S. 299. Die Verwendung erfolgt mit freundlicher Genehmigung des Elsevier Verlags, Urban \& Fischer. 
Handinstrumente werden in den ISO-Größen 06 bis 140 angeboten, welche entsprechend farblich kodiert sind (Tabelle 1-1). Alle Instrumente weisen über ihr Arbeitsteil eine Konizität auf, das bedeutet, dass der Instrumentendurchmesser pro Millimeter von der Instrumentenspitze (D1) bis zum Ende des Arbeitsteils (D16) zunimmt. Manuell verwendete Wurzelkanalinstrumente weisen eine ISO-genormte Konizität (Instrumentendurchmesserzunahme pro Millimeter) von 2\%, also einen Zuwachs von 0,02 mm pro Millimeter Arbeitsteil auf (ISO 2019).

Tabelle 1-1: ISO-Farbkodierung und zugehöriger Instrumentendurchmesser an der Feilenspitze.

\begin{tabular}{|l|l|l|}
\hline Größe & Farbe & $\varnothing$ Feilenspitze $(\mathrm{mm})$ \\
\hline 06 & rosa & 0,06 \\
\hline 08 & grau & 0,08 \\
\hline 10 & lila & 0,10 \\
\hline 15 & weiß & 0,15 \\
\hline 20 & gelb & 0,20 \\
\hline 25 & rot & 0,25 \\
\hline 30 & blau & 0,30 \\
\hline 35 & grün & 0,35 \\
\hline 40 & schwarz & 0,40 \\
\hline 45 & weiß & 0,45 \\
\hline 50 & gelb & 0,50 \\
\hline
\end{tabular}

Herkömmliche manuelle Präparationsinstrumente bestehen in der Regel aus Edelstahl mit verschiedenen Instrumentenquerschnitten (Abbildung 1-2) und können in drei Typen (Reamer, Hedström-Feile, K-Feile) eingeteilt werden.

Reamer werden aus dreieckigen oder quadratischen, maschinell verdrilten Rohlingen hergestellt. Der Schneidekantenwinkel (Winkel der Schneide zu seiner Längsachse) beträgt $10-30^{\circ}$. Die Feile wird mit einer drehend-schabenden Bewegung zur Erschließung des Wurzelkanals verwendet. Anschließend verwendete Hedström-Feilen erfordern Aufgrund ihres Schneidwinkels $\left(60-65^{\circ}\right)$ und geringen Kerndurchmessers eine lineare Arbeitsweise im Wurzelkanal. Die aus runden Rohlingen gefrästen Instrument entfernen bei leichtem Anpressdruck effizient Dentin aus dem Wurzelkanal. Die alternative Verwendung von K-Feilen 
erlaubt durch ihren Schneidekantenwinkel von $25-40^{\circ}$ sowohl eine drehende als auch eine schabende Bewegung im Wurzelkanal.

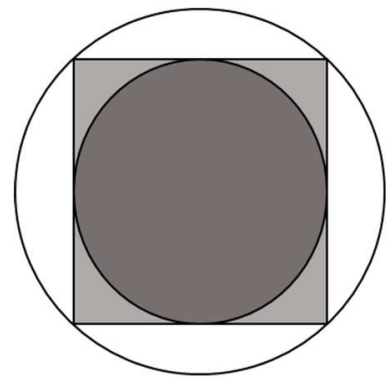

Reamer und K-Feilen mit quadratischem Querschnitt

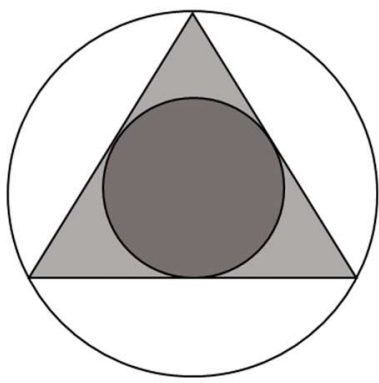

Reamer und K-Feilen mit dreieckigem Querschnitt

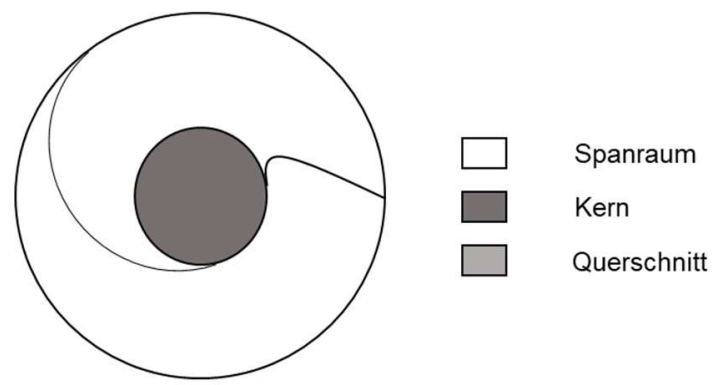

Hedström-Feile

Abbildung 1-2: Instrumentenquerschnitte von Reamern, K-Feilen und Hedström-Feilen.

Je nach Querschnittsform unterscheiden sie sich hinsichtlich ihres Spanraums und Kerndurchmessers, basierend auf Hellwig et al. (2003), S. 301. Die Verwendung erfolgt mit freundlicher Genehmigung des Elsevier Verlags, Urban \& Fischer.

Je größer der Krümmungswinkel und je kleiner der Krümmungsradius des Wurzelkanals ist, desto weniger sind die manuellen Instrumente aufgrund ihrer begrenzten Flexibilität in der Lage, den Kanal verlaufsgerecht zu präparieren (Weine et al. 1975; Esposito und Cunningham 1995; Schäfer et al. 2002). Begradigungen des Kanalverlaufs und daraus resultierende laterale oder apikale Perforationen sollen unbedingt vermieden werden. Bedingt durch die starke Tendenz der Handinstrumente sich in ihre ursprüngliche Ausgangsform zurückzustellen, wird bei gekrümmten Wurzelkanälen besonders im koronalen Bereich der innere Kanalabschnitt präpariert, im apikalen Abschnitt die äußere Kurvatur. Dadurch kommt es im mittleren Abschnitt der Kanalkrümmung zu einer wenig präparierten Engstelle (Elbow) (Weine et al. 1975). Außerdem kann es durch die vermehrte Präparation der äußeren apikalen Kurvatur im Bereich des apikalen Stopps zur Ausbildung einer trichterförmigen Aussackung (Zipping) (Weine et al. 1975), bis hin zur apikalen Perforation (Abbildung 1-3) kommen. 


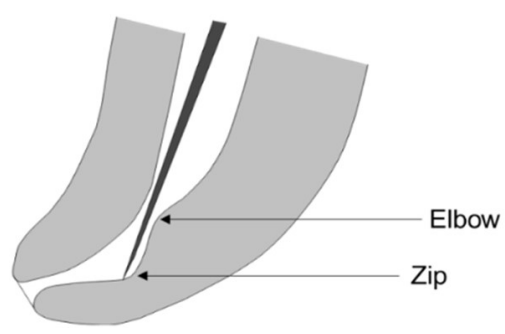

Abbildung 1-3: Zip und Elbow.

Häufig auftretender Fehler durch Präparation mit starren Instrumenten mit wenig präpariertem Elbow und trichterförmiger Aussackung (Zip), basierend auf Hellwig et al. (2003), S. 310. Die Verwendung erfolgt mit freundlicher Genehmigung des Elsevier Verlags, Urban \& Fischer.

Eine vermehrte Bearbeitung der inneren Kurvatur des mittleren Kanalabschnittes erhöht die Gefahr einer lateralen Wurzelperforation. Des Weiteren kann es durch die Instrumenteneigenschaften zur Stufenbildung an der Kanalaußenwand bis hin zur falsch ausgerichteten Präparation (Via falsa) kommen (Weine et al. 1975; Esposito und Cunningham 1995; Schäfer et al. 2002). Um diese Risiken zu minimieren, wurden flexiblere Wurzelkanalpräparationsinstrumente aus NickelTitan-Legierungen entwickelt.

\subsubsection{Maschinelle Nickel-Titan-Instrumente}

Der bemerkenswerteste Fortschritt hinsichtlich der mechanischen Präparation des Wurzelkanalsystems im letzten Jahrhundert war die Entwicklung von Instrumenten aus Nickel-Titan-Legierungen (Versiani et al. 2015). Diese Legierung zählt zu den Formgedächtnislegierungen (shape memory alloy) und hat die Eigenschaft, nach einer starken Verformung temperaturunabhängig die Ausgangsform wieder anzunehmen. Im Jahr 1958 wurde die Legierung im Naval Ordnance Laboratory (White Oak, MD, USA) entwickelt und wird auch als Nitiol bezeichnet (Chaudhari et al. 2019). Der Name Nitinol ist ein Akronym für "Nickel Titanium Naval Ordnance Laboratory". Für den dentalen Gebrauch werden in der Regel Rohlinge aus 55-Nitiol verwendet, welche zu $55 \mathrm{~m} \%$ aus Nickel und $45 \mathrm{~m} \%$ aus Titan bestehen und durch Fräsung hergestellt werden (Thompson 2000). Nitinol ist aufgrund seiner hohen Korrosions- und Verschleißfestigkeit, Pseudoelastizität und Biokompatibilität ein bevorzugtes Material speziell für biomedizinische Anwendungen (Henderson und 
Buis 2011; Mohd Jani et al. 2014). Maschinelle NiTi-Instrumente wurden erstmals in den 1990er Jahren auf den Markt gebracht (Sousa-Neto et al. 2018).

Aufgrund ihrer Flexibilität, erhöhten Torsionsfestigkeit und Beibehaltung der ursprünglichen Kanalkrümmung ermöglichen sie einen Einsatz in einer kontinuierlich rotierenden oder reziproken Bewegung. Diese wiederum reduziert die Arbeitszeit, die Ermüdung des Behandlers und das Risiko von Betriebsunfällen (Ceyhanli et al. 2016; Sousa-Neto et al. 2018). Im Vergleich zur Präparation mit Edelstahlinstrumenten führt die Verwendung maschineller Nickel-Titan-Instrumente zu besserer Formgebung, weniger Kanalbegradigung, einem geringeren apikalen Transport von Dentinspänen sowie einem geringeren Perforationsrisiko (Esposito und Cunningham 1995; Jamleh et al. 2015). Nach Peters und Barbakow (2002) sind NiTi-Instrumente ermüdungsresistenter als Stahlfeilen, dennoch können auch sie während des klinischen Einsatzes unerwartet brechen. Feilenbrüche treten unter anderem aufgrund von plastischer Verformung bei erhöhter Drehmomentbelastung oder zyklischer Ermüdung auf (Özyürek et al. 2018).

Eine vielversprechende Lösung zur Verbesserung der Dauerfestigkeit von rotierenden Instrumenten besteht daher darin, die Mikrostruktur von NiTiLegierungen durch neuartige thermomechanische Verfahren oder neue Fertigungstechnologien zu optimieren. Viele Hersteller wenden vor oder nach der Fräsung der NiTi-Instrumente eine Wärmebehandlung an, wobei eine NiTi-Formgedächtnislegierung mit verbesserter Flexibilität und Beständigkeit gegen zyklische Ermüdung entsteht (Ye und Gao 2012; Özyürek et al. 2018). Die NiTi-Formgedächtnislegierung kann in zwei verschiedenen temperaturabhängigen Kristallstrukturen (Phasen) vorliegen, die Martensit-Phase (Niedertemperaturphase, kubisch raumzentrierte Kristallstruktur) oder Austenit-Phase (Hochtemperaturphase, kubisch flächenzentrierte Kristallstruktur) genannt wird (Shen et al. 2013).

Wenn Martensit erhitzt wird, beginnt es sich über eine Zwischenphase (R-Phase) mit rhomboedrischer Kristallstruktur in Austenit umzuwandeln. Die Temperatur, bei der dieser Umwandlungsprozess abgeschlossen ist (Austenit-Endtemperatur) und die Legierung ihre superelastische Eigenschaft aufweist, liegt bei herkömmlichen NiTi-Präparationsinstrumenten bei oder unter Raumtemperatur (Rodrigues et al. 2016). Die Legierung erhält damit die Fähigkeit, nach einer Verformung in ihre ursprüngliche Form zurückzukehren. 
Wird Austenit abgekühlt, erfolgt über die R-Phase die Umwandlung in Martensit (Shen et al. 2013). Hier liegt die Temperatur, die diesen Prozess abschließt (Martensit-Endtemperatur) deutlich über der Körpertemperatur (Rodrigues et al. 2016). Eine derartige Legierungsmodifikation findet bei den Controlled MemoryInstrumenten (CM-Wire) (DS Dental, Johnson City, TN, USA) Anwendung. Sie wurden im Jahr 2010 eingeführt (Shen et al. 2013) und liegen vorwiegend in der Martensit-Phase vor, wodurch die Feilen extrem flexibel und widerstandsfähig gegen zyklische Ermüdung sind. Ihnen fehlt die Formgedächtniseigenschaft (Shen et al. 2013; Rodrigues et al. 2016). Zu den CM-Wire-Instrumenten gehört z. B. HyFlex CM (Coltène/Whaledent, Altstätten, Schweiz).

Mehrere Studien wiesen eine höhere Bruch- und Verschleißfestigkeit der $M$ - und CM-Wire-Feilen im Vergleich zu konventionellen NiTi-Instrumenten nach (Ye und Gao 2012; Shen et al. 2013; Capar et al. 2014b). Unterschiede in der Schneidleistung der verschiedenen wärmebehandelten NiTi-Legierungen wurden bisher nicht festgestellt (Rodrigues et al. 2016).

Wärmebehandelte $M$-Wire-Instrumente (Dentsply Sirona, York, PA, USA) wurden im Jahr 2007 auf den Markt eingeführt (Shen et al. 2013). Zu den M-WireInstrumenten gehören ProFile GT Series X, ProFile Vortex und Vortex Blue (alle Dentsply Sirona). Die Legierung der M-Wire-Instrumente befindet sich in der RPhase (Shen et al. 2013; Rodrigues et al. 2016).

Die maschinellen Präparationsinstrumente werden mit Hilfe eines entsprechenden Winkelstücks betrieben und weisen in der Regel eine nicht schneidende Instrumentenspitze (Batt-Spitze) auf. NiTi-Instrumente werden mit 2-6\% oder sogar mit 12\%iger Konizität angeboten (Sousa-Neto et al. 2018). Zur besseren Orientierung hinsichtlich der Feilengrößen wird die Farbmarkierung der ISO-Norm häufig übernommen, wobei sich diese aufgrund der verschiedenen erhältlichen Konizitäten auf die Instrumentenspitze bezieht.

Um die Gefahr von Instrumentenfrakturen zu minimieren, stehen verschiedene Motoren für den Antrieb maschineller Instrumente zur Verfügung. Spezifische Werte für das Drehmoment und die Umdrehungszahl der jeweiligen Instrumente sind vorprogrammiert, können aber auch individuell eingestellt werden. Zusätzlich verfügen diese Motoren über die Funktion beim Erreichen des voreingestellten Drehmoments die Drehrichtung umzukehren (Autoreverse-Funktion) oder die 
Bewegung zu stoppen. Einige Hersteller haben eine elektronische Längenmessung in diese Motoren integriert (z. B. VDW Gold, VDW, München; EndoPilot Comfort, Schlumbohm, Hamburg; MM control, MicroMega Besançon, Frankreich). Neue Endodontie-Winkelstücke, welche mit einem entsprechenden Messgerät verbunden sind, besitzen ebenfalls die Funktion isolierte Messungen durchzuführen oder während der Präparation eine permanente Längenkontrolle zu gewährleisten (z. B. T1 LINE ENDO 6 L, Dentsply Sirona; TriAuto mini, Morita, Dietzenbach).

Nach Anforderung der Instrumentenhersteller ermöglichen diese Motoren entweder eine kontinuierliche Rotation oder eine reziproke Bewegung der Instrumente. Diese reziproke Bewegung ist als eine wiederholte Vorwärts- und Rückwärtsbewegung definiert (Grande et al. 2015). Die Arbeitsbewegung besteht dabei aus einer Bewegung gegen den Uhrzeigersinn (Schneidrichtung) und einer Bewegung im Uhrzeigersinn (Freigabe des Instruments) (Bürklein et al. 2013b). Eine vollständige Rotation des Instruments um die eigene Achse besteht dadurch aus mehreren Zyklen, woraus eine apikalwärts gerichtete Bewegung der Feile resultiert. Beispiele für reziprok rotierende Instrumente sind Reciproc und Reciproc Blue (beide VDW, München), WaveOne und WaveOne Gold (beide Dentsply Sirona).

Für die Präparation des Wurzelkanalsystems stehen NiTi-Systeme mit einem einzigen (z. B. Reciproc, VDW; OneShape, MicroMega; HyFlex EDM, Coltène/ Whaledent; F6 SkyTaper, Komet Dental/ Gebr. Brasseler, Lemgo) oder mehreren Instrumenten verschiedener Größen und Konizitäten (z. B. HyFlex CM, Coltène/ Whaledent; ProTaper Next, Dentsply Sirona; EndoWave, Morita; Mtwo, VDW) zur Verfügung.

Für die vorliegende Studie wurden drei verschiedene Nickel-Titan-Instrumente bzw. Präparationssysteme hinsichtlich ihres Einflusses auf die Entstehung von Mikrorissen in Wurzeldentin miteinander verglichen. Es wurden ein reziprokes EinFeilen-System (Reciproc, VDW), ein rotierendes Ein-Feilen-System (OneShape MicroMega) und ein rotierendes Mehr-Feilen-System (ProTaper NEXT, Dentsply Sirona) für die Wurzelkanalpräparation ausgewählt. 


\subsubsection{Reciproc}

Das aus M-Wire Nickel-Titan hergestellte Ein-Feilen-System Reciproc (RP) (Abbildung 1-4) der Firma VDW wurde im Jahr 2011 auf den Markt eingeführt. Für die unterschiedlich weiten Kanallumina stehen drei verschiedene Instrumente mit regressiver Konizität zur Verfügung. Das R25-Instrument besitzt an der Spitze einen Durchmesser von 0,25 mm und eine Konizität von $8 \%$ innerhalb der ersten drei Millimeter und wird bei Kanälen mit kleinem Durchmesser verwendet. Für größere Kanalquerschnitte steht das R40-Instrument zur Verfügung, das einen Spitzendurchmesser von 0,40 mm und eine Konizität von $6 \%$ innerhalb der ersten drei Millimeter aufweist. Das R50-Instrument verfügt über einen Durchmesser von $0,50 \mathrm{~mm}$ an der Spitze sowie eine initiale Konizität von $5 \%$ und eignet sich für weite Kanäle. Für die Bearbeitung von langen Kanälen stehen neben den Instrumenten mit einem $21 \mathrm{~mm}$ langen Arbeitsteil auch Feilen mit $25 \mathrm{~mm}$ und $31 \mathrm{~mm}$ langen Arbeitsteilen zur Verfügung. Alle Instrumente besitzen eine nicht schneidende Instrumentenspitze und sind durch einen S-förmigen Instrumentenquerschnitt (Abbildung 1-4) mit zwei Schneidekanten gekennzeichnet. Das Reciproc-System wurde für die Präparation des Wurzelkanals mit einem einzigen Instrument entwickelt (single file). Die Arbeitsbewegung erfolgt reziprok, wobei die Rotation in Schneidrichtung größer ist $\left(150^{\circ}\right)$, als in umgekehrter Richtung zur Freigabe des Instrumentes $\left(30^{\circ}\right)$ (Grande et al. 2015).

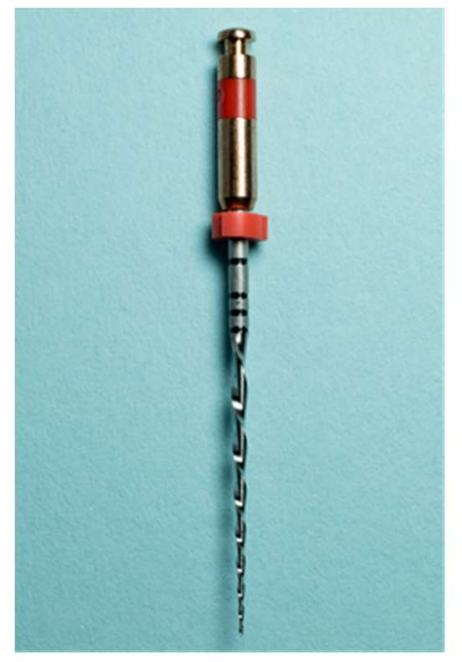

a)

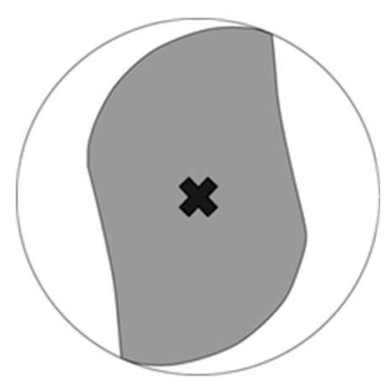

b)

Abbildung 1-4: Reciproc-Instrument R25.

a) Reciproc-Instrument R25 und b) Instrumentenquerschnitt. 


\subsubsection{OneShape}

Das rotierende Ein-Feilen-System OneShape (OS) (Abbildung 1-5) der Firma MicroMega wurde 2012 entwickelt. Dieses Instrument besteht aus einer herkömmlichen Austenit-55-Nickel-Titan-Legierung, weist an der Spitze einen Durchmesser von $0,25 \mathrm{~mm}$ und eine kontinuierliche Konizität von $6 \%$ über die gesamte Länge des Instrumentes auf. Laut Hersteller stehen Feilen mit 21 mm, 25 $\mathrm{mm}$ und $29 \mathrm{~mm}$ Länge zur Verfügung. Diese Feile schneidet mit einer $360^{\circ}$-Rotation im Uhrzeigersinn, wobei die Instrumentenspitze nicht schneidend ist. Der asymmetrische Querschnitt der Feile (Abbildung 1-5) ändert sich entlang ihrer Schneide, von einem dreieckigen Querschnitt mit drei Schneidekannten im apikalen Drittel zu einem S-förmigen mit zwei Schneidekannten im koronalen Abschnitt. Die unterschiedlichen Querschnitte reduzieren das aktive Einschrauben der Feile in das Dentin und bieten eine optimale Schneidwirkung ohne den Wurzelkanal zu begradigen (Bürklein et al. 2013b; 2017a).

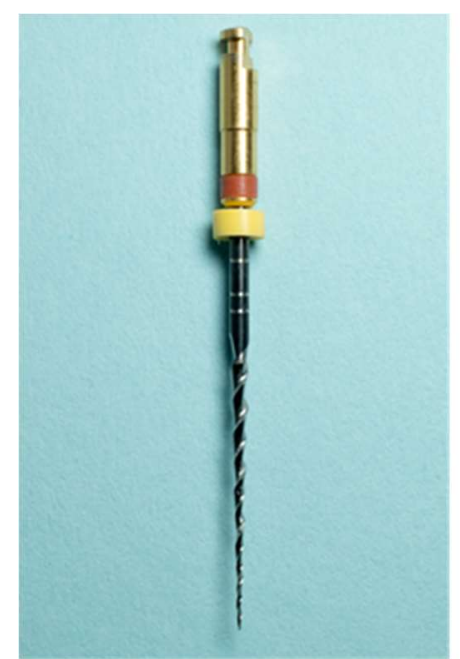

a)
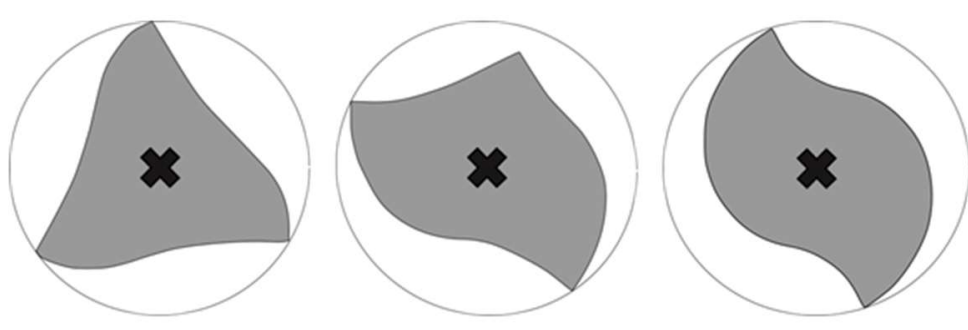

b)

c)

d)

Abbildung 1-5: OneShape-Instrument.

a) OneShape-Instrument und jeweiliger Instrumentenquerschnitt im b) apikalen Drittel, c) mittleren Drittel und d) koronalen Drittel. 


\subsubsection{ProTaper NEXT}

Die Firma Dentsply Sirona entwickelte 2013 das rotierende Mehr-Feilen-System ProTaper NEXT (PTN) (Abbildung 1-6). Die Instrumente bestehen aus M-WireNickel-Titan. Für die Präparation der Wurzelkanäle stehen fünf Instrumente zur Verfügung. Sie sind entsprechend der ISO-Farbskala kodiert. Die Tabelle 1-2 zeigt die unterschiedlichen Durchmesser und variablen Konizitäten in jedem Instrument.

Tabelle 1-2: Übersicht über die verschiedenen Instrumente des Mehr-Feilen-Systems ProTaper NEXT.

\begin{tabular}{|l|l|l|l|}
\hline & & Durchmesser & Konizität \\
\hline ProTaper NEXT & X1 & $0,17 \mathrm{~mm}$ & $4 \%$ \\
\hline & X2 & $0,25 \mathrm{~mm}$ & $6 \%$ \\
\hline & X3 & $0,30 \mathrm{~mm}$ & $7 \%$ \\
\hline & X4 & $0,40 \mathrm{~mm}$ & $6 \%$ \\
\hline & X5 & $0,50 \mathrm{~mm}$ & $6 \%$ \\
\hline
\end{tabular}

Alle Instrumente weisen einen exzentrischen, rechteckigen Querschnitt auf (Abbildung 1-6) der die Festigkeit und Flexibilität des aktiven Abschnittes verbessert.

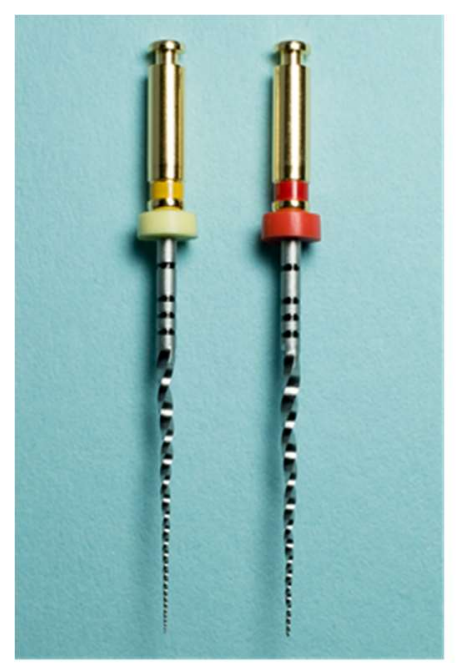

a)

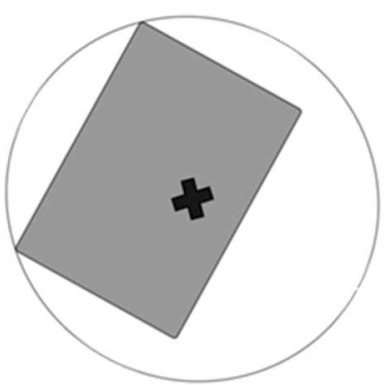

b)

Abbildung 1-6: ProTaper NEXT-Instrument.

a) ProTaper NEXT X1-Instrument links und ProTaper NEXT X2-Instrument rechts. b) Instrumentenquerschnitt. 
Nach Angaben des Herstellers führt das Design der Instrumente zu einer asymmetrischen Drehbewegung, die den Einschraubeffekt in das Dentin durch Minimierung der Kontaktfläche zwischen der Feile und der Dentinwand verringern soll (Capar et al. 2014b; De-Deus et al. 2015).

\subsection{Präparationstechniken}

Die Präparation gekrümmter Wurzelkanäle stellt eine erhöhte Schwierigkeit während der endodontischen Behandlung dar (Schneider 1971; Esposito und Cunningham 1995). Neben der Herausforderung, den Wurzelkanal durch die Instrumentierung nicht $\mathrm{zu}$ begradigen, sollen außerdem Perforationen oder Veränderungen des Kanalverlaufs verhindert werden (Weine et al. 1975). Die koronalen Bereiche des Wurzelkanals werden im ersten Schritt erweitert, so dass die nachfolgenden Instrumente spannungsfrei in den Kanal eingebracht werden können. Jaiswal et al. (2019) empfehlen die Anwendung von Gleitpfadfeilen, um den Kanal koronal zu erweitern und somit einen möglichst geraden Zugang zu den weiter apikal gelegenen Kanalabschnitten zu ermöglichen. Um die genannten Risiken zu minimieren, haben sich verschiedene Präparationstechniken etabliert, wobei sie sich hinsichtlich der Richtung des Dentinabtrags unterscheiden (Blum et al. 1999). Die Wurzelkanäle können apikal-koronal, koronal-apikal oder in Kombination aus beiden Richtungen und sowohl mit manuellen als auch mit maschinellen Instrumenten präpariert werden.

Die von Ingle (1961) empfohlene standardisierte Technik sieht vor, dass alle Präparationsinstrumente der Größe nach auf voller Arbeitslänge in den Kanal eingebracht werden, bis apikal der gewünschte Kanaldurchmesser erreicht ist (Single-Length-Technik). Die Instrumente haben bei dieser Technik über eine lange Strecke Friktion mit der Kanalwand, wodurch eine erhöhte Gefahr der Kanalbegradigung besteht und die apikale Präparation erschwert ist.

Als Weiterentwicklung der Standardtechnik gilt die erstmals von Clem (1969) beschriebene Step-back-Technik. Bei dieser apikal-koronalen Technik werden die Instrumente bis zu einer bestimmten ISO-Größe auf ganzer Arbeitslänge in den Kanal eingebracht. Die Präparationstiefe der letzten drei bis vier Instrumente wird im Anschluss bei jedem Step-back-Schritt jeweils um $1 \mathrm{~mm}$ Arbeitslänge verkürzt 
und somit die Konizität der Präparation erhöht. Nach Mullaney (1979) bietet diese Technik eine optimale Präparation moderat gekrümmter Kanäle.

Für besonders stark gekrümmte Wurzelkanäle eignet sich insbesondere die Crowndown-Technik (Goerig et al. 1982). Diese koronal-apikale Präparationstechnik wurde von Morgan und Montgomery (1984) entwickelt und ermöglicht durch eine primäre, stark konische Instrumentierung des koronalen Kanaldrittels einen frühen Abtransport von Dentinspänen mit Hilfe von Spüllösungen. Durch die frühzeitige Darstellung und Erweiterung des koronalen und mittleren Kanaldrittels wird ein geradliniger Zugang zum apikalen Drittel geschaffen. Hierfür werden häufig GatesGlidden-Bohrer oder speziellen Eingangserweiterer (One Flare, MicroMega; IntroFile, FlexMaster, VDW; PathFile, Dentsply Sirona) empfohlen. Die weitere Präparation des apikalen Kanalabschnittes wird mit Instrumenten abnehmender Größe bis zum Erreichen der vollständigen Arbeitslänge durchgeführt. Anschließend erfolgt die apikale Erweiterung mit Instrumenten größerer Konizität bis der gewünschte Kanaldurchmesser erreicht ist (Kimura et al. 2019).

Einige Hersteller bieten neuartige NiTi-Systeme mit nur einem Instrument für die gesamte Wurzelkanalpräparation an. Ein geradliniger, spannungsfreier koronaler Zugang ist wie auch bei den anderen Techniken von Bedeutung. Die Instrumente werden in leichten Auf- und Abbewegungen in den Wurzelkanal eingebracht, bis die vollständige Arbeitslänge erreicht ist. Dabei orientieren sich die Herstellervorgaben an der Crown-down-Technik. Neben einer verkürzten Arbeitszeit besteht ein weiterer Vorteil dieser Instrumente in der Reduzierung von Kosten und einer einfachen Handhabung (Yared 2008; Bürklein et al. 2013b).

\subsection{Spüllösungen}

Obwohl moderne Präparationsinstrumente den größten Teil des Kanalinhalts des Wurzelkanals entfernen und die Kanalwände mechanisch bearbeiten, bleibt mehr als $35 \%$ der Dentinoberfläche unberührt (Peters et al. 2001). Aus diesem Grund spielt die chemische Wirkung der Spüllösungen in allen Bereichen des Wurzelkanalsystems eine unverzichtbare Rolle, insbesondere in den für die Instrumentierung unzugänglichen Wurzelabschnitten. Die Anforderungen an Spüllösungen sind neben der mechanischen Wirkung und der Fähigkeit zur 
Auflösung des Gewebes auch die antimikrobielle Effektivität sowie eine geringe Toxizität (Souza et al. 2014). Darüber hinaus sollen sie die während der Präparation entstandenen Dentinspäne und die Schmierschicht (Smear layer) auf der Dentinwand entfernen.

Natriumhypochlorit $(\mathrm{NaOCl})$ ist aufgrund seiner antimikrobiellen und gewebelösenden Aktivität die am häufigsten verwendete endodontische Spülflüssigkeit (Stojicic et al. 2010). Durch diese gewebelösende Aktivität besitzt sie die Eigenschaft, die organischen Bestandteile der Schmierschicht aufzulösen. Nach Stojicic et al. (2010) steigt die Gewebeauflösung nahezu linear mit der Konzentration von Natriumhypochlorit an. Außerdem stellten sie fest, dass sich die Wirksamkeit von Natriumhypochlorit bei einem Temperaturanstieg auf $45^{\circ} \mathrm{C}$ erheblich steigerte. Allerdings konnte in einigen klinischen Untersuchungen kein signifikanter Unterschied zwischen den verschiedenen $\mathrm{NaOCl}$-Konzentrationen hinsichtlich der antimikrobiellen Wirksamkeit nachgewiesen werden (Cvek et al. 1976; Byström und Sundqvist 1985; Verma et al. 2019). Da hohe Konzentrationen jedoch potenziell zytotoxisch für das periapikale Gewebe sind (Gernhardt et al. 2004; Aubut et al. 2010) und sowohl der Elastizitätsmodul und die Biegefestigkeit des Dentins signifikant verringert werden (Sim et al. 2001), werden in der klinischen Anwendung geringe Konzentrationen bevorzugt (Verma et al. 2019). Handelsübliche $\mathrm{NaOCl}$-Lösungen werden mit hohem pH-Wert (11-12) angeboten.

Für die Entfernung des anorganischen Bestandteils des Smear layers werden Chelatoren verwendet. Diese Chelatoren besitzen die Fähigkeit, mehrwertige freie Ionen in ringförmigen Komplexen zu binden, wobei hier die Kalzium-lonen aus dem Dentin gebunden werden. Anschließend verwendete, desinfizierende Spüllösungen können so einfacher die freigelegten Dentintubuli penetrieren und somit in der Tiefe des infizierten Kanalwanddentins wirken. Neben dem am häufigsten angewendeten Chelator Ethylendiamintetraessigsäure (EDTA) eignet sich auch Zitronensäure in Konzentrationen zwischen 10\% und 20\%. Durch die nichtselektive Bindung der Kalzium-lonen treten allerdings bei längerer Einwirkzeit von mehr als 1-3 min Erosionen des Dentins auf (Baldasso et al. 2017). 


\subsection{Bedeutung der Mikrorisse und Frakturen im Wurzeldentin}

\subsubsection{Definition von Riss und Fraktur}

Der Begriff Riss entspricht einem unvollständigen Bruch einer Substanz. Bricht diese Substanz vollständig in zwei oder mehr Fragmente, so spricht man von einer Fraktur (Rivera und Walton 2007). Diese strukturellen Defekte finden sich sowohl an der Zahnkrone als auch an der Wurzel und übergreifend in beiden Bereichen. Riss- bzw. Frakturlinien können in vertikaler und horizontaler Ebene verlaufen. Außerdem können sie bei allen Zahngruppen auftreten und werden durch Okklusionskräfte und/oder Zahnbehandlungen sowie Traumata verursacht (Cohen et al. 2006; Rivera und Walton 2007).

\subsubsection{Die Ausbreitung von Rissen im Dentin}

In ihrer Studie stellten Jainaen et al. (2009) fest, dass die Ausrichtung und Dichte der Dentintubuli und die der mineralisierten Kollagenfibrillen den Weg der Risse durch das Wurzeldentin beeinflussen. In pulpanahen Bereichen mit einer hohen Tubulidichte ist es unwahrscheinlich, dass der fortschreitende Riss einen Dentintubulus auf seinem Weg überspringt. Daher wandern die Risse von einem Tubulus zum anderen (Abbildung 1-7).

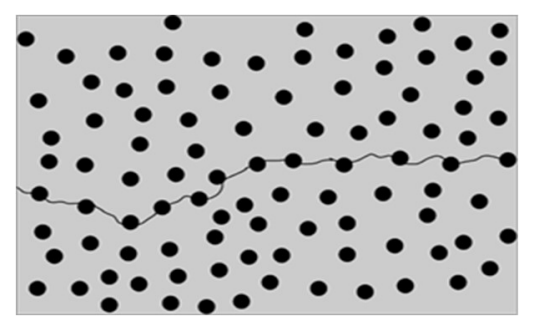

Abbildung 1-7: Schematische Darstellung des Rissverlaufs zwischen den Dentintubuli, basierend auf Jainaen et al. (2009), S. e77. Die Verwendung erfolgt mit freundlicher Genehmigung des Elsevier Verlages.

Außerdem wird die Rissausbreitung vorwiegend durch die Spannungen innerhalb der Gewebe gesteuert (Jainaen et al. 2009). Peritubuläres Dentin weist einen geringeren Anteil an Kollagen auf und ist stärker mineralisiert als intertubuläres Dentin. Durch die geringere Dichte der pulpafernen Matrix sind bereits schwache Kräfte ausreichend, um einen zum Dentintubulus vertikal verlaufenden Riss auszulösen, wohingegen parallel zum Tubulus verlaufende Risse durch größere Krafteinflüsse entstehen (Jainaen et al. 2009). 


\subsubsection{Klassifikation vertikaler Zahnfrakturen}

Jede Fraktur, an der die Zahnwurzel beteiligt ist, sei es an dem koronalen oder dem apikalen Anteil, wird als "vertikale Wurzelfraktur" bezeichnet (Rivera und Walton 2007).

Nach Rivera und Walton (2007) werden Längsfrakturen in fünf Klassifikationen (Risslinien, Höckerfrakturen, gebrochener Zahn, geteilter Zahn und vertikale Wurzelfraktur) eingeteilt, aufsteigend von der niedrigsten bis zur schwersten Substanzschädigung:

Risslinien beschränken sich auf den Zahnschmelz, erstrecken sich vertikal verlaufend auf bukkalen sowie oralen Flächen und treten häufig bei Erwachsenen auf. Es ist unwahrscheinlich, dass diese Schmelzinfrakturen Vorläufer für Dentinfrakturen sind (Rivera und Walton 2007). Höckerfrakturen sind durch eine von der Zahnkrone ausgehende, vollständige oder unvollständige Fraktur gekennzeichnet. Diese kann sich bis in subgingivale Bereiche erstrecken und verläuft über die Randleiste zur oralen oder bukkalen Außenseite des Zahnes. Frakturierte Zähne weisen eine in mesio-distaler Richtung verlaufende, unvollständige Fraktur auf (Hiatt 1973; Cohen et al. 2006). Die Frakturlinie kann sich von der Krone bis subgingival zur Wurzel erstrecken und beide Randleisten betreffen. Die Tiefe der Frakturlinie an der Wurzel variiert (Abbildung 1-8) und die Zahnsegmente sind nicht trennbar.

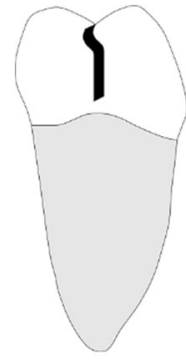

a)

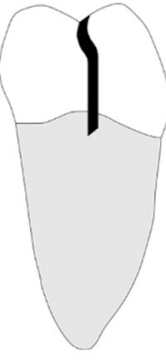

b)

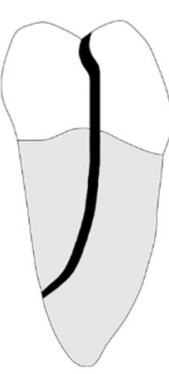

c)

Abbildung 1-8: Schematische Darstellung von Frakturverläufen.

Ansicht von approximal, a) die Frakturlinie auf Schmelzareal begrenzt, b) die Frakturlinie erstreckt sich bis in das Dentin, c) die Frakturlinie durchzieht die Wurzel, basierend auf Rivera und Walton (2007), S. 85. Die Verwendung erfolgt mit freundlicher Genehmigung des John Wiley \& Sons Verlags.

Im weiteren Verlauf entwickelt sich aus einem frakturierten Zahn ein geteilter Zahn. Die Richtung der nun vollständigen Fraktur ist deshalb entsprechend in mesio- 
distaler Ausrichtung auf der Krone. Die Fraktur erstreckt sich auf die gesamte Wurzel, wobei typischerweise die Zahnsegmente voneinander trennbar sind.

\subsubsection{Klinische Relevanz der Wurzelrisse und -frakturen}

Einzelne Mikrorisse können sich in ihrem Verlauf vereinigen, sich in ihrem Ausmaß vergrößern und somit zu einer vollständigen Wurzelfraktur führen (Cohen et al. 2006). In den letzten Jahren erlangte das Auftreten von Wurzelfrakturen bei gesunden und endodontisch behandelten sowie restaurierten Zähnen mehr Aufmerksamkeit in der Zahnmedizin (Llena-Puy et al. 2001; Zadik et al. 2008; Touré et al. 2011). Wurzelfrakturen können in Längsrichtung oder schräg zur Wurzelachse verlaufen und betreffen entweder nur die Wurzel oder sowohl die Wurzel als auch die Krone (Tamse 1988). Bereits 1999 stellten Fuss et al. (1999) fest, dass vertikale Wurzelfrakturen an dritter Stelle nach stark beschädigten, nicht mehr restaurierbaren Zähnen und einem endodontischen Misserfolg als Hauptgrund für eine Extraktion eines Zahnes angesehen werden. In einer Studie zur Analyse von Gründen für die Extraktion endodontisch behandelter Zähne stellten Touré et al. (2011) fest, dass die ersten Unterkiefermolaren die am häufigsten extrahierten Zähne sind $(29,4 \%)$, gefolgt von den zweiten und dritten Unterkiefermolaren $(21,9 \%)$ und den ersten Oberkiefermolaren (16,6\%). Neben parodontalen Erkrankungen (40,3\%) waren ein endodontischer Misserfolg $(19,3 \%)$ und vertikale Wurzelfrakturen $(13,4 \%)$ die Hauptgründe, die zur Zahnentfernung führten. Die Diagnose einer vertikalen Wurzelfraktur ist aufgrund des verzögerten Auftretens der Anzeichen und der Manifestation von rein endodontischen oder parodontalen Problemen schwierig (Tamse 1988). Nach Tamse (1988) stellen sowohl eine Verbreiterung des parodontalen Ligamentes entlang einer oder beider Seiten der Wurzel als auch ein Knochenverlust bei einem einzelnen Zahn wichtige radiologische Befunde dar. Außerdem sind leichte Schmerzen und Schwellungen, sowie lokalisiert erhöhte Sulkussondierungstiefen die hauptsächlich klinischen Symptome für eine Wurzellängsfraktur. In den letzten Jahren haben sich verschiedene hypothetische Ansätze für die Entstehung von Wurzelfrakturen entwickelt, einschließlich der Annahme, dass Mikrorisse im Dentin als Vorläufer von Wurzellängsfrakturen anzusehen sind (De-Deus et al. 2017a). Gründe für die Rissentstehung erklärte man unter anderem durch eine entstandene Dehydration 
des Dentins (Tamse 1988), übermäßige laterale Kräfte während der Kompaktion von Guttapercha (Wilcox et al. 1997; Soros et al. 2008) oder durch eine übermäßige Instrumentierung mit entsprechendem Substanzabtrag des Wurzelkanaldentins (Wilcox et al. 1997). Die Entstehung von Mikrorissen im Wurzeldentin durch eine Instrumentierung mit maschinell beriebenen Nickel-Titan-Instrumenten wurde in mehreren Studien beschrieben (Bier et al. 2009; Liu et al. 2013; Capar et al. 2014b). Da die mechanische Bearbeitung des Wurzelkanals einen wichtigen Stellenwert in der modernen Endodontologie besitzt (De-Deus et al. 2017a), hat die Rissentstehung im Wurzeldentin in der Forschung zunehmend an Bedeutung gewonnen.

\subsection{Methoden zur Beurteilung von Mikrorissen im Wurzeldentin}

Mit der Erkenntnis, dass Mikrorisse im Wurzeldentin durch die endodontische Therapie entstehen könnten, wurden auch verschiedene methodische Ansätzen zur Bildgebung und Beurteilung der Risse verwendet (Versiani et al. 2015). Neben der Endoskopie und Infrarotthermografie fanden außerdem die Stereomikroskopie, optische Kohärenztomografie, Rasterelektronenmikroskopie, Transillumination, Transmissionselektronenmikroskopie und Mikro-Computertomografie Anwendung.

All diese Techniken haben im Laufe der Jahre ihr Potenzial für die endodontische Forschung gezeigt. Einige von innen liefern jedoch im Vergleich zueinander unterschiedliche Ergebnisse. Diese inhärenten Einschränkungen führte zur Suche nach immer neuen Methoden mit verbesserten diagnostischen Möglichkeiten (Versiani et al. 2015). In den letzten Jahren etablierten sich zur Evaluation von Mikrorissen vor allem stereomikroskopische Analysen von Sägeschnitten und die Mikro-Computertomografie.

\subsubsection{Stereomikroskopische Untersuchung von Sägeschnitten}

Die meisten Untersuchungen zu Dentindefekten beruhen auf der direkten Auswertung mit einem Auflichtmikroskop, hauptsächlich mit einem Stereomikroskopsystem (Versiani et al. 2015; Coelho et al. 2016). Viele Autoren verwendeten Stereomikroskope mit einer festen Vergrößerung oder mit Zoomfunktion. Der Vergrößerungsbereich liegt dabei in der Regel zwischen 12- und 
40-facher Vergrößerung (Bier et al. 2009; Bürklein et al. 2013a; Hin et al. 2013; Arias et al. 2014). Die Wurzelproben werden ausgehend von der Wurzelspitze im Abstand von 3, 6 und 9 mm (Bürklein et al. 2013a; Hin et al. 2013; Karataş et al. 2015; Coelho et al. 2016) bei niedriger Geschwindigkeit und unter Wasserkühlung z. B. mit einer Schwingkreissäge (Bier et al. 2009; Coelho et al. 2016) oder dünnen Diamantscheiben schrittweise zersägt (Versiani et al. 2015). Die Methoden der verwendeten Sägetechniken sind sehr umfangreich, angefangen bei der Verwendung einfacher Handstücke und Karborund-Scheiben bis hin zur Verwendung spezieller und hoch entwickelter Sägemaschinen, die dünne Diamantscheiben mit präziser Geschwindigkeits- und Blattdrucksteuerung verwenden (Versiani et al. 2015). Nach der Wurzelkanalpräparation werden die Proben zersägt und anschließend stereomikroskopisch analysiert. Eine verbesserte Visualisierung wird unter anderem durch die Verwendung einer Kaltlichtquelle (Bürklein et al. 2013a) oder lichtemittierender Dioden-Transillumination (LED) (Coelho et al. 2016) erzeugt. In vielen Veröffentlichungen, bei denen die Schnittmethode angewendet wurde, wird ein deutlicher Zusammenhang der Wurzelkanalpräparation und der Entstehung von Dentinrissen beschrieben (Yoldas et al. 2012; Liu et al. 2013; Capar et al. 2014b). Die unbehandelten Kontrollgruppen wiesen dabei keinerlei Risse im Dentin auf. In wenigen Studien wurde eine ähnliche Inzidenz von Mikrorissen zwischen den Kontrollgruppen und den experimentellen Gruppen beobachtet (Arias et al. 2014).

Die Schnittmethode hat aufgrund des destruktiven Charakters einen erheblichen Nachteil, der wiederum die Hauptursache für die in der Literatur berichteten kontroversen Ergebnisse sein könnte (De-Deus et al. 2015; 2016). Die unbehandelten Kontrollgruppen zeigten in der Regel bei Anwendung der Sägeschnittmethode keine Dentindefekte. Die potenzielle Schädigung der Dentinstruktur durch das Zusammenspiel der mechanischen Belastung des Dentins während der Präparation, den Einfluss der Spüllösungen und die anschließende mechanische Belastung während der Herstellung der Querschnitte der experimentellen Gruppen wurde von den Autoren nicht berücksichtigt (De-Deus et al. 2014; 2015; 2016). Der präoperative Zustand des Dentins bleibt bei dieser Methode unbekannt. Ein direkter Vergleich zwischen dem prä- und postoperativen Zustand des Dentins von ein und derselben Probe ist mit dieser Untersuchungsmethode nicht möglich. 
Idealerweise sollten ätiologische Faktoren, die an Dentinschäden beteiligt sind, durch zerstörungsfreie experimentelle Modelle beurteilt werden, die eine prä- und postoperative Untersuchung des Dentins ermöglichen. Auf diese Weise ist es möglich, präoperativ vorliegende Dentindefekte zu bestimmen.

\subsubsection{Mikro-Computertomografie}

Die Mikro-Computertomografie (Mikro-CT) ist ein nicht-invasives Bildgebungsverfahren, welches mit Hilfe von Röntgenstrahlung und digitalen Röntgendetektoren Bilder einer Probe auf Mikroebene erzeugt (Bayram et al. 2017b; De-Deus et al. 2017b; Liao et al. 2018). Da der Bildbearbeitungsprozess nicht destruktiv ist, können die inneren Merkmale derselben Probe viele Male untersucht werden und die Proben bleiben nach jedem Scannen für zusätzliche biologische und mechanische Tests verfügbar (Swain und Xue 2009). Folglich dient jeder Zahn als seine eigene Kontrollgruppe, wobei hunderte von zweidimensionalen Schnitten pro Probe ausgewertet werden können (De-Deus et al. 2017a). Bereits in den frühen 1980er Jahren wurde der erste Mikro-CT-Scanner von Elliott und Dover (1982) für die Anwendung experimenteller Fragestellungen entwickelt (Feldkamp et al. 1984; Ritman 2004; Versiani et al. 2015). Erste Forschungen konzentrierten sich vor allem auf die Untersuchung dreidimensionaler Mikrostrukturen von Trabekelknochen (Feldkamp et al. 1989). Feldkamp et al. (1989) gelang es bereits dreidimensionale Abbildungen mit einer Auflösung von $50 \mu \mathrm{m}$ zu generieren.

Technisch und physikalisch ist ein Mikro-CT ähnlich einem Computertomografen (CT) aufgebaut. Im Gegensatz zum CT wird hier das Objekt zwischen der Röntgenröhre und dem digitalem Röntgendetektor auf einem sich um die eigene Achse rotierendem Objekttisch fixiert. Sowohl die Röntgenquelle als auch der Filter, Objekttisch und Detektor sind Bestandteile der Haupteinheit eines Mikro-CTs. Mit der Haupteinheit sind die Konsole (Computer) und eine Kontrollbox verbunden (Abbildung 1-9). 


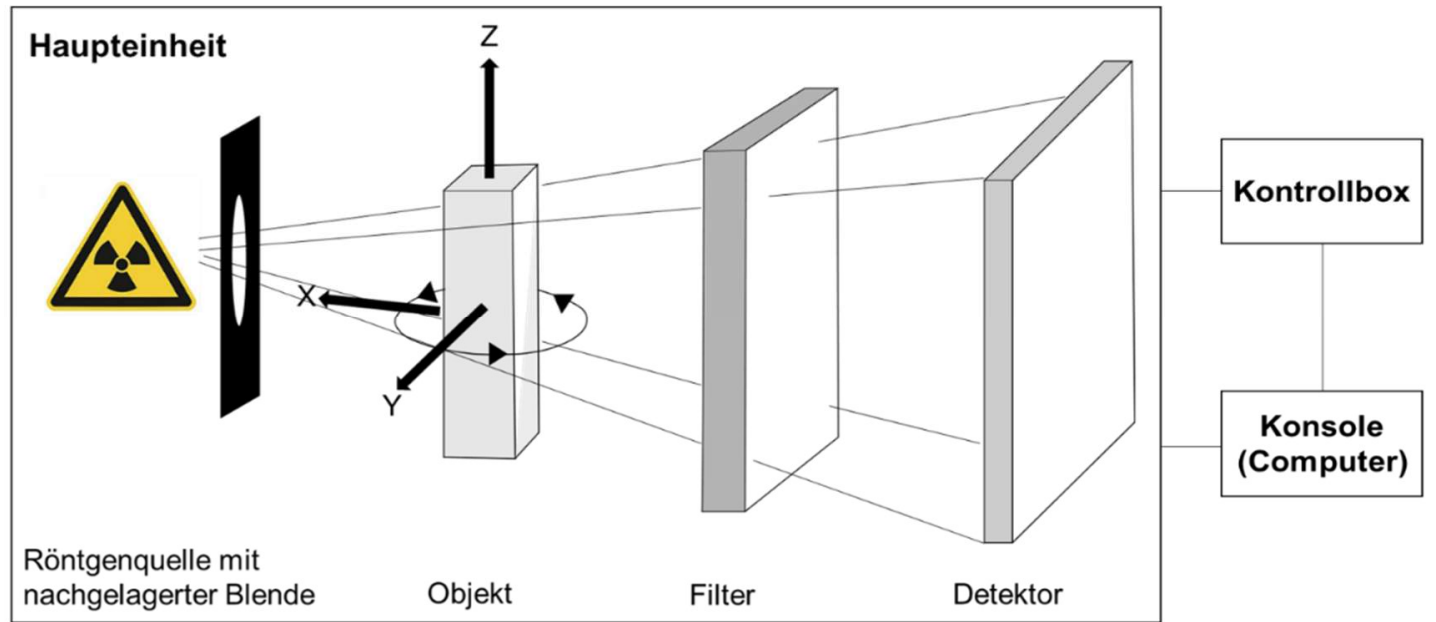

Abbildung 1-9: Schematischer Aufbau eines Mikro-CTs.

Die in der Röntgenröhre erzeugten Röntgenstrahlen werden durch eine nachgelagerte Blende gebündelt, wodurch die Belichtungszeit des Detektors mit Röntgenstrahlung bestimmt wird. Durch die Einstellung der Stromstärke wird die Strahlungsintensität reguliert. Die Höhe des Energiespektrums der Röntgenstrahlung wird durch die angelegte Spannung bestimmt. Üblicherweise finden im Mikro-CT Strahlengeometrien wie Parallel-, Fächer- oder Kegelstrahlen Anwendung. Mit der Einführung von Synchrotronstrahlungsanlagen der dritten Generation wurden Aufnahmen mit Auflösungen von $1 \mu \mathrm{m}$ und kleiner möglich. Hierbei wird aus dem kontinuierlichen Energiespektrum ein monochromatischer Strahl selektiert (Engelke et al. 1999). Auf Grund der höheren Intensität des monochromatischen Strahles gegenüber konventionellen Röntgenquellen, ist diese Energiequelle bei Fragestellungen mit besonders hochauflösender Bildgebung $(<5 \mu \mathrm{m})$ zu bevorzugen (Engelke et al. 1999). Durch die Anwendung verschiedener Filter, wie Aluminium- oder Kupferfilter verschiedener Dicke, lässt sich das Energiespektrum der Röntgenstrahlung zusätzlich kontrollieren. Bestimmte Wellenlängen der Strahlung werden dabei absorbiert.

Gegenüber der Strahlenquelle befindet sich der Detektor. Der Szintillator und eine Charge-Coupled-Device (CCD)-Kamera sind Bestandteile des Detektors und durch Fiberglasoptik miteinander verbunden. Die beim Auftreffen der Röntgenstrahlung auf den Detektor entstehenden Lumineszenzsignale werden von der Kamera registriert.

Die Konsole beinhaltet den Computer und den Bildschirm. Hier werden sowohl alle Scan-Parameter eingestellt als auch der Scan-Prozess überwacht. Die Bearbeitung 
und Rekonstruktion des primären Datensatzes der gescannten Objekte findet hier ebenso statt. Das Ein- und Ausschalten der Röntgenstrahlen, die Einstellungen der angelegten Spannung und die Stromstärke sowie die Temperatur des Detektors wird über die Kontrollbox reguliert.

Einer der ausschlaggebenden Unterschiede zum Computertomografen findet sich in der Ortsauflösung, d. h. in dem räumlichen Abstand zweier gemessener Signale, bei der diese noch als getrennt voneinander erkannt werden. Während CTs eine Ortsauflösung von 0,3 mm erreichen wird mit dem Mikro-CT, abhängig von der Fragestellung, eine Ortsauflösung im Bereich von 1-200 $\mu \mathrm{m}$ erzielt (Haddad et al. 1994; Ritman 2004; Burghardt et al. 2011). Der in dieser Studie verwendete hochauflösende Mikro-Computertomograf SkyScan1272 der Firma Bruker (Billerica, MA, USA) erreicht nach Herstellerangaben eine Ortsauflösung von $0,35 \mu \mathrm{m}$ und erlaubt den Scan von Objekten mit einer Größe von bis zu 7,5 cm. Die Limitation hinsichtlich der Größenauswahl der Proben ist auf eine, im Vergleich zum $\mathrm{CT}$, geringere Fokusgröße und damit verkleinerten Röhrenleistung begründet (Engelke et al. 1999). Mit zunehmender Größe des zu untersuchenden Objektes und einer feineren Auflösung der erzeugten Bilder nimmt die Datenmenge erheblich zu. Mit einer Größe von 270 Megabyte (MB) und einer Farbtiefe von 16 bit werden Volumendatensätze durch $512^{3}$ Bildpunkten erzeugt, bei $1024^{3}$ Bildpunkten und gleicher Farbtiefe entstehen 2150 MB. Für die Weiterbearbeitung und Datensicherung wird so ein enormes Datenvolumen erzeugt, dessen Speicherung entsprechend gesichert werden muss (Engelke et al. 1999).

Während des Scanvorgangs wird eine Vielzahl von Röntgenbildern der Probe aus verschiedenen Winkeln aufgenommen. Nach der Aufzeichnung der Röntgenbilder werden dann die Projektionsdaten des Objekts als Grundlage für einen Rekonstruktionsalgorithmus verwendet (Swain und Xue 2009; Versiani et al. 2015). Dieser, von Feldkamp et al. (1984) entwickelte, Algorithmus berechnet auf der Grundlage dieses zweidimensionalen Rohdatensatzes ein dreidimensionales Bild des Objekts (Grass et al. 1999). Dabei werden die zweidimensionalen Bilder mit einem entsprechenden Computerprogramm überlagerungsfrei rekonstruiert. Bedingt durch ungewünschte Artefakte oder Bewegungen der Probe während des Scanvorgangs und daraus resultierenden Verzerrungen im Bild ermöglicht die Anwendung einer Rekonstruktionssoftware eine Verringerung dieser Störfaktoren und lässt eine bessere Beurteilung der Schnittbilder zu. Unter anderem können 
Aufhärtungsartefakte, Ringartefakte, Post-Alignment und die Glättungsfunktion eingestellt werden: Die Aufhärtungsartefakte treten auf, wenn ein Röntgenstrahl mit polychromatischer Energie, durch ein Objekt hindurchtritt und dabei Photonen mit niedriger Energie selektiv abgeschwächt oder sogar vollständig absorbiert werden. Dieses Phänomen führt zu Artefakten an der Objektoberfläche der rekonstruierten Schnittbilder und liefert falsche Informationen über den Zustand der Probe. Die während des Scanvorgangs verwendeten Filter aus Aluminium oder Kupfer ermöglichen in Abhängigkeit ihrer Dicke das Energiespektrum der Röntgenstrahlung zu kontrollieren. Eine vollständige Reduktion von Artefakten kann ihre Anwendung jedoch nicht erreichen.

In Abhängigkeit von der Dichte der Probe kann eine Aufhärtungskorrektur (BeamHardening Correction) (Abbildung 1-10) von 0-100\% bestimmt werden.

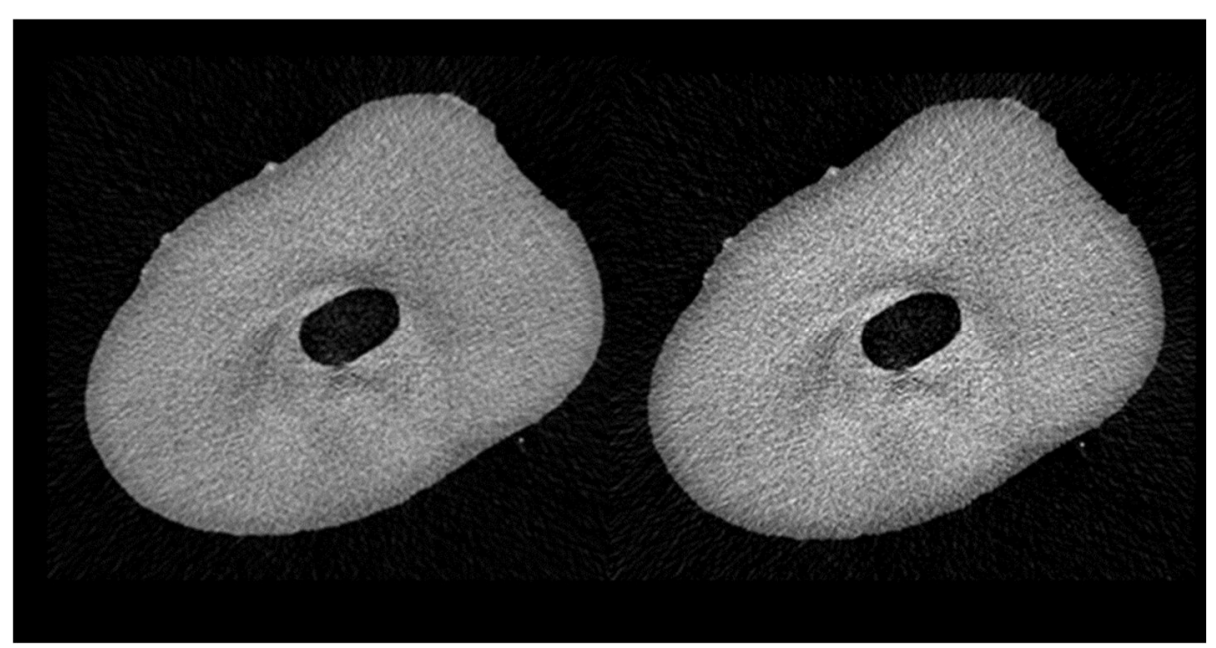

Abbildung 1-10: Beam-Hardening Correction.

Linker Querschnitt mit 40\%iger Korrektur, rechts mit 60\%iger Korrektur.

Ringartefakte (Abbildung 1-11) erscheinen auf den Schnittbildern als kreisrunde, abwechselnd helle und dunkle Ringe, durch die strahlendichte und strahlentransparente Bereiche vorgetäuscht werden. Diese Artefakte werden durch einzelne defekte Sensoren am Detektor, Staubpartikel, Temperaturschwankungen oder nicht sachgemäßer Kalibrierung des Mikro-CTs verursacht. Die Einstellungen dieser Ringartefakt-Korrektur (Ring Artefact Correction) muss so gewählt werden, dass bei gleichzeitiger Eliminierung der Ringartefakte unnötige Unschärfen vermieden werden. 


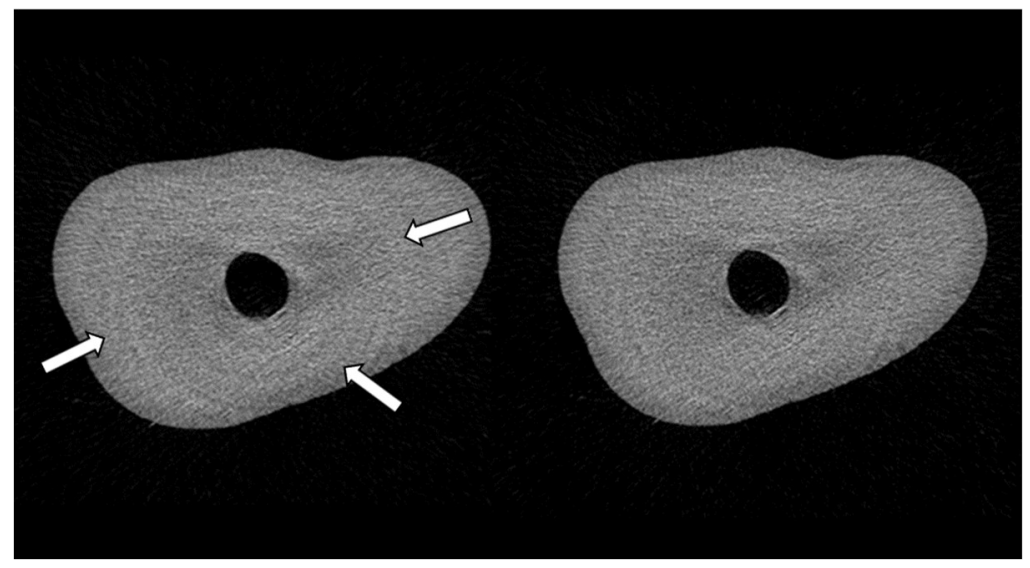

Abbildung 1-11: Ring Artefact Correction.

Ringartefakte vor (links) und nach der Korrektur (rechts).

Unter Post-Alignment versteht man eine kompensierende Nachkorrektur der Ausrichtung des Objektes. Aufgrund einer mechanischen Fehlausrichtung bei Rotationen treten Verzerrungen oder Flügelbildungen (Abbildung 1-12) an der Kontur der Objekte auf, welche durch diese Korrektur ausgeglichen werden.

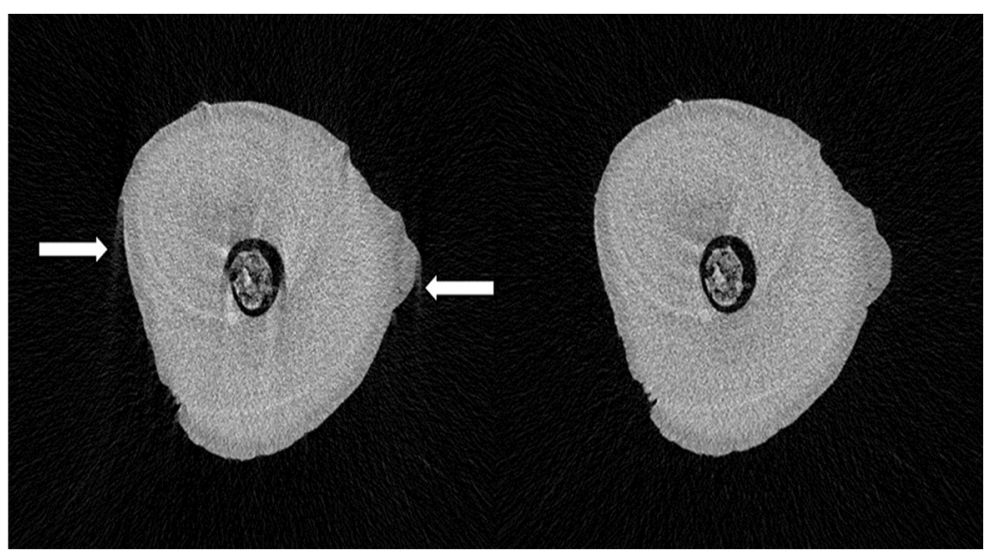

Abbildung 1-12: Post-Alignment Correction.

Flügelbildung vor (links) und nach der Korrektur (rechts).

Bei der Glättungsfunktion (Smoothing) wird jeder einzelne Pixel in Abhängigkeit seiner umliegenden Pixel angeglichen und somit geglättet. Diese Funktion reduziert daher das Bildrauschen, kann jedoch bei feinen Strukturen zu Unschärfen und falsch negativen Ergebnissen bei der Risserkennung führen.

Mit dem Mikro-CT kann ein breites Spektrum von Proben untersucht werden, einschließlich mineralisierter Gewebe wie Zähne, Knochen sowie Materialien, wie z. B. Keramiken, Polymere, Biomaterial-Gerüste usw. (Swain und Xue 2009). Die 
Mikro-CT-Bildgebung kann auch Weichgewebe, wie etwa Lungen- oder Herzgewebe abbilden. Jorgensen et al. (1998) zeigten, dass das Mikro-CT ein geeignetes Instrument für die Visualisierung kleinster Kapillarvolumina an isolierten und fixierten Nagetierorganen ist. Nielsen et al. (1995) erkannten das enorme Potential des Mikro-CTs für die endodontische Forschung. Dabei beziehen sich die Fragestellungen unter anderem auf die Morphologie der Wurzeln und Wurzelkanäle (Lee et al. 2015; Bürklein et al. 2017b) oder die Flächen- und Volumenänderungen nach erster Instrumentierung (Capar et al. 2014a) und nach Revisionsbehandlungen (Rödig et al. 2014a, b; Rodrigues et al. 2016). Capar et al. (2014a) und De-Deus et al. (2019) nutzen das Micro-CT zur Beurteilung der Effektivität von Spüllösungen und Transport von Gewebe innerhalb des Kanals.

In der Literatur liegt eine Vielzahl von Studien zur Rissentstehung im Wurzeldentin durch Instrumentierung der Wurzelkanäle vor, welche das Mikro-CT als Methode zur Bildgebung und Beurteilung nutzen (De-Deus et al. 2014; 2015; 2016; 2017a; Jamleh et al. 2015; Pop et al. 2015; Bayram et al. 2017a, b; Cassimiro et al. 2017; Zuolo et al. 2017; Aksoy et al. 2019).

Im Jahr 2014 untersuchten De-Deus et al. die Häufigkeit von Mikrorissen im Wurzeldentin mesialer Unterkiefermolaren nach der Präparation mit Reciproc (VDW), WaveOne (Dentsply Sirona) und BioRaCe (FKG Dentaire, La-Chaux-de-Fonds, Schweiz). In den 65.340 prä- und postoperativen Aufnahmen wurden in 8,72\% ( $n=5697)$ in der Gruppe Reciproc, 11,01\% $(n=7197)$ in der Gruppe WaveOne und $7,91 \%$ ( $n=5169)$ in der Gruppe BioRaCe der Querschnitte Mikrorisse beobachtet. Alle postoperativen Dentindefekte waren bereits auf den entsprechenden präoperativen Mikro-CT-Scans vorhanden. Auch in Folgestudien von De-Deus et al., bei denen die Instrumentensysteme ProTaper NEXT (Dentsply Sirona) und Twisted File Adaptive (TFA; SybronEndo, Orange, CA, USA) (De-Deus et al. 2015) sowie ProTaper Universal (Dentsply Sirona) (De-Deus et al. 2016) hinsichtlich ihres Einflusses auf die Entstehung von Mikrorissen im Wurzeldentin analysiert wurden ergaben, dass alle postoperativ vorhandenen Risse bereits in den präoperativen Aufnahmen festgestellt wurden.

Eine weitere In-vitro-Studie von Bayram et al. (2017b) zur Präparation von Wurzelkanälen an 40 Unterkieferfrontzähnen mit HyFlex CM und HyFlex EDM (beide Coltène/ Whaledent), Vortex Blue (Dentsply Sirona) und TRUShape 
(Dentsply Sirona) ergab, dass keine neuen Risse durch die maschinelle Instrumentierung entstanden waren. Insgesamt wurden auf 12,31\% der 36.152 präund postoperativen Schnittbilder Mikrorisse festgestellt. Alle in den postoperativen Scans identifizierten Dentindefekte waren bereits in den entsprechenden präoperativen Aufnahmen vorhanden.

In einer ähnlichen Studie von Cassimiro et al. (2017), bei der eine größere Fallzahl an Unterkieferfrontzähnen gewählt wurde $(n=60)$, wurde nach der Präparation mit den NiTi-System ProTaper NEXT (Dentsply Sirona), WaveOne Gold (Dentsply Sirona)und K3XF (SybronEndo, Glendora, CA, USA) ebenfalls keine Korrelation zwischen der Präparation eines Wurzelkanals und die Entstehung von Mikrorissen festgestellt. Auch hier waren alle postoperativen Risse bereits präoperativ vorhanden.

Dem gegenüber finden sich in der Literatur auch Studien, bei denen postoperativ eine signifikant höhere Anzahl an Mikrorissen im Wurzeldentin im Vergleich zum präoperativen Befund festgestellt wurden. In einer Studie von Pop et al. (2015) wurde der Effekt der rotierenden und reziproken Instrumentenbewegung untersucht. Mit Hilfe des Mikro-CTs wurde festgestellt, dass die Wurzelkanalpräparation bei beiden Arbeitsbewegungen sowohl die Anzahl als auch die Länge der Mikrorisse signifikant erhöhte. Zu gleichen Ergebnissen kamen Jamleh et al. (2015) beim Vergleich eines rotierenden Mehr-Feilen-Systems (ProTaper, Dentsply Sirona) mit einem reziproken Ein-Feilen-System (WaveOne, Dentsply Sirona), da unabhängig von der Art der Instrumentenbewegung eine signifikante Zunahme an Mikrorissen in den post-operativen Mikro-CT-Aufnahmen auftrat. Untersuchungen von Bayram et al. (2017a) und Aksoy et al. (2019) zeigten, dass Nickel-TitanInstrumente der neueren Generation (XP-Endo Shaper, FKG Dentaire; Reciproc blue, VDW) keine neuen Risse verursachten. Das in beiden Studien verwendete Mehr-Feilen-System ProTaper Universal (Dentsply Sirona) erhöhte allerdings den prozentualen Anteil von Mikrorissen im Vergleich zu den präoperativen Mikro-CTAufnahmen signifikant.

Die in der Literatur voneinander abweichenden Ergebnisse bei der Analyse der Mikrorisse sind unter anderem durch verschiedene Ansätze der Probenauswahl und -beurteilung, der Scanparameter des Mikro-CTs, des Präparationsprotokolls, der Nomenklatur und Klassifikation der Risse sowie Lagerungsbedingungen der Proben 
zu erklären (De-Deus et al. 2015; Versiani et al. 2015; Rödig et al. 2018b). Die wenigsten Studien geben Informationen über die Lagerung der Proben vor und/oder nach dem Scanvorgang bzw. über den Trocknungszustand der Proben während des Scannens (De-Deus et al. 2014; 2015; Cassimiro et al. 2017). Rödig et al. (2018b) erkannten einen Einfluss des Feuchtigkeitsgehalts des Dentins auf die Erkennbarkeit von Mikrorissen im Dentin mittels des Mikro-CT. Demnach wurden nach einer Trocknungszeit von zwei Stunden signifikant mehr Risse auf den MikroCT-Aufnahmen sichtbar als bei Proben, welche im feuchten Zustand gescannt wurden. Nach 24 h Trocknungszeit wurden signifikant mehr Mikrorisse identifiziert als nach zwei Stunden. Die Hypothese, dass eine Austrocknung der Proben von $24 \mathrm{~h}$ zu neuen Mikrorissen führen könne, wurde hierbei widerlegt.

\subsection{Ziel der Arbeit}

Das Ziel dieser In-vitro-Studie ist es, den Einfluss von rotierenden und reziproken Nickel-Titan-Instrumenten auf die Entstehung von Mikrorissen im Wurzeldentin nach Präparation gerader und gekrümmter Wurzelkanäle mit Hilfe der MikroComputertomografie zu untersuchen.

Dazu wurden ein reziprokes Ein-Feilen-System (Reciproc, VDW), ein rotierendes Ein-Feilen-System (OneShape, MicroMega) und ein rotierendes Mehr-FeilenSystem (ProTaper NEXT, Dentsply Sirona) miteinander verglichen

Die folgende Nullhypothese wurde untersucht:

Die Wurzelkanalpräparation mit Reciproc, OneShape und ProTaper NEXT führt unabhängig von der Wurzelkanalkrümmung nicht zur Bildung neuer Mikrorisse im Dentin. 


\section{Material und Methode}

\subsection{Zahnauswahl und Vorbereitung der Proben}

Für den Versuchsaufbau wurden 74 extrahierte, menschliche Prämolaren und 90 extrahierte, menschliche Molaren gesammelt. Die Verwendung dieser extrahierten Zähne wurde unter der Antragsnummer 27/8/13 von der Ethikkommission der Universitätsmedizin Göttingen genehmigt. Die Zähne wurden fortlaufend mit einem wasserfesten Stift nummeriert und während der gesamten Versuchszeit in demineralisiertem Wasser gelagert. Für die Gruppen der geraden Wurzelkanäle wurden Prämolaren und für die gekrümmten Kanäle wurden ausschließlich die palatinalen Wurzeln der Oberkiefer- und die distalen Wurzeln der UnterkieferMolaren verwendet. Hierzu wurden die Wurzeln der Molaren mit einer rotierenden, diamantierten Trennscheibe an der Furkation abgetrennt.

Tabelle 2-1: Ein- und Ausschlusskriterien der Proben.

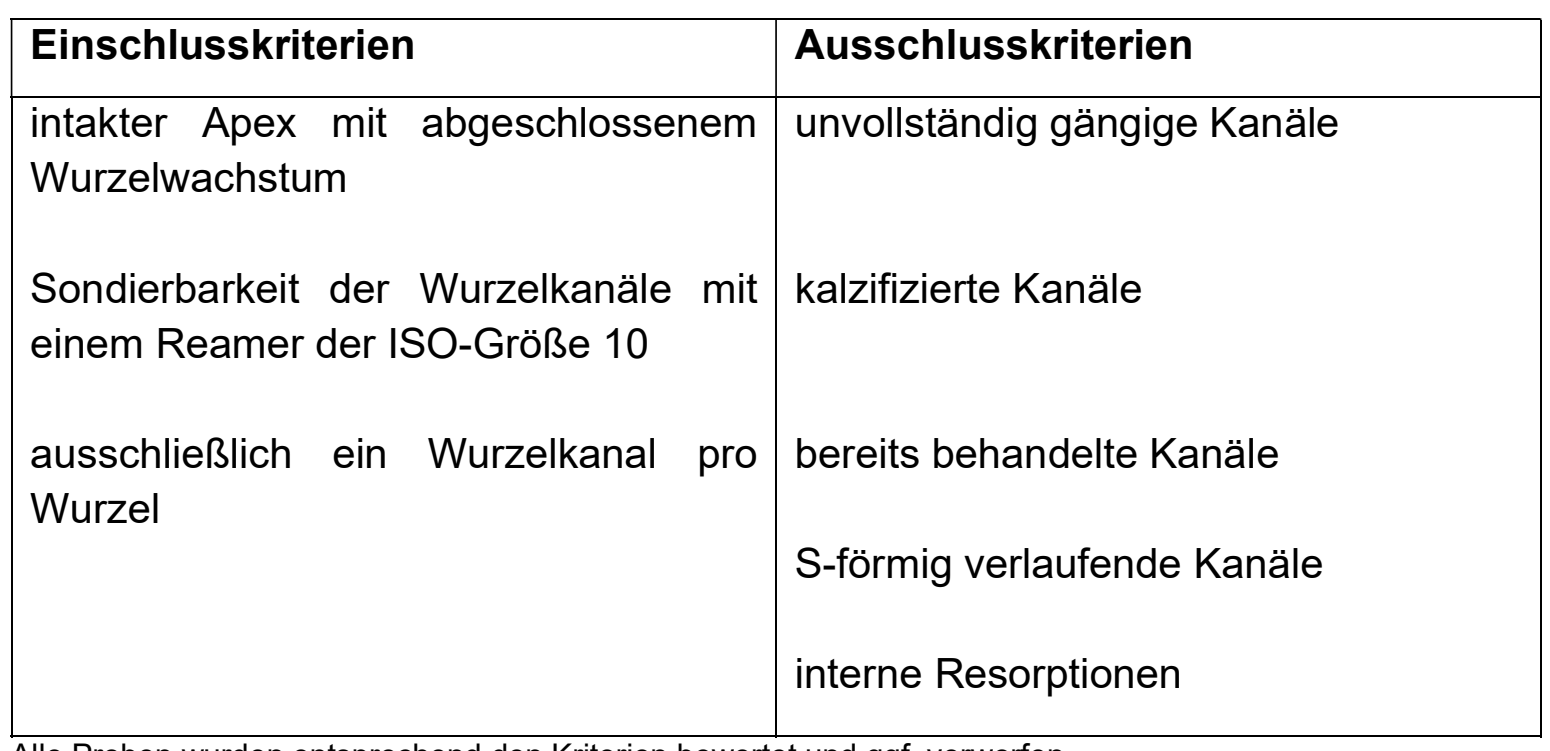

Alle Proben wurden entsprechend den Kriterien bewertet und ggf. verworfen.

Nach dieser Vorauswahl (Tabelle 2-1) wurde bei allen Proben mit einem Diamantbohrer unter Wasserkühlung eine endodontische Zugangskavität präpariert. Die Kanaleingänge wurden mit Hilfe eines Gates-Glidden-Bohrers dargestellt und die Proben an-schließend von koronal auf eine standardisierte Länge des Wurzelkanals von $15 \mathrm{~mm}$ mit einer Diamanttrennscheibe gekürzt. Zur Bestimmung der Kanallänge wurden die Wurzelkanäle mit einem Reamer der ISO- 
Größe 10 bis leicht über das Foramen apicale hinaus instrumentiert. Anschließend wurde die Feile so weit wieder aus dem Wurzelkanal herausgezogen, bis die Instrumentenspitze apikal gerade nicht mehr zu sehen war.

Alle Wurzeln wurden mit einem Stereomikroskop (Zeiss Stemi SV 11, Carl Zeiss, Jena) unter 25-facher Vergrößerung auf äußere Mikrorisse, Frakturen, Karies und andere Defekte untersucht. Hierzu wurden von jeder Probe vier digitale Fotografien von mesial, bukkal, distal und oral durch eine am Mikroskop befestigte Kamera (Motic Cam 3mp, Motic, Wetzlar) angefertigt. Diese Fotoaufnahmen wurden mit der Bildbearbeitungssoftware Motic Images Plus 2.0 (Motic) betrachtet und bewertet. Proben, die eines oder mehrere der oben aufgeführten Ausschlusskriterien aufwiesen, wurden aussortiert.

Im Anschluss wurden die Wurzeln in bukko-lingualer und mesio-distaler Richtung digital geröntgt (Röhrenspannung $70 \mathrm{kV}$, Röhrenstrom $4 \mathrm{~mA}$, Belichtungszeit $0,035 \mathrm{~s}$ ). Für die Festlegung des Abbildungsmaßstabes wurde bei jeder Röntgenaufnahme ein Referenzzylinder aus Metall mit einer standardisierten Länge von $15 \mathrm{~mm}$ mit belichtet. Diese Röntgenaufnahmen wurden für die Berechnung des Krümmungswinkels nach Schneider (1971) und des Krümmungsradius nach Schäfer et al. (2002) verwendet. Die Messungen wurden von zwei kalibrierten Bewertern einmalig mit dem Bildbearbeitungsprogramm ImageJ (Version 1.51) durchgeführt. Anschließend wurde für jede Probe aus beiden Messungen der jeweilige Mittelwert gebildet. Zur Berechnung des Krümmungswinkels ( $\alpha$ ) nach Schneider wurden der Kanaleingang (Punkt $A$ ), der Beginn der Kanalkrümmung (Punkt B) und der röntgenologische Apex (Punkt C) markiert. Die Punkte A und B, sowie $B$ und $C$ wurden miteinander verbunden (Abbildung 2-1). Der gerade Anteil des Kanals befindet sich zwischen $A$ und $B$, der gekrümmte zwischen $B$ und $C$. 


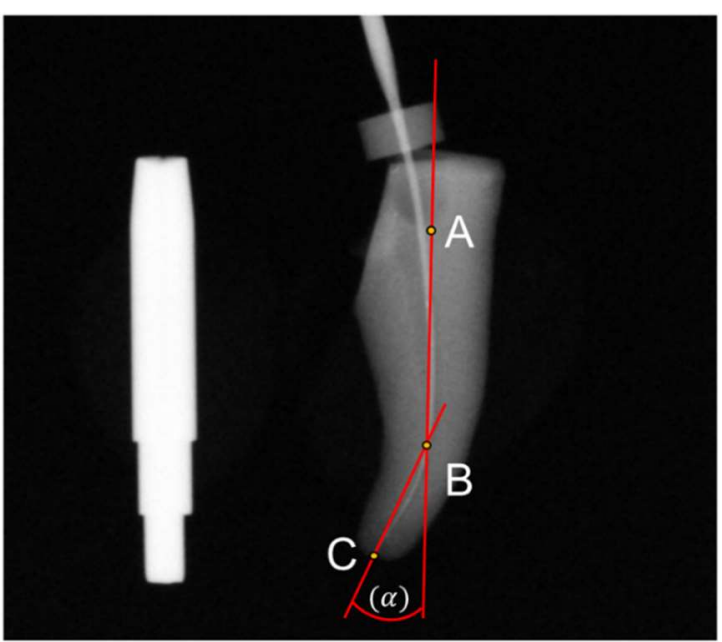

Abbildung 2-1: Bestimmung des Krümmungswinkels nach Schneider et al. (1971).

Punkt A Kanaleingang, Punkt B Beginn der Kanalkrümmung, Punkt C röntgenologischer Apex, ( $\alpha$ ) Krümmungswinkel.

Berechnung des Krümmungswinkels $(\alpha)$ :

Punkt $A=\left(X_{1}, Y_{1}\right)$

Punkt $B=\left(X_{2}, Y_{2}\right)$

Punkt $\mathrm{C}=\left(\mathrm{X}_{3}, \mathrm{Y}_{3}\right)$

$$
(\alpha)=180^{\circ}-\cos ^{-1}\left(\frac{\left(x_{1}-x_{2}\right)\left(x_{3}-x_{2}\right)+\left(y_{1}-y_{2}\right)\left(y_{3}-y_{2}\right)}{\frac{\sqrt{\left(x_{1}-x_{2}\right)^{2}+\left(y_{1}-y_{2}\right)^{2}}}{\sqrt{\left(x_{3}-x_{2}\right)^{2}+\left(y_{3}-y_{2}\right)^{2}}}}\right)
$$

Der Krümmungsradius wurde mittels des Bogenmaßes (Schäfer et al. 2002) der festgelegten Punkte und folgender Formel berechnet: $\quad r=\frac{s}{2 \sin \alpha}$

Der Faktor s entspricht der Distanz zwischen den Punkten A und B.

Berechnung des Krümmungsradius $r_{K}$ :

$$
r_{K}=\sqrt{\left(x_{3}-x_{2}\right)^{2}+\left(y_{3}-y_{2}\right)^{2}} * 2 \sin (a)
$$


Die Einschlusskriterien hinsichtlich des Krümmungswinkels und des -radius wurden bei den gerade Wurzeln mit einem Krümmungswinkel von $<10^{\circ}$ in beiden Ebenen definiert, wobei der Radius der Krümmung unberücksichtigt blieb. Die gekrümmten Wurzeln mussten einen Krümmungswinkel von 20-40 ${ }^{\circ}$ und einem Krümmungsradius von 3-4 $\mathrm{mm}$ in mindestens einer Ebene aufweisen.

Nach dem Aussortieren der Proben nach den oben genannten Kriterien verblieben je 39 gerade und 39 gekrümmte Wurzeln für die nachfolgenden Versuche.

\subsection{Präoperative Mikro-CT-Aufnahmen}

Alle Proben wurden jeweils vor dem Scan aus der nassen Lagerung entnommen, die Außenflächen mittels leichter Druckluft und die Kanallumina mit Papierspitzen getrocknet. Um eventuell vorliegende Dentinrisse auf den Schnittbildern deutlicher erkennen zu können, wurden die Proben anschließend für zwei Stunden bei Raumtemperatur und einer durchschnittlichen Luftfeuchtigkeit von 40-60\% trocken gelagert (Rödig et al. 2018b).

Der Mikro-Computertomograf SkyScan 1272 der Firma Bruker wurde für das Scannen, Rekonstruieren und Registrieren der Aufnahmen verwendet. Vor jeder täglichen Scanfolge wurde der Scanner hinsichtlich des Schwarz-Weiß-Abgleichs der Bilder einmalig und ohne Probe kalibriert. Jede Probe wurde einzeln und trocken gescannt. In einem durchsichtigen Trägerröhrchen (Abbildung 2-2) wurden die Wurzeln mit Hilfe von trockenen Styroporstücken mittig und nahezu achsengerecht ausgerichtet und fixiert. Alle Mikro-CT-Aufnahmen wurden im Tagged Image File Format (TIFF) gespeichert. 

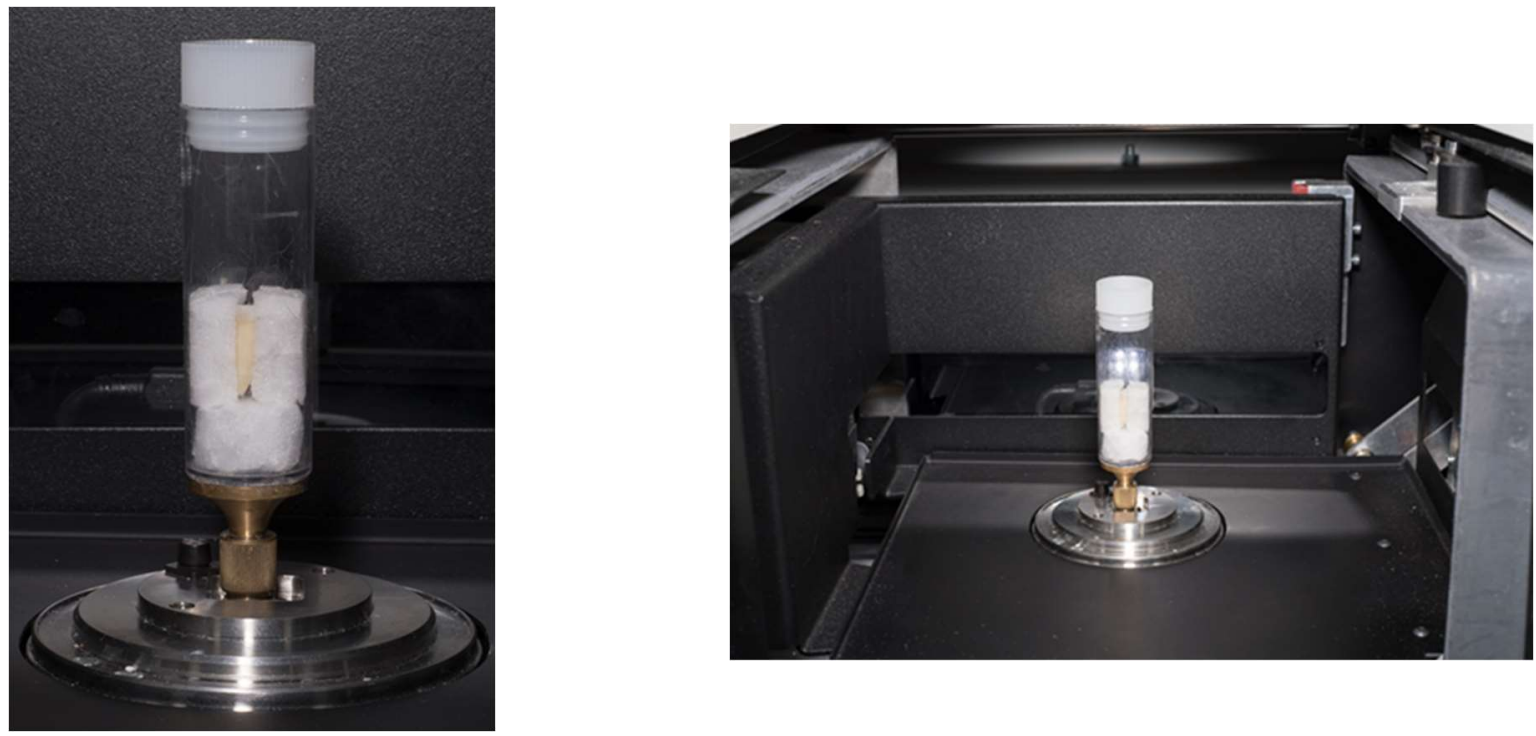

Abbildung 2-2: Positionierung der Probe im Trägerröhrchen (links) und Mikro-CT (rechts).

Vor dem Scan wurde die Position der Probe im Gerät unter kontinuierlicher Röntgenkontrolle überprüft und gegebenenfalls durch eine Seitwärts- oder Höhenverschiebung des Objektträgers korrigiert. Um sicher zu stellen, dass die Probe beim folgenden Scannen um ihre eigene Achse immer im Aufnahmebereich positioniert war, wurde eine Rotation um $360^{\circ}$ simuliert. Die Tabelle 2-2 zeigt die verwendeten Einstellparameter für jeden prä- und postoperativen Scan.

Tabelle 2-2: Einstellungsparameter des Scans.

\begin{tabular}{|l|l|}
\hline Einstellungsoption & Wert \\
\hline Röhrenspannung & $80 \mathrm{kV}$ \\
\hline Stromstärke & $125 \mu \mathrm{A}$ \\
\hline Filter & Aluminium, Dicke 1,0 mm \\
\hline Pixelgröße & $10,5 \mu \mathrm{m}$ \\
\hline Binning & $2452 \times 1640$ \\
\hline Detektor-Modus & $2 \times 2$ \\
\hline Belichtungszeit & $2,2 \mathrm{~s}$ \\
\hline Scandauer & $130 \mathrm{~min}$ \\
\hline
\end{tabular}

Für alle prä- und postoperativen Scans wurden die aufgeführten Einstellungen übernommen. 
Für eine Reduktion des Bildrauschens, wurde der Frame Average auf 3 festgelegt und aus drei Aufnahmen ein Bild berechnet. Während des Scans wurde die Probe um $180^{\circ}$ gedreht, wobei insgesamt 940 Bilder in Rotationsschritten von $0,2^{\circ}$ aufgenommen wurden.

\subsection{Rekonstruktion der präoperativen Mikro-CT-Aufnahmen}

Um mögliche Bewegungen der Probe während des Scanvorgangs und damit verbundene Unschärfen der Schnittbilder auszugleichen, wurden nach jedem Scan drei zusätzliche Bilder einer Probe in größeren, rotierenden Abständen aufgenommen. Vor der Rekonstruktion wurden diese Aufnahmen zur Korrektur möglicher Positionsabweichung in X- und Y- Richtung herangezogen und mit den eigentlichen Schnittbildern der gleichen Position des Hauptscans verglichen.

Für die Rekonstruktion der Schnittbilder wurde die NRecon-Rekonstruktionssoftware, Version 1.7.0.3, von SkyScan (Bruker) verwendet. Die rekonstruierten Querschnittsaufnahmen der erfassten Mikro-CT-Projektionen wurden dabei von einer zweidimensionalen Abbildung in eine dreidimensionale virtuelle Darstellung der Proben überführt. Für eine Reduktion der Artefakte wurde ein modifizierter Feldkamp-Algorithmus mit automatischer Anpassung an die Scan-Geometrie bei jedem Mikro-CT-Scan durchgeführt. Die rekonstruierten Schnittbilder wurden im Portable Network Graphics Format (PNG) im entsprechenden Dateienordner der jeweiligen Probe gespeichert. Pro Rekonstruktion wurden 1400 bis 1600 Querschnittsbilder erzeugt. Die Rekonstruktion umfasste die Aufhärtungskorrektur (Beam-Hardening Correction) 40\%, Ringartefaktkorrektur (Ring Artefact Correction) 11-18, Ausrichtungskorrektur (Post-Alignment) 3,5-5 und Glättungsfunktion (Smoothing) 0.

Die präoperativen mikrocomputertomografischen Aufnahmen dienten zum einen als Kontrolle für die postoperativen Mikro-CT-Aufnahmen und zum anderen zum Ausschluss von Proben, bei denen metallische Bestandteile (z. B. Amalgampartikel) Artefakte (Abbildung 2-3) in der Mikro-CT-Aufnahme verursachten. Diese Artefakte erschweren eine spätere Auswertung der Mikro-CT-Aufnahmen hinsichtlich der Identifikation von Dentinrissen. 


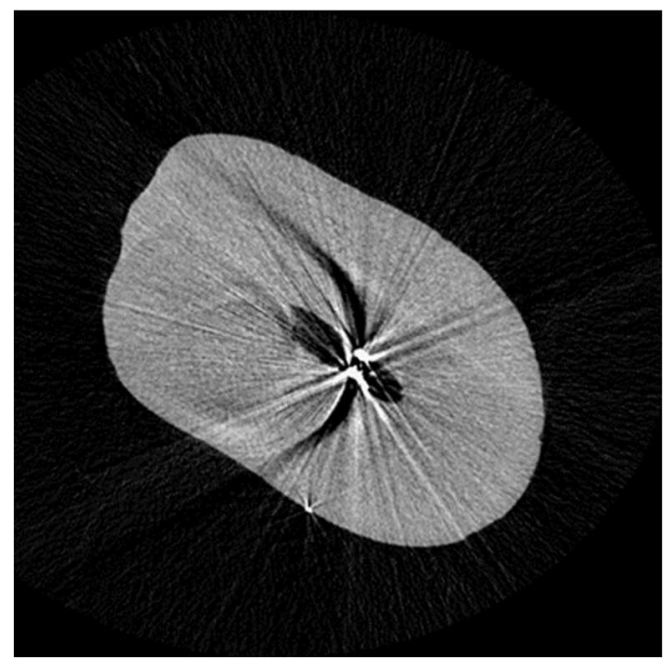

Abbildung 2-3: Metallische Artefakte im Wurzelkanal und der Außenfläche.

Die präoperativen Schnittbilder aller Proben wurden vor der Durchführung des Hauptversuchs von zwei Bewertern auf starke Artefakte überprüft. Dabei wiesen drei Proben der geraden und drei Proben der gekrümmten Wurzelkanäle sehr ausgeprägte Artefakte auf, so dass eine Bewertung der Schnittbilder im Hinblick auf Dentinrisse nicht möglich war. Diese Proben wurden verworfen, so dass für die Studie abschließend 33 Proben mit geraden und 33 Proben mit gekrümmten Wurzelkanälen zur Verfügung standen. 


\section{$2.4 \quad$ Gruppeneinteilung}

Die nach den präoperativen Mikro-CT-Aufnahmen ausgewählten Prämolaren und Molaren wurden anhand der Krümmungswinkel und -radien der Kanäle in sechs Gruppen unterteilt (Tabelle 2-3 und Tabelle 2-4). Dabei wurde jeder der drei Präparationstechniken jeweils eine Gruppe mit geraden und eine Gruppe mit gekrümmten Wurzeln randomisiert zugeordnet. Die statistische Analyse zur homogenen Verteilung der Mittelwerte zwischen den drei Gruppen erfolgte mit dem Kruskal-Wallis-Test $(P<0,05)$. Demnach wurden je 11 Proben mit geradem und 11 Proben mit gekrümmtem Wurzelkanal einer Präparationstechnik zugeordnet $(n=11)$.

Tabelle 2-3: Homogene Verteilung der Proben hinsichtlich ihrer Wurzelkanalkrümmungswinkel.

\begin{tabular}{|l|l|l|l|l|}
\hline & \multicolumn{2}{|l|}{$\begin{array}{l}\text { Gerade } \\
\text { Wurzelkanäle }\end{array}$} & \multicolumn{2}{l|}{$\begin{array}{l}\text { Gekrümmte } \\
\text { Wurzelkanäle }\end{array}$} \\
\hline Gruppe & Krümmung $1\left[^{\circ}\right]$ & Krümmung 2 $\left[^{\circ}\right]$ & Krümmung 1 $\left[^{\circ}\right]$ & Krümmung 2 $\left[^{\circ}\right]$ \\
\hline RP & $3,1 \pm 1,8$ & $5,3 \pm 3,1$ & $24,6 \pm 4,2$ & $7,8 \pm 5,4$ \\
\hline OS & $3,7 \pm 2,7$ & $5,3 \pm 3,2$ & $24,4 \pm 2,9$ & $8,4 \pm 5,3$ \\
\hline PTN & $3,8 \pm 3,0$ & $5,6 \pm 3,5$ & $25,0 \pm 6,6$ & $8,4 \pm 6,2$ \\
\hline & $\mathrm{P}=0,93$ & $\mathrm{P}=0,97$ & $\mathrm{P}=0,92$ & $\mathrm{P}=0,93$ \\
\hline
\end{tabular}

Werte in Grad [ ${ }^{\circ}$ ], ( $\mathrm{n}=11$ Wurzeln pro Gruppe), RP: Reciproc, OS: OneShape, PTN: ProTaper NEXT, Krümmung 1: Wurzelkrümmung in mesio-distaler Ebene, Krümmung 2: Wurzelkrümmung in bukko-oraler Ebene.

Tabelle 2-4: Homogene Verteilung der Proben hinsichtlich ihrer Wurzelkanalradien.

\begin{tabular}{|l|l|l|l|l|}
\hline & \multicolumn{2}{|l|}{$\begin{array}{l}\text { Gerade } \\
\text { Wurzelkanäle }\end{array}$} & $\begin{array}{l}\text { Gekrümmte } \\
\text { Wurzelkanäle }\end{array}$ \\
\hline Gruppe & Radius 1 [mm] & Radius 2 [mm] & Radius 1 [mm] & Radius 2 [mm] \\
\hline RP & $84,9 \pm 70,7$ & $62,0 \pm 69,0$ & $8,89 \pm 3,31$ & $73,3 \pm 155,4$ \\
\hline OS & $129,0 \pm 118,4$ & $101,7 \pm 146,1$ & $8,4 \pm 2,9$ & $39,4 \pm 46,4$ \\
\hline PTN & $270,1 \pm 674,3$ & $64,4 \pm 70,5$ & $9,2 \pm 2,4$ & $41,2 \pm 52,0$ \\
\hline & $P=0,84$ & $P=0,83$ & $P=0,81$ & $P=0,90$ \\
\hline
\end{tabular}




\subsection{Arbeitsschritte}

\subsubsection{Herstellung des parodontalen Ligamentes}

Für eine möglichst realistische Nachahmung der klinischen Situation wurde in Anlehnung an die Studie von (De-Deus et al. 2016) ein künstliches parodontales Ligament (PDL) hergestellt (Abbildung 2-4). Der Zeitpunkt dieser Herstellung lag dabei jeweils zwei Stunden vor Durchführung des postoperativen Scans. Die Wurzeloberfläche wurde nach Entnahme aus dem demineralisierten Wasser mit leichter Druckluft getrocknet. Das Trocknen der Wurzelkanäle erfolgte mit Papierspitzen der ISO-Größe 15. Um später eine gleichmäßige Schichtstärke des Polyethers um die Proben zu erzeugen, wurde jede Wurzel mit einem ca. 0,3 mm dicken Gewebeklebeband (PERFECT, tesa SE, Norderstedt) faltenfrei ummantelt. Dabei wurde darauf geachtet, dass sich die Klebeenden nicht überlappen, um zirkulär eine gleichmäßige Abdeckung zu erzielen. Zur Isolation wurde die Gewebebandoberfläche dünn mit Vaseline benetzt. Nach dem Anmischen des Kaltpolymerisat Technovit 4071 (Kulzer, Hanau) nach Herstellerangaben, wurden die Proben bis $1 \mathrm{~mm}$ unter dem koronalen Rand in den Kunststoff eingetaucht. Für eine bessere Handhabung und achsengerechte Positionierung der Proben im Kaltpolymerisat wurde ein Reamer der ISO-Größe 15 in den Kanal eingebracht. Nach der vollständigen Erhärtung des Kunststoffes wurden die Proben vorsichtig aus dem Kaltpolymerisat herausgelöst und das Klebeband sowie alle Klebereste sorgfältig entfernt. Anschließend wurde eine dünne gleichmäßige Schicht aus Polyether-Abformmaterial (Impregum F, 3M ESPE, St. Paul, MN, USA) auf die Wurzeloberflächen aufgetragen und die Probe in der Polymerisatform repositioniert.

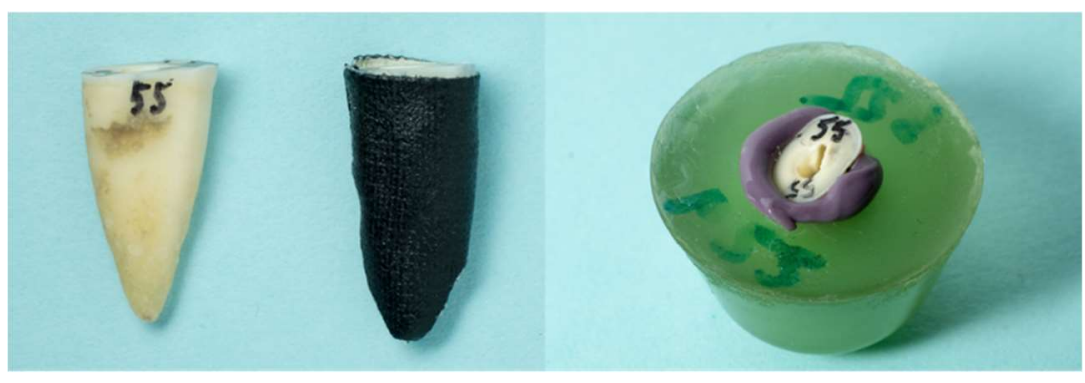

a)

b)

c)

Abbildung 2-4: Herstellung des PDLs.

a) Wurzel eines Prämolaren, b) Probe mit Gewebeklebeband umhüllt, c) Probe in Polyether und Kaltpolymerisat eingebettet. 
Nach dem Abbinden des Polyethers wurde der Reamer entfernt. Für die gesamte Dauer der Wurzelpräparation verblieben die Proben in dieser Form. Erst nach der Abschlussspülung wurden sie aus der Kunststoffform entnommen und eventuell verbliebene Reste des Polyethers vor dem postoperativen Mikro-CT-Scan entfernt.

\subsubsection{Wurzelkanalpräparation}

Je nach Gruppenzugehörigkeit wurden je 11 gerade und 11 gekrümmte Wurzelkanäle mit dem reziproken Ein-Feilen-System Reciproc (RP), dem rotierenden Ein-Feilen-System OneShape (OS) oder dem rotierenden Multi-FeilenSystem ProTaper NEXT (PTN) präpariert. Diese Nickel-Titan-Instrumente wurden mit Hilfe des Endomotors VDW.SILVER RECIPROC betrieben. Um die Vergleichbarkeit der einzelnen Präparationssysteme untereinander zu erhöhen, wurden gleiche bzw. ähnliche Instrumentengrößen und -konizitäten ausgewählt (RP 25/.08, OS 25/.08, PTN 25/.06). Die Arbeitslänge wurde auf 14 mm standardisiert. Jede der Proben wurde mit einem Gesamtvolumen von $20 \mathrm{ml} 3 \%$ iger Natriumhypochlorit-Lösung (NaOCl), $5 \mathrm{ml}$ 10\%iger Zitronensäure-Lösung und $5 \mathrm{ml}$ destilliertem Wasser gespült (De-Deus et al. 2017b). Zu diesem Zweck wurden die Spülflüssigkeiten mit der Endo-Eze-Spülkanüle (Ultradent Products, South Jordan, UT, USA) mit einem Durchmesser von 0,30 mm und einer Länge von $25 \mathrm{~mm}$ in die Wurzelkanäle eingebracht. Die Präparation der Wurzelkanäle mit dem Reciproc R25-Instrument erfolgte nach standardisierter Motoreinstellung des Herstellers VDW. Das OneShape-Instrument wurde mit $400 \mathrm{Umin}^{-1}$ und 2,5 $\mathrm{Ncm}$ betrieben. Für die Instrumente des ProTaper NEXT-Systems wurde der Motor entsprechend den Herstellerangaben auf $300 \mathrm{Umin}^{-1}$ und $2 \mathrm{Ncm}$ programmiert. Um die Gängigkeit des Gleitpfades zu überprüfen, wurde bei allen Proben vor der Präparation mit den entsprechenden Instrumenten die Arbeitslänge mit einem Reamer der ISO-Größe 15 kontrolliert und anschließend mit $5 \mathrm{ml} \mathrm{NaOCl}$ gespült. Proben, welche dem ProTaper NEXT-System zugeordnet wurden, wurden nach der präoperativen Gleitpfadkontrolle mit 2,5 ml NaOCl gespült. Alle Nickel-Titan-Instrumente wurden entsprechend der Herstellerangaben verwendet. 


\subsubsection{Präparation mit Reciproc R25}

Zur Präparation des koronalen Kanaldrittels wurde das Instrument mit Hubbewegungen in einer Amplitude von $3 \mathrm{~mm}$ nach apikal geführt. Anschließend wurde der Wurzelkanal mit $5 \mathrm{ml} \mathrm{NaOCl}$ gespült. Zur Überprüfung der Arbeitslänge wurde ein Reamer der ISO-Größe 15 in den Kanal eingebracht. Die weitere Präparation des Wurzelkanals erfolgte wie oben beschrieben bis zwei Drittel der Arbeitslänge erreicht wurden. Nach erneuter Spülung mit $5 \mathrm{ml} \mathrm{NaOCl}$ und Rekapitulation der Arbeitslänge erfolgte die Präparation auf vollständiger Arbeitslänge. Im Anschluss erfolgte eine Abschlussspülung mit $5 \mathrm{ml} \mathrm{NaOCl}, 5 \mathrm{ml}$ Zitronensäure und $5 \mathrm{ml}$ Aqua dest.

\subsubsection{Präparation mit OneShape}

Das OneShape-Instrument wurde bis zum Erreichen der koronalen zwei Drittel der Arbeitslänge in $3 \mathrm{~mm}$ langen Hubbewegungen nach apikal geführt. Anschließend erfolgte eine Spülung des Kanals mit $5 \mathrm{ml} \mathrm{NaOCl}$ und die Rekapitulation der Arbeitslänge mit einem Reamer der ISO-Größe 15. Während der weiteren Präparation wurde das Instrument in dem gleichen Bewegungsmuster bis $3 \mathrm{~mm}$ vor Erreichen der Arbeitslänge nach apikal geführt. Nach einer weiteren Spülung des Wurzelkanals mit $5 \mathrm{ml} \mathrm{NaOCl}$ und erneuter Rekapitulation der Arbeitslänge wurde die Feile in Hubbewegungen auf vollständige Arbeitslänge in den Kanal eingebracht. Es erfolgte eine Abschlussspülung mit $5 \mathrm{ml} \mathrm{NaOCl}, 5 \mathrm{ml}$ Zitronensäure und $5 \mathrm{ml}$ Aqua dest.

\subsubsection{Präparation mit ProTaper NEXT}

Das X1-Instrument wurde bis zum Erreichen der halben Arbeitslänge mit Hubbewegungen von $3 \mathrm{~mm}$ Amplitude nach apikal geführt. Anschließend wurde das Kanallumen mit $5 \mathrm{ml} \mathrm{NaOCl}$ gespült und die Arbeitslänge mit einem Reamer der ISO-Größe 15 kontrolliert. Danach wurde die X1-Feile wie zuvor beschrieben auf vollständige Arbeitslänge eingebracht. Nach erneuter Spülung mit $5 \mathrm{ml} \mathrm{NaOCl}$ und Kontrolle des Gleitpfades wurde die X2-Feile mit dem gleichen Bewegungsmuster bis zum Erreichen der halben Arbeitslänge nach apikal geführt. Nach erneutem Spülen mit $5 \mathrm{ml} \mathrm{NaOCl}$ und Rekapitulation wurde die Präparation bis zum Erreichen 
der vollständigen Arbeitslänge fortgesetzt. Im Anschluss wurde der Wurzelkanal mit 2,5 ml NaOCl, $5 \mathrm{ml}$ Zitronensäure und $5 \mathrm{ml}$ Aqua dest. gespült.

Alle NiTi-Instrumente wurden nach jeweils drei Hubbewegungen manuell von Debris und Dentinspänen im Interimsstand gereinigt. Die Instrumente wurden jeweils für die Präparation von zwei Wurzelkanälen verwendet und anschließend verworfen. Bei Anzeichen von vorzeitigem Verschleiß, Deformation oder Abnutzung wurde das Instrument sofort aussortiert.

Nach der Wurzelkanalpräparation wurden die Proben vorsichtig aus dem künstlichen parodontalen Ligament herausgelöst, eventuell vorhandene Reste des Polyethers entfernt und die äußere Oberfläche erneut mit leichter Druckluft von Feuchtigkeit getrocknet. Die Wurzelkanaltrocknung durch das Einbringen von Papierspitzen wurde ebenfalls wiederholt. Die Dauer des Hauptversuches betrug ca. 20 min. Im Anschluss lagerten die Proben trocken bei einer durchschnittlichen Luftfeuchtigkeit von $40-60 \%$ bis die Trocknungszeit von zwei Stunden erreicht wurde.

\subsection{Postoperative Mikro-CT-Aufnahmen}

Im Anschluss an die Wurzelkanalpräparation wurden die Proben erneut je einzeln, trocken und nahezu achsengerade mit Styroporstücken im Trägerröhrchen fixiert und am Miko-CT-Trägertisch befestigt. Die tägliche Kalibrierungsmaßnahme und alle Einstellung der präoperativen Scans wurden dabei übernommen.

\subsection{Rekonstruktion der postoperativen Mikro-CT-Aufnahmen und 3D- Registrierung}

Die Rekonstruktion der postoperativen Mikro-CT-Aufnahmen wurde entsprechend der präoperativen Rekonstruktion der Schnittbilder durchgeführt. Für die Beurteilung von Mikrorissen im Wurzeldentin nach der Instrumentierung der Wurzelkanäle wurden die prä- und postoperativen Querschnittsbilder der Proben in definierter Schnittbildebene miteinander verglichen. Da eine exakt gleiche Positionierung der Probe bei beiden Scanvorgängen im Mikro-CT nicht gewährleistet war, wurden die rekonstruierten prä- und postoperativen Schnittbilder 
einer Probe bei der 3D-Registrierung nahezu deckungsgleich in allen drei Raumebenen übereinandergelegt (Abbildung 2-5). Für die 3D-Registrierung wurde die Bildbearbeitungssoftware DataViewer (Version 1.5.4) der Firma Bruker verwendet. Das Rekonstruktionsprogramm errechnet aus dem Referenzdatensatz der präoperativen Messung, die größtmögliche Übereinstimmung in allen drei Raumebenen zum rekonstruierten postoperativem Datensatz. Dadurch werden präund postoperative Schnittbilder derselben Wurzelkanalebenen einer Probe erzeugt. Diese neuen Daten wurden entsprechend jeder Probe als reference-targetSchnittbilder im PNG Format gespeichert und für die anschließende Bildanalyse verwendet.

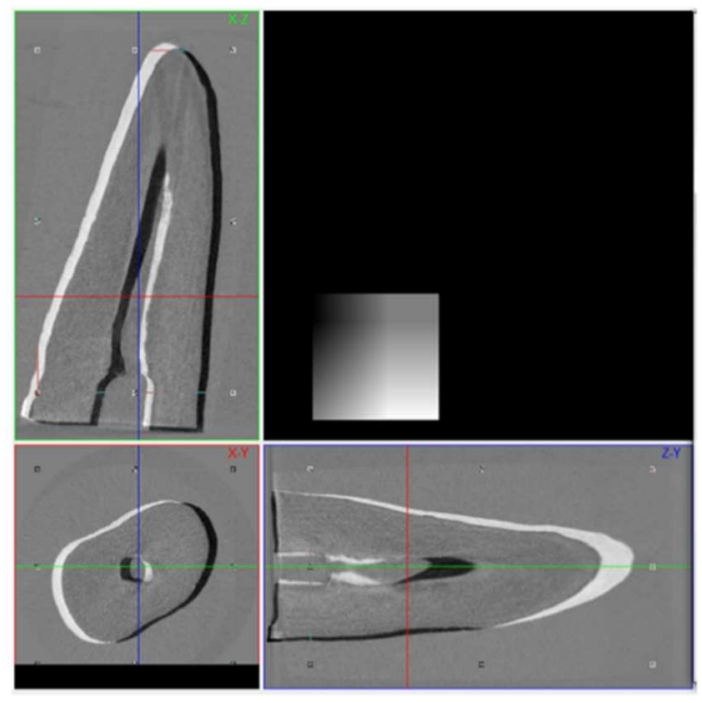

a)

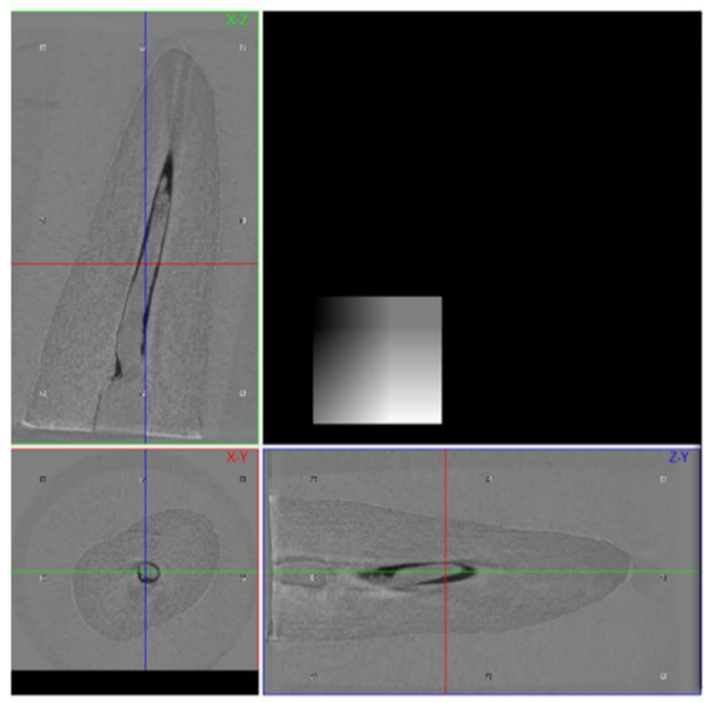

b)

Abbildung 2-5: 3D-Registrierung.

Die Überlagerung erfolgte in drei Ebenen, welche jeweils von den drei Bildern (Ebene X-Z-grün, Ebene X-Y-rot, Ebene Z-Y-blau) dargestellt wird. Die Lage der reference-Wurzel (präop, schwarze Kontur) wurde der targetWurzel (postop, weiße Kontur) angepasst. Darstellung a) zeigt die Situation vor der 3D-Überlagerung der präund postoperativen Bilder. Darstellung b) zeigt die Situation nach Ausrichtung der Schnittbilder zueinander.

\subsection{Auswahl der Schnittbilder und Analyse}

Für die Beurteilung der Rissentstehung im Wurzeldentin wurden alle prä- und postoperativen Scans $(n=75263$ ) von zwei kalibrierten Bewertern ausgewertet. Zunächst wurden die postoperativen Bilder verblindet in der Bildbearbeitungssoftware DataViewer (Version 1.5.4) analysiert und die Anzahl der Querschnitte, in denen Mikrorisse beobachtet wurden, dokumentiert. Beide Untersucher notierten das Vorkommen der Mikrorisse als ja- / nein-Entscheidung. 
Anschließend wurden die entsprechenden prä- mit den positiven postoperativen Querschnittsbildern verglichen, um das Vorhandensein der Mikrorisse zu verifizieren. Mikrorisse wurden als dünne Risslinien oder Defekte definiert, die sich entweder vom Wurzelkanallumen zum Dentin oder von der äußeren Wurzeloberfläche in das Dentin erstreckten, einschließlich vollständiger Frakturen, die sich vom Wurzelkanal bis zur äußeren Wurzeloberfläche durchzogen (Abbildung 2-6). Parallel zum Kanal verlaufende Risse, Risse von kariösen Defekten ausgehend oder Risse im Bereich der Furkation, wie in Abbildung 2-7, wurden nicht als Riss gewertet.

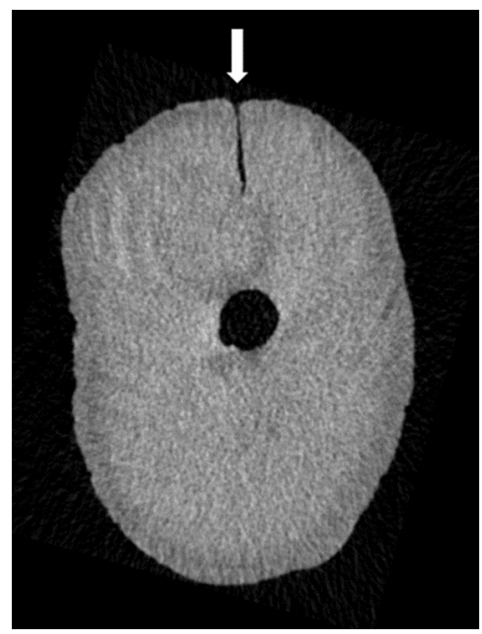

Abbildung 2-6: Querschnittaufnahme mit einem positiv gewerteten Mikroriss.

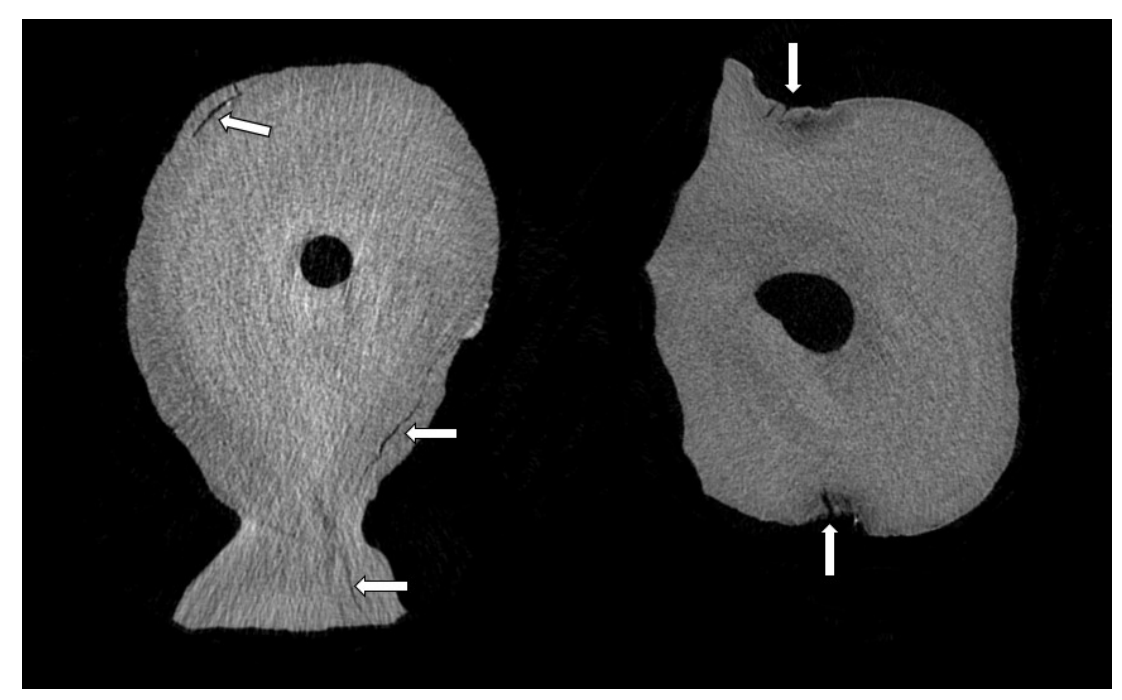

Abbildung 2-7: Querschnittaufnahmen mit nicht als Mikroriss gewerteten Defekten.

Aus dem Bereich der Furkation hervorgehende und zirkulär verlaufende (linkes Schnittbild) und aus kariösen Defekten (rechtes Schnittbild) entstandene Dentinrisse. 
Zur Validierung des Screening-Prozesses wurde die Bildanalyse zweimal im Abstand von zwei Wochen unter gleichen Bedingungen wiederholt. Bei Unstimmigkeiten zwischen den Bewertern wurden die Bilder erneut betrachtet und ein Konsens erzielt. Die Ergebnisse wurden für jede Probe in eine Excel-Tabelle (Microsoft) übertragen und anschließend der entsprechenden Gruppe zugeordnet. 


\section{Ergebnisse}

Insgesamt wurden 75263 Querschnittsbilder von geraden $(n=40290)$ und gekrümmten ( $n=34973)$ Wurzeln analysiert. Dabei zeigten $3,46 \%$ der geraden $(n=1394)$ und $2,41 \%$ der gekrümmten $(n=842)$ Wurzelkanäle Risse im Wurzeldentin. Bei geraden Wurzelkanälen wies die RP-Gruppe 4,67\% $(n=620)$ Mikrorisse auf, die OS-Gruppe 3,64\% ( $n=492)$ und die PTN-Gruppe 2,09\% $(n=282)$. In gekrümmten Wurzelkanälen wiesen 3,86\% $(n=455)$ der Querschnitte in der RPGruppe, 3,18\% $(n=369)$ in der OS-Gruppe und $0,16 \%(n=18)$ in der PTN-Gruppe Mikrorisse auf. Alle postoperativen Mikrorisse im Wurzeldentin bestanden bereits in den präoperativen Scans. Mit Hilfe des Mikro-CTs wurden nach der Präparation mit den drei NiTi-Instrumentensystemen keine neuen Mikrorisse im Wurzeldentin festgestellt. Die Abbildung 3-1 und Abbildung 3-2 zeigen prä- und postoperative Querschnittsaufnahmen. 


\section{Reciproc vor Präparation}

\section{nach Präparation}
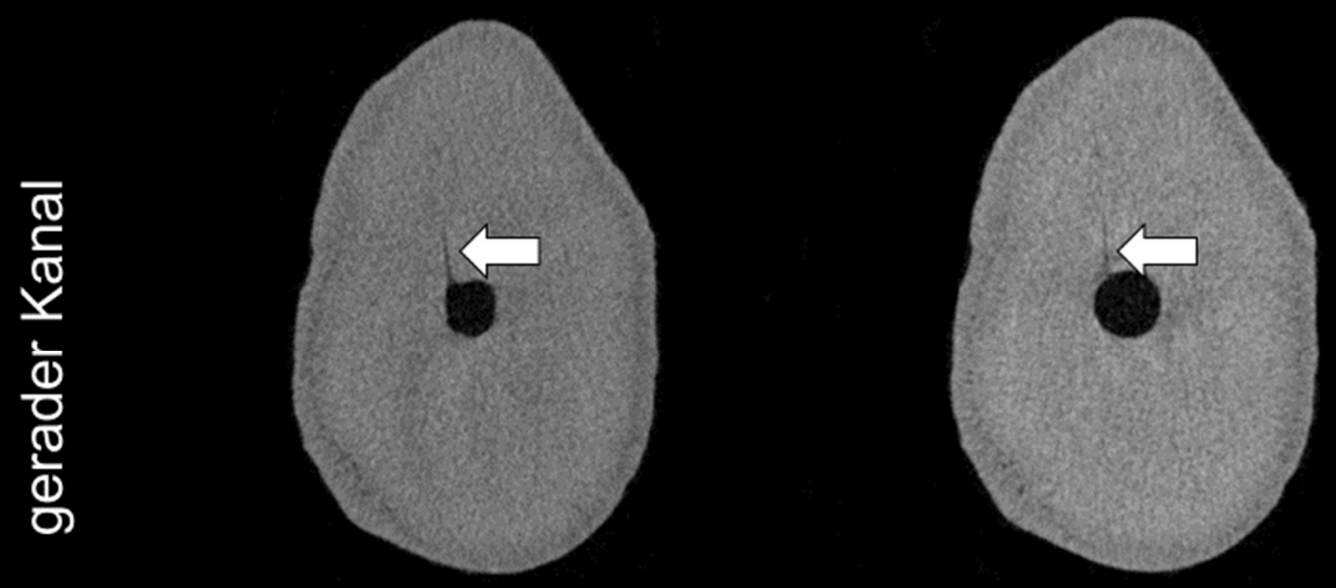

\section{OneShape}
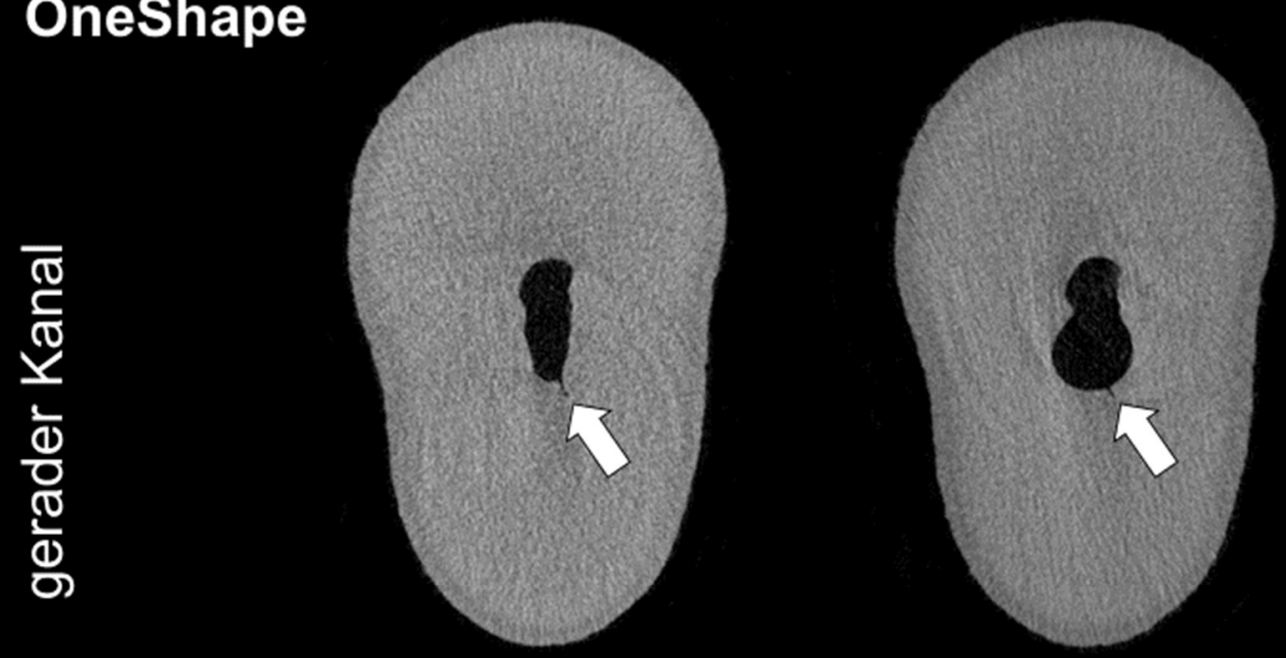

\section{ProTaper NEXT}

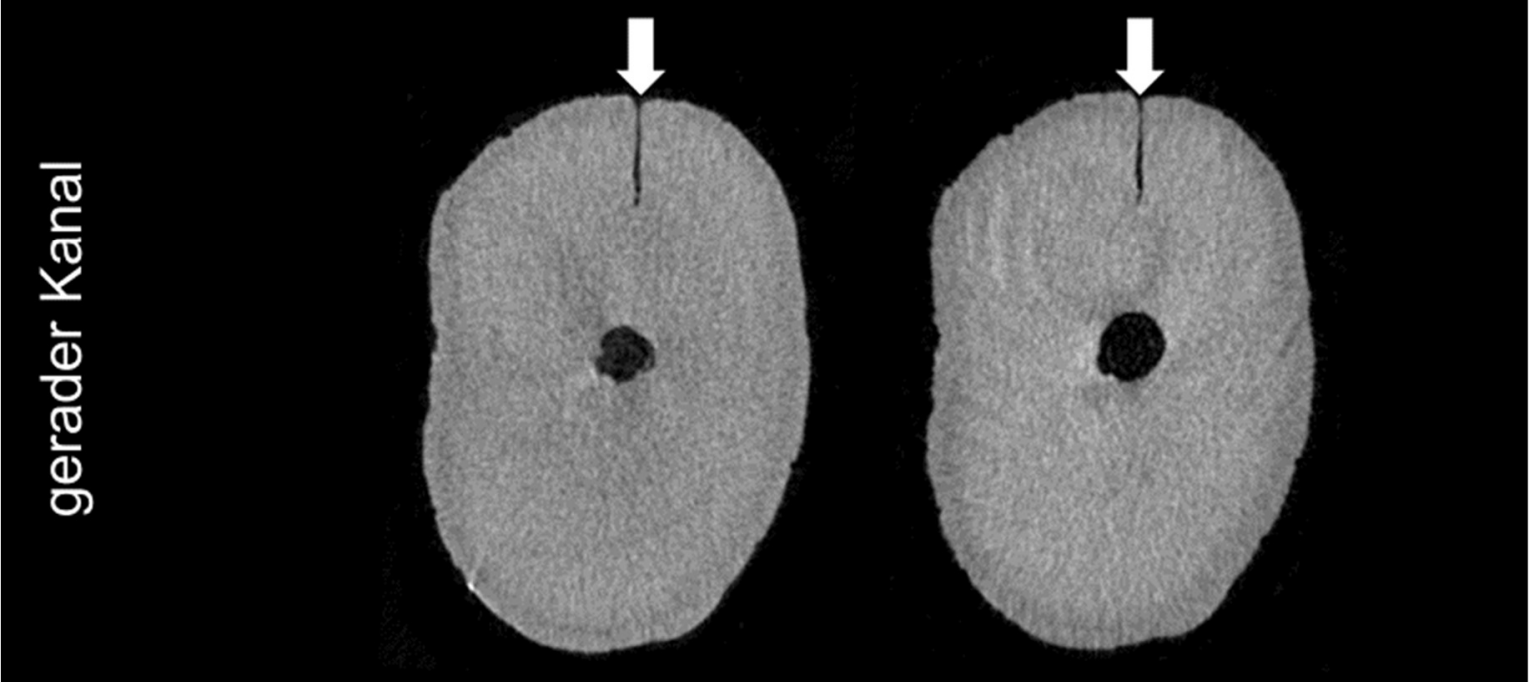

Abbildung 3-1: Querschnittbilder vor und nach der Präparation mit RP, OS und PTN an geraden Kanälen im Vergleich. 


\section{Reciproc vor Präparation}

\section{nach Präparation}
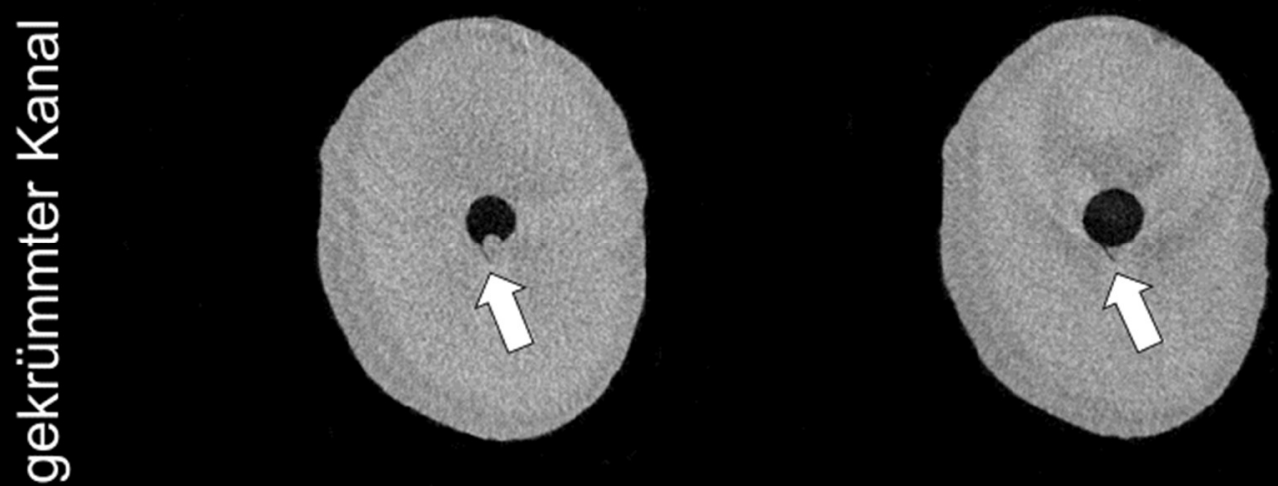

\section{OneShape}

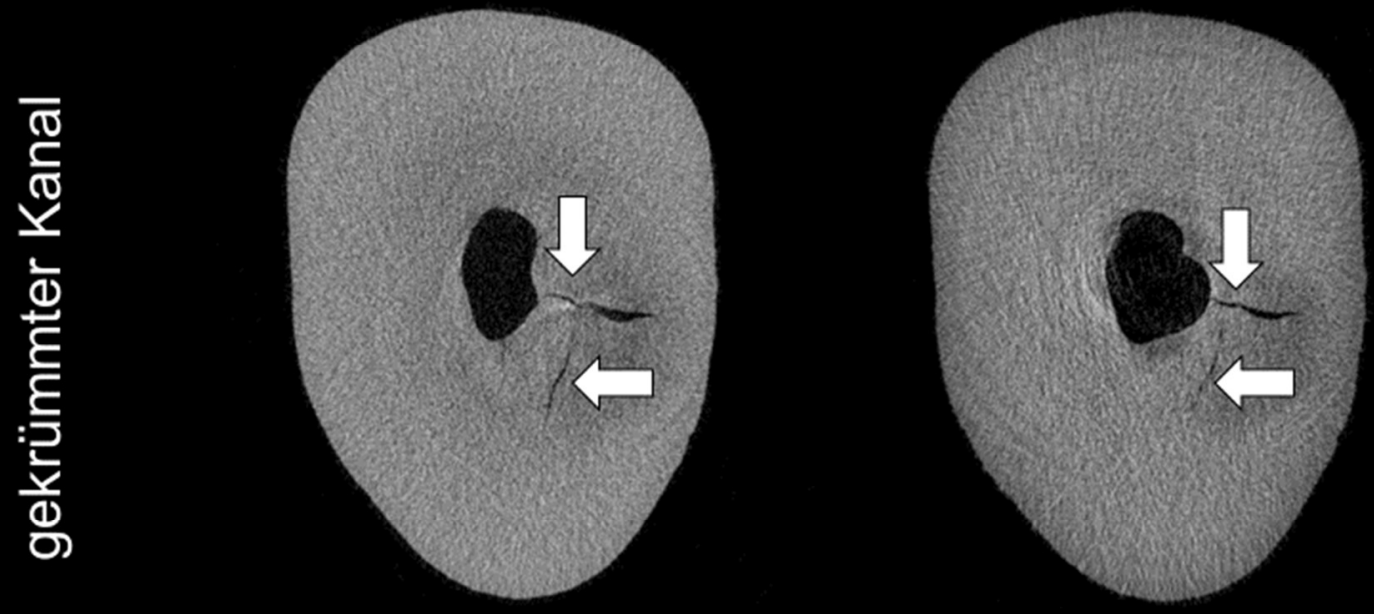

\section{ProTaper NEXT}
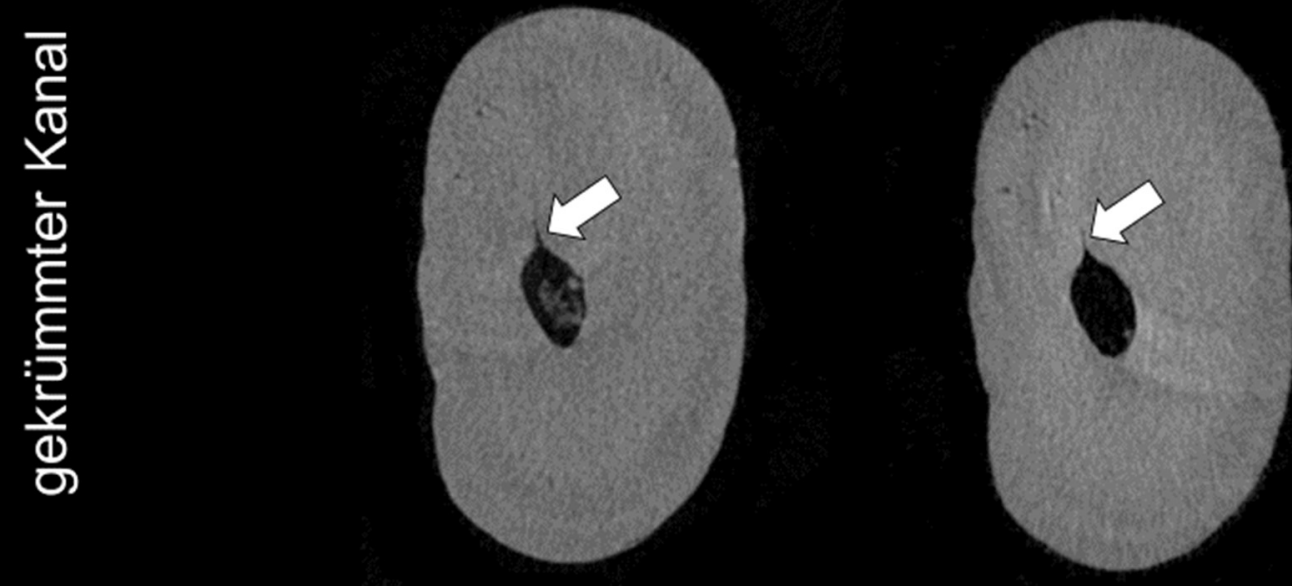

Abbildung 3-2: Querschnittbilder vor und nach der Präparation mit RP, OS und PTN an gekrümmten Kanälen im Vergleich. 


\section{Diskussion}

\subsection{Diskussion von Material und Methode}

\subsubsection{Probenauswahl und Gruppeneinteilung}

Für die vorliegende Studie wurden ausschließlich Wurzeln von Prämolaren des Ober- und Unterkiefers sowie palatinale Wurzeln von Oberkiefer- und distale Wurzeln von Unterkiefermolaren menschlichen Ursprungs verwendet. In der Literatur findet sich eine Vielzahl von Studien mit ähnlicher Fragestellung unter Verwendung des Mikro-CTs, welche ausschließlich Proben mit geraden Wurzelkanälen (Krümmungswinkel $<5^{\circ}$ ) von Frontzähnen (Bayram et al. 2017b; Cassimiro et al. 2017; Zuolo et al. 2017) und Prämolaren (Jamleh et al. 2015; Bayram et al. 2017a) oder ausschließlich Proben mit moderat gekrümmten Wurzelkanälen (Krümmungswinkel $10-20^{\circ}$ ) von Unterkiefermolaren (De-Deus et al. 2014; 2015; 2016; 2017b) berücksichtigten. Im Gegensatz dazu wurden in der vorliegenden Studie der Einfluss von rotierenden und reziproken NiTi-Instrumenten sowohl an geraden (Krümmungswinkel $<5^{\circ}$ ) als auch gekrümmten (Krümmungswinkel 20-40 ${ }^{\circ}$ ) Wurzelkanälen untersucht. Bislang finden sich in der Literatur keine Studien zur Rissentstehung im Wurzeldentin mit einem direkten Vergleich der verschiedenen Präparationstechniken sowohl an geraden als auch an stark gekrümmten Wurzelkanälen. Um standardisierte Bedingungen zu schaffen, wurden jeder der drei Präparationstechniken (Ein-Feilen-System, rotierend; Ein-Feilen-System, reziprok; Mehr-Feilen-System, rotierend) jeweils eine Gruppe mit geraden und eine Gruppe mit gekrümmten Wurzelkanälen randomisiert zugeordnet. Hierfür wurde die Berechnung des Krümmungswinkels nach Schneider (1971) und des Krümmungsradius nach Schäfer et al. (2002) herangezogen. Die Ermittlung des Krümmungswinkels basiert auf einem willkürlich errechneten Winkel als einzigem Parameter, um den Wurzelkanalverlauf in gerade, moderat gekrümmt und gekrümmt einzuordnen. Die Analyse mesialer Wurzeln unterer Molaren hinsichtlich ihrer Kanalkrümmung von Cunningham und Senia (1992) zeigte, dass die röntgenologische Bildgebung in mindestens zwei Ebenen unerlässlich sind. Hierbei handelt es sich allerdings um die Beschreibung eines dreidimensionalen Systems mit Hilfe zweidimensionaler röntgenologischer Abbildungen (Cunningham und Senia 1992). Pruett et al. (1997) stellten fest, dass zwei nach dem SchneiderVerfahren im gleichen Winkel gemessene Kanäle sehr unterschiedliche Radien 
oder abrupte Krümmungen aufweisen können. Viele Autoren ermittelten lediglich den Krümmungswinkel in einer röntgenologischen Ebene (Bürklein et al. 2013a; DeDeus et al. 2014; Pop et al. 2015; Li et al. 2017). Capar et al. (2014a), Bayram et al. (2017b) und Cassimiro et al. (2017) zogen jedoch Röntgenaufnahmen in mesiodistaler und bukko-lingualer Ebene für die Bestimmung der Krümmungswinkel heran. Die Ermittlung des Krümmungswinkels und -radius anhand von zwei Ebenen findet sich in nur wenigen Studien (Capar et al. 2014a; Rödig et al. 2014b; 2018a; Silva et al. 2018), obwohl dies eine deutlich exaktere Methode darstellt und zu einer besseren Standardisierung der Proben beiträgt.

In dieser Studie wurden von den Proben präoperativ Röntgenbilder in mesio-distaler und bukko-lingualer Ebene angefertigt. Anhand dieser Aufnahmen wurde die Berechnung von Krümmungswinkel und -radius von zwei kalibrierten Bewertern durchgeführt. Abweichungen zwischen den Bewertern hinsichtlich der Konstellation der geometrischen Bezugspunkte innerhalb des Kanalverlaufs wurden durch die Ermittlung des Mittelwertes ausgeglichen. Andere Autoren zogen diese Methode zur Ermittlung der Wurzelkanalkrümmung und -radius zur homogenen Verteilung der Proben in die Versuchsgruppen ebenfalls heran (Capar et al. 2014a; De-Deus et al. 2015; Bayram et al. 2017b; Cassimiro et al. 2017). Die Zuordnung der einzelnen Proben in die drei Gruppen (Präparationstechniken) erfolgte randomisiert, wobei die homogene Verteilung der Mittelwerte der Krümmungswinkel und -radien zwischen den Gruppen zu standardisierten Ausgangsbedingungen und besseren Vergleichbarkeit führte.

\subsubsection{Probenvorbereitung}

Präoperativ erfolgte der Ausschluss von Wurzeln mit mehr als einem Kanal, unvollständiger Instrumentierung bis zum Foramen apicale, mit kalzifizierten oder mit bereits präparierten Wurzelkanälen. Um eine einheitliche Länge aller Kanäle von $15 \mathrm{~mm}$ zu erreichen und somit eine vergleichbare Ausgangssituation ohne koronale Störfaktoren $\mathrm{zu}$ erzeugen, wurden die Proben entsprechend von koronal standardisiert eingekürzt.

In der Literatur finden sich verschiedene methodische Ansätze, um das parodontale Ligament zu simulieren. Neben der Ummantelung der Proben mit Wachs (Bortoluzzi 
et al. 2007; Cassimiro et al. 2018) wird alternativ Alufolie (Liu et al. 2013; Capar et al. 2014b; Pedullà et al. 2017) als Platzhalter verwendet, um den Raum zwischen Wurzeloberfläche und simuliertem Knochen zu erzeugen. In vielen Studien werden zur Simulation des Zahnhalteapparates Silikon oder Polyether sowie Acryl- oder Epoxidharzblöcke verarbeitet (Capar et al. 2014a; De-Deus et al. 2014; 2015; 2016; Cassimiro et al. 2017; Aksoy et al. 2019). In dieser Studie wurde ein Kaltpolymerisat auf Basis von hochvernetztem Methylmethacrylat zur Simulation des Alveolarknochens und ein Polyether für die künstliche Erzeugung des PDLs verwendet. Dieses künstliche parodontale Ligament soll die während der Wurzelkanalpräparation auftretenden Spannungen zwischen Wurzel und „Knochen“ absorbieren und die Bewegung des Zahnes (sowohl Rotation als auch Stoßbewegungen nach apikal) begrenzen (Okitsu et al. 2005; Cassimiro et al. 2017). Die viskoelastischen Eigenschaften des natürlichen PDLs (Dorow et al. 2002; Toms et al. 2002; Dorow et al. 2003) können mit diesen Materialien jedoch nicht vollständig nachgeahmt werden. Viskoelastische Phänomene können auf Flüssigkeitsflüsse und interne Konformationsänderungen von Faserstrukturen (Kollagen und Elastin) zurückgeführt werden (Natali et al. 2004). Die Konstruktion eines künstlichen PDL mit diesen einzigartigen viskoelastischen Eigenschaften ist bisher noch nicht gelungen (Natali et al. 2004; Arias et al. 2014; Brockmeyer et al. 2017). Aus diesem Grund diente das im Rahmen dieser Studie simulierte PDL in erster Linie zur verbesserten Fixation der Probe während des Präparationsvorganges.

Neben der einheitlichen Präparation der Zugangskavität mit Hilfe eines GatesGlidden-Bohrers wurde der Gleitpfad mit einem Reamer der ISO-Größe 15 bis auf einer standardisierten Arbeitslänge von $14 \mathrm{~mm}$ bei allen Proben etabliert. Somit wurde für alle Proben auch innerhalb des Wurzelkanals eine vergleichbare präoperative Ausgangssituation geschaffen.

\subsubsection{Instrumentenauswahl und Präparation}

Im Rahmen einer Wurzelkanalbehandlung sollen die verwendeten Instrumente verbliebenes Pulpagewebe und Dentinspäne entfernen und die Kanalwände entsprechend präparieren, ohne sie substanziell unnötig zu schwächen. Die Begradigung des Kanalverlaufs und daraus resultierende laterale oder apikale Perforationen sollen unbedingt vermieden werden. In den letzten Jahren hat sich 
die Präparation mit Instrumenten aus Nickel-Titan-Legierungen stark etabliert (Gambarini et al. 2010; Capar et al. 2014a; Cassimiro et al. 2017). Die strukturellen Merkmale der endodontischen Präparationssysteme sind weitgehend von der Geometrie des Instrumentenquerschnitts und der Wärmebehandlung der Legierungen abhängig (Versiani et al. 2015). Die technologische Weiterentwicklung hat bei rotierenden Nickel-Titan-Instrumenten zu neuen Konstruktionskonzepten sowie einfacheren und schnelleren Präparationstechniken geführt, die die ursprüngliche Kanalform mit wesentlich weniger iatrogenen Fehlern erhalten (Peters 2004; Gambarini et al. 2010). Dabei unterscheiden sich die Präparationssysteme unter anderem hinsichtlich ihrer Konizitäten entlang des Arbeitsteils und Schneidkantenkonfigurationen ( $\mathrm{Li}$ et al. 2017). Die während der Präparation entstehenden Spannungskonzentrationen im Dentin, welche aus dem Kontakt des endodontischen Instruments mit der Kanalwand resultieren, werden vielfach als eine Ursache für die Entstehung von Mikrorissen im Wurzeldentin diskutiert (DeDeus et al. 2014; Kansal et al. 2014; Ceyhanli et al. 2016; Cassimiro et al. 2018; Sousa-Neto et al. 2018).

Das Ein-Feilen-System Reciproc, welches sowohl in der primären Wurzelkanalpräparation als auch bei Revisionsbehandlungen verwendet werden kann, wurde bereits in einer Vielzahl von Studien hinsichtlich des Einflusses auf die Bildung von Mikrorissen im Dentin an geraden und gekrümmten Wurzelkanälen untersucht (Bürklein et al. 2013a; Liu et al. 2013; Capar et al. 2014a; De-Deus et al. 2014; 2017a; Pedullà et al. 2017; Zuolo et al. 2017; Cassimiro et al. 2018). Durch die reziproke Arbeitsbewegung schneidet sich das Instrument kontinuierlich in apikaler Richtung voran (Yared 2008; Bürklein et al. 2013b; Espir et al. 2018; SousaNeto et al. 2018). Nach Angaben einiger Autoren verringert dieses Bewegungsmuster das Risiko eines Torsionsbruchs, da das Instrument nicht den zunehmenden Belastungen ausgesetzt ist, die durch eine kontinuierliche Drehbewegung verursacht werden (Yared 2008; Varela-Patiño et al. 2010; Lopes et al. 2013; DeDeus et al. 2014; Pedullà et al. 2016; Espir et al. 2018). Neben dieser Feile ist das Instrument WaveOne ebenfalls ein Hauptvertreter für die im Handel erhältlichen EinFeilen-Systeme mit reziprokem Bewegungsmuster (De-Deus et al. 2014). Mehrere Studien belegen die Sicherheit gegenüber Instrumentenfrakturen und Effektivität dieser reziproken Arbeitsweise (Bürklein et al. 2012; Siqueira et al. 2013b; Versiani et al. 2013). Dennoch wurden Bedenken hinsichtlich einer möglichen schädlichen 
Einwirkung dieser Kinematik auf das Wurzeldentin geäußert. Demnach könnten reziproke Präparationsinstrumente die Entwicklung oder Ausbreitung von Dentinmikrorissen und Dentinschäden eher fördern als herkömmliche VollsequenzRotationssysteme (Bürklein et al. 2013a; Cassimiro et al. 2018). Laut der Analysen von Bürklein et al. (2013a) und Cassimiro et al. (2018) anhand von Sägeschnitten erzeugte die Instrumentierung mit dem Feilen-System Reciproc mehr oder verstärkte bereits bestehende Dentindefekte, als die Anwendung von Mehr-FeilenSystemen (Bürklein et al. 2013a).

Ein weiteres Konzept der Ein-Feilen-Instrumentierung besteht darin, dass ein einzelnes Instrument in einer kontinuierlichen Rotationsbewegung verwendet wird. Als Vertreter dieses Präparationssystems wurde für diese Studie das Ein-FeilenSystem OneShape ausgewählt. Die aus konventioneller NiTi-Legierung hergestellte Feile zeigt im apikalen Abschnitt einen fast dreieckigen Querschnitt, der sich progressiv ändert und im koronalen Teil in einen modifizierten Querschnitt mit zwei Schneidkanten übergeht (Liu et al. 2013; Pedullà et al. 2017). Durch dieses Instrumentendesign soll eine optimale Schneidwirkung erzeugt und ein Einschrauben und Verkeilen des Instruments bei kontinuierlicher Rotation verhindert werden (Bürklein et al. 2013b; Li et al. 2017). Laut Bürklein et al. (2013b) gibt es keinen signifikanten Unterschied zwischen den Systemen Reciproc und OneShape in Bezug auf präparationsbedingte Kanalbegradigung, Änderungen der Kanaloberfläche und Zentrierung im Kanal während der Präparation und bestätigt die Sicherheit des Instruments hinsichtlich seines Bruchverhaltens. Zu gleichen Ergebnissen kamen Capar et al. (2014a), wobei weiterhin festgestellt wurde, dass Reciproc im Vergleich zu OneShape einen effektiven und höheren Dentinabtrag ermöglicht. Der Einfluss der Instrumentengeometrie des OneShape-Instruments auf die Entstehung von Rissen im Wurzeldentin wurde bereits in früheren Sägeschnitt(Liu et al. 2013; Pedullà et al. 2017) und Mikro-CT-Studien (Li et al. 2017) diskutiert. Die Autoren kamen zu dem Ergebnis, dass OneShape besonders im koronalen und apikalen Abschnitt der Proben die Bildung von Rissen induziert (Liu et al. 2013; Li et al. 2017; Pedullà et al. 2017). Das Gewindedesign im medialen Teil des Arbeitsteils ist ein Übergangsbereich, der sich von drei Klingen auf zwei ändert. $\mathrm{Li}$ et al. (2017) nahmen an, dass diese Feilenkonstruktion erklären kann, warum im medialen Abschnitt des Wurzelkanals keine Mikrorisse erzeugt wurden. 
Das in dieser Studie verwendete Mehr-Feilen-System ProTaper NEXT besteht aus einer wärmemodifizierten M-Wire-Legierung und verfügt über einen exzentrischen Instrumentenquerschnitt, der die Festigkeit und Flexibilität des aktiven Instrumentenabschnittes verbessert (De-Deus et al. 2015). Aufgrund des rechteckigen Instrumentenquerschnitts führt die Rotationsbewegung zu einer asymmetrischen Drehbewegung, wodurch der Einschraubeffekt des Instruments durch Minimierung der Kontaktfläche zwischen der Feile und der Dentinwand verringert werden soll (De-Deus et al. 2015). Durch diese Instrumentengeometrie kann jede der Feilen des ProTaper NEXT-Systems eine größere Oberfläche innerhalb des Wurzelkanals präparieren als vergleichbar große Instrumente mit symmetrisch zentrierter Rotationsachse (Capar et al. 2014a). Diese Konstruktionsmerkmale können sich auf den Einschraubeffekt des Feilensystems, die intraoperativen Drehmomentwerte und die Verformung der Instrumente auswirken (Bürklein et al. 2014; Drukteinis et al. 2019). Hinsichtlich der Erweiterung des Wurzelkanalvolumens, unpräparierter Oberfläche, Extrusion von Debris, Zentrierung im Kanal, Kanalbegradigung und Präparationszeit ist dieses NiTiFeilen-System vergleichbar mit anderen Einzel- oder Mehr-Feilen-Systemen (Bürklein et al. 2014; Brasil et al. 2017; Drukteinis et al. 2019; van der Vyver et al. 2019).

In einer Studie von van der Vyver et al. (2019) wurde festgestellt, dass bei der Präparation mit PTN mehr Dentin abgetragen wird, als durch die Präparation mit OS. Aufgrund dieses Substanzverlustes könnte die Wurzel anfälliger gegenüber Wurzelfrakturen werden (Gagliardi et al. 2015).

Kim et al. (2010) beschrieben mit Hilfe der Finite-Elemente-Analyse, einem nummerischen Verfahren zur Berechnung von Verformungen und Spannungseinflüssen auf geometrische Körper, die mögliche Korrelation zwischen dem Design von NiTi-Instrumenten und der Entstehung von Dentindefekten. Sie beobachteten, dass die durch diese Instrumente verursachten Spannungskonzentrationen an der Wurzelkanalwand das Risiko von Dentinschäden erhöhten. Das Design des Instrumentenquerschnitts beeinflusst das Ausmaß der Kontaktfläche mit der Wurzelkanaloberfläche, wodurch das erzeugte Spannungspotenzial je nach Präparationssystem unterschiedlich ist. Ein stärkerer Kontakt des Instruments mit den Kanalwänden kann die Bildung von Dentindefekten auslösen (Kansal et al. 2014). 
Die Handhabung und Motoreneinstellung der in dieser Studie verwendeten Präparationsinstrumente erfolgte nach Herstellerangaben. Bei keinem NiTi-System traten Instrumentenfrakturen oder Perforationen der Wurzel auf. Für eine annährend standardisierte Präparation wurden aus dem jeweiligen Präparationssystem die Instrumentengröße von 0,25 mm (PTN X1 0,17 mm, X2 0,25 mm) und annährend gleicher Konizität (RP 8\%, OS 6\%, PTN X1 4\%, X2 6\%) gewählt. Die Qualität der Präparation, d. h. Dentinabtrag, Volumenveränderung, Dentintransport etc. war nicht Gegenstand dieser Studie und wurde dementsprechend nicht bewertet.

\subsubsection{Das Spülprotokoll}

Bedingt durch die komplexe Anatomie des Endodonts wird eine ausreichende Präparation der Wurzelkanaloberfläche mit manuellen und maschinellen NiTiSystemen nicht erreicht. Rund $80 \%$ der Oberfläche von Wurzelkanälen mit ovalem Querschnitt bleiben nach der Instrumentierung unpräpariert (Paqué et al. 2010). Spüllösungen sollen sowohl die mikrobielle Belastung des Kanalsystems reduzieren als auch verbliebenes Pulpagewebe auflösen und entfernen. Des Weiteren sollen die während der Präparation entstehenden Dentinspäne abtransportiert werden. In dieser Studie wurde $20 \mathrm{ml} 3 \%$ iges $\mathrm{NaOCl}, 5 \mathrm{ml}$ 10\%ige Zitronensäure und $5 \mathrm{ml}$ destilliertes Wasser verwendet. Laut Stellungnahme der DGZMK (2006) wird Natriumhypochlorit in einer Konzentration von $0,5 \%$ bis $5 \%$ empfohlen. $\mathrm{NaOCl}$ ist aufgrund seiner antimikrobiellen und gewebelösenden Aktivität die am häufigsten verwendete endodontische Spülflüssigkeit (Stojicic et al. 2010). Die Verwendung von $\mathrm{NaOCl}$-Lösungen bleibt aufgrund der einzigartigen Proteolysekapazität des Gewebes und der antimikrobiellen Effektivität der Goldstandard für die Wurzelkanaldesinfektion (Souza et al. 2014). Sim et al. (2001) stellten allerdings fest, dass durch die Verwendung von 5,25\%igen $\mathrm{NaOCl}$ der Elastizitätsmodul und die Biegefestigkeit von Dentin signifikant abnimmt. Baumgartner und Cuenin (1992) untersuchten die Effektivität von $\mathrm{NaOCl}$-Lösungen unterschiedlicher Konzentrationen (0,5-5,25\%) hinsichtlich der Entfernung von Debris und Smear Layer und kamen zu dem Schluss, dass kein Unterschied besteht. Aufgrund der bei steigender Konzentration zunehmenden zytotoxischen Nebenwirkungen auf das periradikuläre Gewebe wird die Anwendung von niedrig konzentriertem $\mathrm{NaOCl}$ 
empfohlen (Zehnder 2006). Bedingt durch die Reduktion des Elastizitätsmoduls und der Biegefestigkeit des Dentins und damit potenziell die Rissentstehung im Wurzeldentin während der Präparation zu begünstigen, wurde eine Konzentration der NaOCl-Spülung von 3\% gewählt. Höhere Konzentrationen könnten zur Verfälschung der Ergebnisse dieser Studie beitragen. Die gewählte Konzentration repräsentiert eine akzeptable Balance von Wirkung und Nebenwirkung der $\mathrm{NaOCl}$ Spülflüssigkeit.

Nach der Wurzelkanalpräparation wurde neben $\mathrm{NaOCl}$ zur Entfernung der organischen Bestandteile der Schmierschicht auch 10\%ige Zitronensäure für die Entfernung der anorganischen Matrix verwendet. Diese präparationsbedingt entstehende Schmierschicht besteht aus Dentin, Pulparesten und Bakterien und kann zur Verblockung der Dentintubuli führen. In der endodontischen Anwendung werden Konzentrationen von 10-20\% empfohlen. Der Einsatz höher konzentrierter Chelatoren führt allerdings zum Auflösen des peritubulären Dentins (DGZMK 2006), wodurch sich die tubulären Durchmesser vergrößern (Chockattu et al. 2017). Die damit verbundene Dentinerosion kann die Entstehung und Ausbreitung von Mikrorissen während der endodontischen Behandlung begünstigen (Adl et al. 2015; Baldasso et al. 2017). Um diesen Einflussfaktor zu minimieren, wurde eine entsprechend niedrige Konzentration der Zitronensäure gewählt. Verbleibende Rückstände der Spüllösungen können aufgrund ihrer höheren Einwirkdauer auf der Dentinoberfläche zu vermehrter Erosion und Verlust der Elastizität des Dentins führen (Sim et al. 2001; Zehnder 2006; Ramírez-Bommer et al. 2018). Um die weitere Beeinflussung der Dentinoberfläche durch diese Rückstände nach der Abschlussspülung zu vermeiden, erfolgte die Spülung der Wurzelkanäle mit destilliertem Wasser und eine anschließende Trocknung mit Papierspitzen.

\subsubsection{Darstellung der Mikrorisse und Bildbewertung}

Für die Darstellung der Mikrorisse im Wurzeldentin wurde in dieser Arbeit der MikroComputertomograf SkyScan 1272 der Firma Bruker verwendet. Die Anwendung von Mikro-CTs in der endodontischen Forschung wurde neben der stereomikroskopischen Bewertung von Sägeschnitten, mit oder ohne Verwendung verschiedener Färbelösungen (Landrigan et al. 2010), in der Literatur vielfach beschrieben (Jamleh et al. 2015; Pop et al. 2015; Bayram et al. 2017a; Cassimiro 
et al. 2017; De-Deus et al. 2017a; 2019; Li et al. 2017; Aksoy et al. 2019). Die Anwendung der Mikro-CT-Technologie ist derzeit allerdings auf In-vitro-Studien begrenzt. Zum einen werden hochenergetische Röntgenstrahlen, die bei der Durchdringung dichter Materialien wirksamer sind, verwendet. Zum anderen liegen die Belichtungszeiten der Objekte bei mehreren Minuten bis Stunden und stellen eine enorme Strahlenbelastung dar.

Die Qualität der erzeugten Mikro-CT-Aufnahmen wird von verschiedenen Faktoren beeinflusst. Metallische Restaurationen oder Füllungsbestandteile verursachen Artefakte und haben somit einen negativen Einfluss auf die Beurteilung der entstandenen Schnittbilder. Des Weiteren können während des Scanprozesses sogenannte Bewegungsartefakte auftreten. Diese entstehen, wenn sich die Probe während des Scanvorgangs in ihrer Lage verändert.

Der Einsatz der Mikro-CT-Technologie in der zahnmedizinischen Forschung hat zu einem umfassenderen Verständnis hinsichtlich der Bildung von Mikrorissen im Dentin geführt (De-Deus et al. 2017a). Hierbei wird eine hochgenaue und zerstörungsfreie Technologie, mit der die Proben in allen Raumebenen während des gesamten experimentellen Verfahrens untersucht werden können, genutzt. Folglich dient jeder Zahn als seine eigene Kontrolle, wodurch die interne Validität des Versuchs erhöht wird (Versiani et al. 2015; De-Deus et al. 2017b). Hunderte von 2D-Schnittbildern können pro Probe nach verschiedenen Behandlungsschritten ausgewertet werden. Die Ausdehnung vorhandener Defekte im Dentin lassen sich somit zu jedem Untersuchungszeitpunkt innerhalb der gesamten Probe auch in ihrem Verlauf verfolgen (De-Deus et al. 2014; 2015; 2016). So werden bereits präoperativ vorhandene Risse erkannt und eventuell durch endodontische Maßnahmen neu entstandene Risse können präzise lokalisiert werden.

Die Ergebnisse unlängst durchgeführter Mikro-CT-Studien mit rotierenden und reziproken Instrumenten zeigten, dass in den postoperativen Bildern beobachtete Mikrorisse bereits im entsprechenden präoperativen Bild vorhanden waren und kein kausaler Zusammenhang zwischen der Bildung von Mikrorissen im Dentin und der Wurzelkanalpräparation festgestellt wurde (De-Deus et al. 2014; 2015; 2016; Bayram et al. 2017b; Cassimiro et al. 2017; Rödig et al. 2018b). Diese Ergebnisse stehen im Gegensatz zu früheren Veröffentlichungen, in denen ein direkter Zusammenhang zwischen der Instrumentierung der Wurzelkanäle und der 
Initiierung und Ausbreitung von Mikrorissen im Dentin gezeigt wurde (Bürklein et al. 2013a; Liu et al. 2013; Capar et al. 2014b; Jamleh et al. 2015; Karataş et al. 2015; Bayram et al. 2017b; Cassimiro et al. 2018). Die Gründe für diese unterschiedlichen Ergebnisse können unter anderem durch abweichende Präparationsprotokolle, methodische Ansätze hinsichtlich der Rissdetektion, Auswahl der Proben, sowie Lagerungsbedingungen der Proben, Terminologie und Klassifizierung der Dentindefekten erklärt werden (Versiani et al. 2015). Nicht immer finden sich in der Literatur Studien mit all diesen umfangreichen Angaben, so dass die Beurteilung der Ergebnisse nicht immer valide ist.

Der destruktive Ansatz der häufig angewendeten Schnittmethode zur Beurteilung der Rissentstehung wird in einer Vielzahl von Studien diskutiert (Bürklein et al. 2013a; Hin et al. 2013; Liu et al. 2013; Karataş et al. 2015; Cassimiro et al. 2018). Besonders der unbekannte präoperative Zustand des Dentins der Proben erschwert die valide Auswertung der wenigen Dentinscheiben nach dem Schneiden der Wurzel (Versiani et al. 2015; De-Deus et al. 2016). Bedingt durch die Auswertung von nur wenigen Schnitten im Vergleich zur Anwendung eines Mikro-CTs, besteht die Möglichkeit, dass vertikale Risse zwischen den Schnittebenen nicht in der Auswertung berücksichtigt werden (Versiani et al. 2015). Die vertikale Ausbreitung von Rissen entlang der Wurzel kann bei dieser Methode nicht bewertet werden. Idealerweise sollten ätiologische Faktoren, welche die Entstehung von Rissen im Wurzeldentin begünstigen, durch eine zerstörungsfreie experimentelle Methode beurteilt werden, welche eine prä- und postoperative Untersuchung des Dentin ermöglichen (De-Deus et al. 2016). So lassen sich Rückschlüsse ziehen, ob die postoperativ detektierten Risse bereits präoperativ vorhanden waren. Die Anwendung des Mikro-CTs ermöglicht damit, ein Verständnis für den komplexen und multifaktoriellen Entstehungsmechanismus der Rissbildung und -ausbreitung sowie Kausalität durch endodontischen Verfahren zu schaffen (De-Deus et al. 2016).

Häufig fehlt es auch an Informationen über den Feuchtigkeitsgehalt der Proben während des Scanvorgangs, d. h. ob die Proben trocken oder feucht unmittelbar vor und während des Scans gelagert wurden. Einige Autoren sehen einen Zusammenhang zwischen dem Feuchtigkeitsgehalt der Proben während der gesamten Versuchszeit und der Entstehung von Mikrorissen im Wurzeldentin (Bürklein et al. 2013a; De-Deus et al. 2017b). Laut De-Deus et al. (2017b) hatte ein 
25-minütiger Scanvorgang unter trockenen Bedingungen keinen Einfluss auf die Mikrostruktur des Dentins. Rödig et al. (2018b) untersuchten ebenfalls den Einfluss des Feuchtigkeitsgehalts im Wurzeldentin auf die Erkennung von Mikrorissen mit Hilfe des Mikro-CTs. Nach nasser Lagerung der Proben wurden kaum Risse beobachtet, wobei eine 2-stündige Trockenzeit der Proben zu einer signifikanten Zunahme der Risse führte. Die Hypothese, dass neue Rissen durch eine Trocknungszeit von 24 Stunden entstehen würden, wurde widerlegt (Rödig et al. 2018b). Es ist somit möglich, dass das Scannen feuchter Proben zu falsch negativen Ergebnissen führen kann (Rödig et al. 2018b). Aufgrund dieser Erkenntnisse wurde in dieser Studie eine standardisierte Trocknungszeit der Proben von zwei Stunden vor Beginn des Scanprozesses gewählt.

In Anlehnung an Studien mit vergleichbaren Versuchsaufbau (De-Deus et al. 2014; 2015; 2016; Bayram et al. 2017b; Cassimiro et al. 2017) wurden in dieser Studie alle vorhandenen postoperativen Schnittbilder verblindet von zwei Untersuchern auf das Vorhandensein von Mikrorissen bewertet. Diese wurden vorab definiert und die Bewerter entsprechend kalibriert. Als Mikrorisse wurden dünne Risslinien oder Defekte definiert, die sich entweder vom Wurzelkanallumen zum Dentin oder von der äußeren Wurzeloberfläche in das Dentin erstreckten, einschließlich vollständiger Frakturen, die sich vom Wurzelkanal bis zur äußeren Wurzeloberfläche durchzogen. Parallel zum Kanal verlaufende Risse, Risse von kariösen Defekten ausgehend oder Risse im Bereich der Furkation wurden nicht als Riss gewertet. Die Dokumentation der Risse beschränkte sich auf eine ja-/neinEntscheidung und berücksichtigte nicht die Ausdehnung oder Formveränderung der Dentindefekte. Positiv bewertete Bilder wurden mit den präoperativen Aufnahmen verglichen. Zur Validierung des Screening-Prozesses wurde die Bildanalyse zweimal im Abstand von zwei Wochen unter gleichen Bedingungen wiederholt. Die Ergebnisse stimmten innerhalb eines Untersuchers und zwischen den Untersuchern bei beiden Analysen überein.

Ein entscheidender Nachteil der Untersuchungen an extrahierten Zähnen liegt in der Gewinnung der Proben. Sie sind während des Extraktionsvorganges starken Kräften ausgesetzt, welche eine Prädisposition für die Entstehung von Rissen im Wurzeldentin darstellen könnte (Arias et al. 2014). Einen neuen methodischen Ansatz sehen einige Autoren in der Verwendung von Leichenpräparaten bei denen die Proben in situ verbleiben (Arias et al. 2014; Bahrami et al. 2017; De-Deus et al. 
2017a). Die Untersuchungen beschränken sich derzeit auf Proben mit gerader Wurzel (Frontzähne und Prämolaren) in mandibulären und maxillären Knochenblöcken. Da die Proben während der Präparation in ihrem natürlichen Zahnhalteapparat verbleiben, können die während der Instrumentierung auf das Dentin einwirkenden Kräfte optimal durch die viskoelastischen Eigenschaften des PDL absorbiert werden. Als Ursache der in den Mikro-CT-Studien vorhandenen präoperativen Risse werden neben den übermäßigen Kräften während des Extraktionsvorgangs außerdem vorangegangene okklusale Funktionsstörungen oder Traumata diskutiert (Barreto et al. 2012; De-Deus et al. 2017a).

In einer ersten Studie mit derartigen Leichenpräparaten von Arias et al. (2014) wurden jeweils sechs untere Schneidezähne mit einem Ein-Feilen-System (WaveOne) und einem Mehr-Feilen-System (ProFile GT, Dentsply Sirona) instrumentiert. Die Auswertung erfolgte mittels der destruktiven Schnittmethode und der Betrachtung der Schnitte unter einem Stereomikroskop und ist daher kritisch zu beurteilen. In allen Schnittebenen der präparierten Proben und ebenfalls in der unpräparierten Kontrollgruppe wurden Mikrorisse festgestellt. De-Deus et al. (2017a) stellte weiterhin in einer weiteren In-situ-Studie mittels Mikro-CTAufnahmen fest, dass die Wurzelkanalpräparation an oberen Prämolaren durch die NiTi-Systeme Reciproc und ProTaper Universal keine neuen Mikrorisse induzierte.

\subsection{Diskussion der Ergebnisse}

In dieser Studie wurde der Einfluss drei verschiedener NiTi-Systeme und Präparationstechniken auf die Inzidenz von Mikrorissen im Wurzeldentin an geraden und gekrümmten Wurzelkanälen unter Verwendung des Mikro-CTs untersucht. Dabei führte keines der verwendeten Präparationssysteme zur Entstehung neuer Risse im Dentin. Weiterhin konnte kein Unterschied zwischen den drei NiTi-Systemen festgestellt werden. Auch das Ausmaß der Wurzelkanalkrümmung hatte keinen Effekt auf die Entstehung von Dentinrissen. Alle postoperativen Querschnittsaufnahmen, in denen Mikrorisse identifiziert wurden, zeigten bereits in den präoperativen Aufnahmen entsprechende Dentindefekte. Diese Ergebnisse stimmen mit früheren Mikro-CT-Studien überein, welche keinen Zusammenhang zwischen der Instrumentierung der Wurzelkanäle mit NiTi- 
Instrumenten und der Entstehung von Mikrorissen im Wurzeldentin zeigten (DeDeus et al. 2014; 2016; Cassimiro et al. 2017).

In der Literatur finden sich Untersuchungen an Sägeschnitten mit kontroversen Ergebnissen (Bürklein et al. 2013a; Liu et al. 2013; Capar et al. 2014b; Karataş et al. 2015; Pedullà et al. 2017; Cassimiro et al. 2018). Unter Anwendung dieser destruktiven Methode wurde festgestellt, dass die Verwendung von NiTiInstrumenten eine ursächliche Rolle bei der Entstehung von Dentindefekten haben könnte (Bier et al. 2009; Yoldas et al. 2012; Liu et al. 2013). Eine Untersuchung von Mehr-Feilen-Systemen an mesialen Kanälen unterer Molaren berichtet in 30\% der mit der vollständigen Sequenz des ProTaper Universal-Systems (SX - F3) präparierten Proben Dentindefekte (Yoldas et al. 2012). Bürklein et al. (2013a) verwendeten das gleiche NiTi-System (SX - F4) und stellten nach der Präparation von Unterkiefer-Frontzähnen anhand der stereomikroskopischen Auswertung der Sägeschnitte eine Rate von 23,3\% positiver Befunde fest. Zu ähnlichen Ergebnissen kamen Capar et al. (2014b) nach der Instrumentierung von Prämolaren mit geradem Wurzelkanalverlauf unter Verwendung von PTN (28\%). In dieser Studie wurde die Auswertung anhand von Sägeschnitten in vier Ebenen $(2 \mathrm{~mm}$, $4 \mathrm{~mm}, 6 \mathrm{~mm}$ und $8 \mathrm{~mm}$ ) ausgehend vom Apex durchgeführt.

Mit Hilfe der Sägeschnittmethode wurde weiterhin ermittelt, dass die Präparation mit dem Ein-Feilen-System Reciproc in allen Wurzelkanalbereichen zur Bildung von Mikrorissen beitrug. Im Vergleich zum Mehr-Feilen-System PTN erzeugte RP im mittleren und oberen Kanalbereich von Unterkiefer-Frontzähnen signifikant weniger

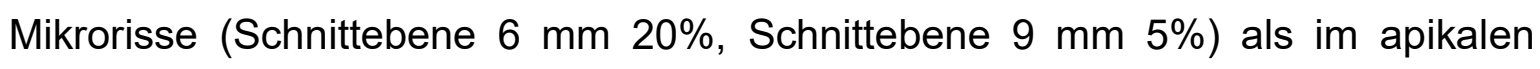
Wurzelabschnitt (Schnittebene $3 \mathrm{~mm}$ ) (Cassimiro et al. 2018). Die Untersuchung der mit Methylblau eingefärbten Schnitte zeigte, dass es keine signifikanten Unterschiede zwischen RP und PTN hinsichtlich der Rissbildung im apikalen Bereich gab (Cassimiro et al. 2018). Allerdings wurden nur die mit MethylblauFarbstoff gefärbten Risse als positiver Riss gewertet. Risse mit einem kleineren Lumen ohne Farbstoffinfiltration wurden bei der Datenerhebung nicht erfasst. Beide Systeme verursachten dennoch im apikalen Wurzeldrittel Dentindefekte (Bürklein et al. 2013a; Karataş et al. 2015; Cassimiro et al. 2018). Auch Liu et al. (2013) kamen zu dem Schluss, dass Ein-Feilen-Systeme weniger Risse im Wurzeldentin, als sequenzielle Mehr-Feilen-Systeme erzeugten. Alle verwendeten Instrumente führten zu der Bildung von Dentindefekten (OS 35\%, RP 5\%, ProTaper (Dentsply 
Sirona) 50\%). Pedullà et al. (2017) bestätigten die Ergebnisse von Lui et al. (2013), wobei vermehrt Mikrorisse im apikalen Abschnitt beobachtet wurden. In allen experimentellen Gruppen, darunter OS und RP, wurden besonders in diesem Wurzelbereich Mikrorisse festgestellt, wobei diese Ergebnisse keine statistische Signifikanz aufwiesen.

Die widersprüchlichen Ergebnisse, die zwischen der vorliegenden Studie und den zuvor erwähnten Untersuchungen beobachtet wurden, können in erster Linie durch Unterschiede in der Untersuchungsmethode (Sägeschnitte vs. Mikro-CT) erklärt werden.

Bei der Verwendung der Schnittmethode werden Wurzelquerschnitte von unpräparierten Proben (Kontrollgruppe) mit den Querschnitten präparierter Wurzeln verglichen. Der präoperative Zustand der Proben sowie der Zustand des Wurzeldentins vor der Herstellung der einzelnen Schnitte bleibt unbekannt. Einen direkten Vergleich des prä- und postoperativen Zustandes derselben Wurzel lässt diese Untersuchungsmethode nicht zu und verringert somit die Zuverlässigkeit der Ergebnisse. Die hieraus gezogenen Schlussfolgerungen über den Zusammenhang verschiedener Präparationsinstrumente und -techniken auf die Entstehung von Dentindefekten beruhen dabei auf der zweidimensionalen Betrachtung von drei bis vier Wurzelquerschnitten pro Probe. Der Verlauf der Mikrorisse in Längsrichtung der Probe bleibt somit nicht nachvollziehbar und unbeachtet. Das Mikro-CT bietet eine zerstörungsfreie experimentelle Methode, welche eine prä- und postoperative Untersuchung des Dentins ermöglicht. Im Vergleich zur Schnittmethode können hier mehrere hunderte prä- und postoperative Querschnitte von ein und derselben Probe untersucht werden. Die unbehandelten Kontrollgruppen der Sägeschnittmethode zeigten in der Regel keine Dentindefekte. Die potenzielle Schädigung der Dentinstruktur durch das Zusammenspiel der mechanischen Belastung des Dentins während der Präparation, den Einfluss der Spüllösungen und die anschließende mechanische Belastung während der Herstellung der Querschnitte der experimentellen Gruppen wurde von den Autoren nicht berücksichtigt (De-Deus et al. 2014; 2015; 2016).

Darüber hinaus wurde angenommen, dass unterschiedliche Präparationstechniken und Instrumentendesigns für unterschiedliche Dentinschäden und die Auslösung von Mikrorissen verantwortlich sind (Wilcox et al. 1997; Bier et al. 2009; Hin et al. 
2013; Arias et al. 2014). Der Einfluss des Designs der Schneidekanten, Konizität, Legierung und Bewegungsmuster ist immer noch umstritten. Unter anderem wurde spekuliert, dass die Präparation mit Ein-Feilen- im Gegensatz zu Mehr-FeilenSystemen zu mehr Stress auf der Kanalwand führt (Bürklein et al. 2013a; Arias et al. 2014). Außerdem wurde vermutet, dass mit steigender Konizität eines Instruments die Spannungen an der Wurzelkanalwand zunimmt und sich damit die Inzidenz für Dentindefekte erhöht (Bier et al. 2009).

Die Bewegungskinematik und Konizität der in dieser Studie verwendeten Feilensysteme hatte keinen Einfluss auf die Entstehung neuer Risse. Da alle postoperativ vorhandenen Risse bereits präoperativ vorhanden waren, konnte kein kausaler Zusammenhang in der Wirkung reziproker oder rotierender Bewegungsmuster der Präparationsinstrument auf die Rissneubildung im Wurzeldentin hergestellt werden. Dieses Ergebnis bestätigt frühere Mikro-CTStudien mit rotierenden und reziproken Feilensystemen, bei denen nach der Präparation keine neuen Rissen im Wurzeldentin erzeugt wurden (Capar et al. 2014a; De-Deus et al. 2014; 2015; Cassimiro et al. 2017).

Des Weiteren wurde in der vorliegenden Studie kein Zusammenhang zwischen der Kanalkrümmung und der Bildung neuer Risse im Dentin nachgewiesen. Autoren vergangener Studien gingen davon aus, dass die Dentinwände von gekrümmten Wurzelkanälen durch eine rotierende Präparation größeren Drehmomentbelastungen ausgesetzt sind und ein potenziell erhöhtes Risiko der Mikrorissbildung besteht ( $\mathrm{Li}$ et al. 2015; Cassimiro et al. 2017). In der Literatur finden sich eine Vielzahl von Studien mit ähnlicher Fragestellung unter Verwendung des Mikro-CTs, welche ausschließlich Proben mit geraden Wurzelkanälen (Krümmungswinkel $<5^{\circ}$ ) von Frontzähnen (Bayram et al. 2017b; Cassimiro et al. 2017; Zuolo et al. 2017) und Prämolaren (Jamleh et al. 2015; Bayram et al. 2017a) oder ausschließlich Proben mit moderat gekrümmten Wurzelkanälen (Krümmungswinkel 10-20 ${ }^{\circ}$ ) von Unterkiefermolaren (De-Deus et al. 2014; 2015; 2016; 2017b) berücksichtigt. Nach der Klassifikation der Wurzelkanalkrümmungswinkel von Schneider (1971) wurden Proben in der Gruppe der gekrümmten Wurzelkanäle deutlich höhere Werte (20$40^{\circ}$ ) eingeschlossen. Bislang finden sich in der Literatur keine Studien zur Rissentstehung im Wurzeldentin mit einem direkten Vergleich der verschiedenen Präparationstechniken sowohl an geraden als auch an stark gekrümmten Wurzelkanälen. 


\subsection{Schlussfolgerungen}

1. Die Verwendung von NiTi-Instrumenten mit reziproker und rotierender Bewegungskinematik hatte keinen Einfluss auf die Entstehung von Mikrorissen im Dentin.

2. Unterschiede zwischen der Präparation mit dem Mehr-Feilen-System ProTaper NEXT und den Ein-Feilen-Systemen Reciproc und OneShape hinsichtlich der Entstehung von Mikrorissen im Dentin wurde nicht festgestellt.

3. Das Ausmaß der Wurzelkanalkrümmung hatte keinen Effekt auf die Entstehung von Dentinrissen. 


\section{$5 \quad$ Zusammenfassung}

Das Ziel dieser In-vitro-Studie war es, den Einfluss von rotierend und reziprok betriebenen Ein- und Mehr-Feilen-NiTi-Systemen auf die Entstehung von Mikrorissen im Dentin gerader und gekrümmter Wurzelkanälen mit Hilfe der MikroComputertomografie zu untersuchen.

Für die Versuche standen zunächst 74 extrahierte Prämolaren- und 90 extrahierte Molarenwurzeln menschlichen Ursprungs zur Verfügung. Nach Bestimmung der Krümmungswinkel und -radien mit Hilfe von Röntgenaufnahmen in zwei Ebenen wurden präoperative Mikro-CT-Scans nach einer standardisierten Trocknungszeit der Proben von 2 Stunden angefertigt. Diese dienten zum einen als präoperative Kontrollgruppe und zum anderen zur Überprüfung der Proben hinsichtlich intrakanalärer metallischer Bestandteile. Nach der Analyse der präoperativen Querschnittaufnahmen wurden die Proben mit vorhandenen Artefakten von den Versuchen ausgeschlossen. Anhand der Ergebnisse der Krümmungswinkel- und radiusbestimmung wurden die für die Versuche geeigneten Proben $(n=33$ gerader Wurzelkanal, $n=33$ gekrümmter Wurzelkanal) statistisch analysiert und homogen auf die drei Gruppen (Präparationstechniken) aufgeteilt. Die Präparation der Wurzelkanäle erfolgte mit dem reziproken Ein-Feilen-System Reciproc (25/.08), dem rotierenden Ein-Feilen-System OneShape (25/.06) oder dem rotierenden Mehr-Feilen-System ProTaper NEXT (25/.06). Anschließend folgte nach einer zweistündigen Trocknungszeit der Proben der postoperative Mikro-CT Scan mit denselben Parametern. Bei der Analyse der postoperativen Schnittbilder wurde das Vorhandensein von Rissen für jede Querschnittsaufnahme als ja-/neinEntscheidung dokumentiert. Die positiven Aufnahmen wurden mit dem präoperativen Datensatz verglichen. 40290 Querschnitte von geraden und 34973 von gekrümmten Wurzelkanälen wurden analysiert $(n=75263)$. Insgesamt wurden in $2,79 \%(n=2236)$ der Mikro-CT-Aufnahmen Mikrorisse identifiziert. In allen drei Gruppen wurden sowohl bei geraden als auch bei gekrümmten Wurzelkanälen Risse festgestellt. Alle postoperativen Risse waren bereits in den präoperativen Aufnahmen vorhanden. Obwohl die Proben vorab mit einem Stereomikroskop auf äußere Defekte hin untersucht wurden, wurden mittels des Mikro-CTs mit einer abweichenden Inzidenz von $0,16 \%$ bis $4,67 \%$ bereits präoperative Risse belegt. Neben der Bewegungskinematik (reziprok oder rotierend) der NiTi-Instrumente 
hatte auch die Anzahl der Feilen keinen Einfluss auf die Entstehung neuer Risse im Wurzeldentin. Es wurde kein Zusammenhang zwischen der Kanalkrümmung und der Entstehung von Dentindefekten durch die Wurzelkanalpräparation nachgewiesen. 


\section{$6 \quad$ Anhang}

Tabelle A-1: Liste verwendeter Materialien und Geräte.

\begin{tabular}{|l|l|}
\hline Materialen und Geräte & Hersteller \\
\hline $\begin{array}{l}\text { Bildbearbeitungssoftware Image J } \\
1.51\end{array}$ & NIH, Bethesda; Maryland; USA \\
\hline $\begin{array}{l}\text { Bildbetrachtungssoftware Motic } \\
\text { Images Plus 2.0 }\end{array}$ & Motic Deutschland GmbH, Wetzlar \\
\hline Diamantbohrer & $\begin{array}{l}\text { Komet, Gebr. Brasseler GmbH \& Co. } \\
\text { KG, Lemgo }\end{array}$ \\
\hline CUTFIX Einmal- Skalpell 15 & B. Braun Melsungen AG, Melsungen \\
\hline Einwegspritze 5ml & B. Braun Melsungen AG, Melsungen \\
\hline Endo-Eze-Tips, Ø 0,30 mm, L 25 mm & $\begin{array}{l}\text { Ultradent Products Inc., South Jordan, } \\
\text { Utah, USA }\end{array}$ \\
\hline Endomotor VDW.SILVER RECIPROC & VDW GmbH, München \\
\hline Gates-Glidden-Bohrer Größe 2 und 3 & $\begin{array}{l}\text { Komet, Gebr. Brasseler GmbH \& Co. } \\
\text { KG, Lemgo }\end{array}$ \\
\hline Gewebeklebeband PERFECT & tesa SE, Norderstedt \\
\hline Handstück KaVo EXPERTmatic E10 C & KaVo Dental Ltd, Biberach \\
\hline Impregum F Base Paste & $3 \mathrm{M}$ ESPE, St. Paul, Minnesota, USA \\
\hline Impregum F Catalysit Paste & $3 \mathrm{M}$ ESPE, St. Paul, Minnesota, USA \\
\hline Mikroskopkamera Motic Cam 3mp, 2.0 & Motic Deutschland GmbH, Wetzlar \\
\hline
\end{tabular}




\begin{tabular}{|c|c|}
\hline Materialien und Geräte & Hersteller \\
\hline Natriumhypochlorit- Lösung 3\% & $\begin{array}{l}\text { Aug. Hedinger } \mathrm{GmbH} \& \text { Co. KG, } \\
\text { Stuttgart }\end{array}$ \\
\hline OneShape file $25 / .08$ & MICRO-MEGA, Besançon, Frankreich \\
\hline $\begin{array}{l}\text { Papierspitzen Absorbent Points, ISO } \\
\text { Größe } 15\end{array}$ & $\begin{array}{l}\text { Henry Schein Inc., Melville, New York, } \\
\text { USA }\end{array}$ \\
\hline $\begin{array}{l}\text { ProTaper NEXT file X1 17/.04, file X2 } \\
25 / .06\end{array}$ & $\begin{array}{l}\text { Dentsply Sirona Inc., York, } \\
\text { Pennsylvania, USA }\end{array}$ \\
\hline POLY Löffel 18/10 & Bochem Instrumente $\mathrm{GmbH}$, Weilburg \\
\hline Reamer, ISO 10, ISO 15 & $\begin{array}{l}\text { Henry Schein Inc., Melville, New York, } \\
\text { USA }\end{array}$ \\
\hline Reciproc file $25 / .08$ & VDW GmbH, München \\
\hline $\begin{array}{l}\text { Rekostruktionssofware NRecon, } \\
\text { Version 1.7.0.3, SkyScan }\end{array}$ & Bruker, Billerica, Massachusetts, USA \\
\hline Röntgengerät Trophy ELITYS & $\begin{array}{l}\text { Kodak, Croissy-Beaubourg, } \\
\text { Frankreich }\end{array}$ \\
\hline RESEMIX Becher 5ml & Scheu-Dental GmbH, Iserlohn \\
\hline Stereomikroskop Zeiss Stemi SV 11 & Carl Zeiss AG, Jena \\
\hline Technovit 4071 Powder & Kulzer GmbH, Hanau \\
\hline Technovit 4071 Liquid & Kulzer $\mathrm{GmbH}$, Hanau \\
\hline Trennscheibe, diamantiert & $\begin{array}{l}\text { Komet, Gebr. Brasseler GmbH \& Co } \\
\text { KG, Lemgo }\end{array}$ \\
\hline Vaseline & $\begin{array}{l}\text { Apotheke des Klinikums, } \\
\text { Universitätsmedizin Göttingen }\end{array}$ \\
\hline $\begin{array}{l}\text { Winkelstück KaVo EXPERTmatic } \\
\text { LUX E20L }\end{array}$ & KaVo Dental Ltd, Biberach \\
\hline
\end{tabular}




\begin{tabular}{|l|l|}
\hline Materialien und Geräte & Hersteller \\
\hline $\begin{array}{l}\text { Winkelstück KaVo EXPERTmatic LUX } \\
\text { E25 L }\end{array}$ & KaVo Dental Ltd, Biberach \\
\hline Winkelstück Reciproc direct & VDW GmbH, München \\
\hline Zitronensäure-Lösung 10\% & $\begin{array}{l}\text { Apotheke des Klinikums, } \\
\text { Universitätsmedizin Göttingen }\end{array}$ \\
\hline
\end{tabular}




\section{$7 \quad$ Literaturverzeichnis}

Adl A, Sedigh-Shams M, Majd M (2015): The Effect of Using RC Prep during Root Canal Preparation on the Incidence of Dentinal Defects. J Endod 411, 376-379

Aksoy Ç, Keriş EY, Yaman SD, Ocak M, Geneci F, Çelik HH (2019): Evaluation of XP-endo Shaper, Reciproc Blue, and ProTaper Universal NiTi Systems on Dentinal Microcrack Formation Using Micro-Computed Tomography. J Endod 45, 338-342 Arias A, Lee YH, Peters Cl, Gluskin AH, Peters OA (2014): Comparison of 2 Canal Preparation Techniques in the Induction of Microcracks: A Pilot Study with Cadaver Mandibles. J Endod 40, 982-985

Aubut V, Pommel L, Verhille B, Orsière T, Garcia S, About I, Camps J (2010): Biological properties of a neutralized $2.5 \%$ sodium hypochlorite solution. Oral Surg Oral Med Oral Endod 109, e120-e125

Bahrami P, Scott R, Galicia JC, Arias A, Peters OA (2017): Detecting Dentinal Microcracks Using Different Preparation Techniques: An In Situ Study with Cadaver Mandibles. J Endod 43, 2070-2073

Baldasso FER, Roleto L, da Silva VD, Morgental RD, Kopper PMP (2017): Effect of final irrigation protocols on microhardness reduction and erosion of root canal dentin. Braz Oral Res $\underline{31}$

Barreto MS, do Amaral Moraes R, da Rosa RA, Moreira CHC, Só MVR, Bier CAS (2012): Vertical Root Fractures and Dentin Defects: Effects of Root Canal Preparation, Filling, and Mechanical Cycling. J Endod $\underline{38}, 1135-1139$

Baumgartner JC, Cuenin PR (1992): Efficacy of several concentrations of sodium hypochlorite for root canal irrigation. J Endod 18, 605-612

Bayram HM, Bayram E, Ocak M, Uygun AD, Celik HH (2017a): Effect of ProTaper Gold, Self-Adjusting File, and XP-endo Shaper Instruments on Dentinal Microcrack Formation: A Micro-computed Tomographic Study. J Endod 43, 1166-1169

Bayram HM, Bayram E, Ocak M, Uzuner MB, Geneci F, Celik HH (2017b): Microcomputed Tomographic Evaluation of Dentinal Microcrack Formation after Using New Heat-treated Nickel-titanium Systems. J Endod 43, 1736-1739 
Bender IB, Seltzer S, Soltanoff W (1966a): Endodontic success-A reappraisal of criteria Part I. Oral Surg Oral Med Oral Pathol 22, 780-789

Bender IB, Seltzer S, Soltanoff W (1966b): Endodontic success-A reappraisal of criteria Part II. Oral Surg Oral Med Oral Pathol 22, 790-802

Bier CAS, Shemesh H, Tanomaru-Filho M, Wesselink PR, Wu MK (2009): The Ability of Different Nickel-Titanium Rotary Instruments To Induce Dentinal Damage During Canal Preparation. J Endod $\underline{35}$, 236-238

Blum JY, Machtou P, Micallef J-P (1999): Location of contact areas on rotary Profile1 instruments in relationship to the forces developed during mechanical preparation on extracted teeth. Int Endod J $\underline{32}, 108-114$

Bortoluzzi EA, Souza EM, Reis JMSN, Esberard RM, Tanomaru-Filho M (2007): Fracture strength of bovine incisors after intra-radicular treatment with MTA in an experimental immature tooth model. Int Endod J $\underline{40}$, 684-691

Brasil SC, Marceliano-Alves MF, Marques ML, Grillo JP, Lacerda MFLS, Alves FRF, Siqueira JF, Provenzano JC (2017): Canal Transportation, Unprepared Areas, and Dentin Removal after Preparation with BT-RaCe and ProTaper Next Systems. J Endod $\underline{43}, 1683-1687$

Brockmeyer P, Kramer K, Böhrnsen F, Gruber RM, Batschkus S, Rödig T, Hahn W (2017): Removable thermoplastic appliances modified by incisal cuts show altered biomechanical properties during tipping of a maxillary central incisor. Progr Orthodont $\underline{18,28}$

Burghardt AJ, Link TM, Majumdar S (2011): High-resolution Computed Tomography for Clinical Imaging of Bone Microarchitecture. Clin Orthop Relat Res $\underline{469}, 2179$ 2193

Bürklein S, Hinschitza K, Dammaschke T, Schäfer E (2012): Shaping ability and cleaning effectiveness of two single-file systems in severely curved root canals of extracted teeth: Reciproc and WaveOne versus Mtwo and ProTaper: Single-file systems - shaping and cleaning. Int Endod J 45, 449-461

Bürklein S, Schäfer E, Tsotsis P (2013a): Incidence of Dentinal Defects after Root Canal Preparation: Reciprocating versus Rotary Instrumentation. J Endod 39, 501504 
Bürklein S, Benten S, Schäfer E (2013b): Shaping ability of different single-file systems in severely curved root canals of extracted teeth. Int Endod J $\underline{46}, 590-597$ Bürklein S, Mathey D, Schäfer E (2014): Shaping ability of ProTaper NEXT and BTRaCe nickel-titanium instruments in severely curved root canals. Int Endod J $\underline{48}$, 774-781

Bürklein S, Jäger PG, Schäfer E (2017a): Apical transportation and canal straightening with different continuously tapered rotary file systems in severely curved root canals: F6 SkyTaper and OneShape versus Mtwo. Int Endod J $\underline{50}$, 983990

Bürklein S, Heck R, Schäfer E (2017b): Evaluation of the Root Canal Anatomy of Maxillary and Mandibular Premolars in a Selected German Population Using Conebeam Computed Tomographic Data. J Endod 43, 1448-1452

Byström A, Sundqvist G (1985): The antibacterial action of sodium hypochlorite and EDTA in 60 cases of endodontic therapy. Int Endod J $18,35-40$

Capar ID, Ertas H, Ok E, Arslan H, Ertas ET (2014a): Comparative Study of Different Novel Nickel-Titanium Rotary Systems for Root Canal Preparation in Severely Curved Root Canals. J Endod 40, 852-856

Capar ID, Arslan H, Akcay M, Uysal B (2014b): Effects of ProTaper Universal, ProTaper Next, and HyFlex Instruments on Crack Formation in Dentin. J Endod $\underline{40}$, 1482-1484

Cassimiro M, Romeiro K, Gominho L, de Almeida A, Costa L, Albuquerque D (2017): Occurence of dentinal defects after root canal preparation with R-phase, M-Wire and Gold Wire instruments: a micro-CT analysis. BMC Oral Health 17, 93

Cassimiro M, Romeiro K, Gominho L, Almeida A de, Belo L, Albuquerque D (2018): Effects of Reciproc, ProTaper Next and WaveOne Gold on Root Canal Walls: A Stereomicroscope Analysis. Iranian Endod J 13, 228-233

Ceyhanli KT, Erdilek N, Tatar I, Celik D (2016): Comparison of ProTaper, RaCe and Safesider instruments in the induction of dentinal microcracks: a micro-CT study. Int Endod J $\underline{49}, 684-689$ 
Chaudhari R, Vora JJ, Mani Prabu SS, Palani IA, Patel VK, Parikh DM, de Lacalle LNL (2019): Multi-Response Optimization of WEDM Process Parameters for Machining of Superelastic Nitinol Shape-Memory Alloy Using a Heat-Transfer Search Algorithm. Materials $\underline{12}, 1277$

Chockattu S, Deepak B, Goud Km (2017): Comparison of efficiency of ethylenediaminetetraacetic acid, citric acid, and etidronate in the removal of calcium hydroxide intracanal medicament using scanning electron microscopic analysis: An in-vitro study. J Conserv Dent $\underline{20}, 6$

Clem WH (1969): Endodontics: the adolescent patient. Dent Clin North Am 13, $482-$ 493

Coelho MS, Card SJ, Tawil PZ (2016): Visualization Enhancement of Dentinal Defects by Using Light-Emitting Diode Transillumination. J Endod 42 , 1110-1113

Cohen S, Berman L, Blanco L, Bakland L, Kim J (2006): A Demographic Analysis of Vertical Root Fractures. J Endod $\underline{32}, 1160-1163$

Cooper PR, Smith AJ (2013): Molecular mediators of pulp inflammation and regeneration: Molecular mediators of pulp inflammation and regeneration. Endod Topics $\underline{28}, 90-105$

Cunningham CJ, Senia ES (1992): A three-dimensional study of canal curvatures in the mesial roots of mandibular molars. J Endod 18 , 294-300

Cvek M, Nord CE, Hollender L (1976): Antimicrobial effect of root canal débridement in teeth with immature root. A clinical and microbiologic study. Odontol Revy $\underline{27}, 1-$ 10

De-Deus G, Silva EJNL, Marins J, Souza E, Neves A de A, Gonçalves Belladonna F, Alves H, Lopes RT, Versiani MA (2014): Lack of Causal Relationship between Dentinal Microcracks and Root Canal Preparation with Reciprocation Systems. J Endod $\underline{40}, 1447-1450$

De-Deus G, Belladonna FG, Souza EM, Silva EJNL, Neves A de A, Alves H, Lopes RT, Versiani MA (2015): Micro-computed Tomographic Assessment on the Effect of ProTaper Next and Twisted File Adaptive Systems on Dentinal Cracks. J Endod $\underline{41}, 1116-1119$ 
De-Deus G, Belladonna FG, Marins JR, Silva EJNL, Neves A de A, Souza EM, Machado A de C, Lopes RT, Versiani MA (2016): On the Causality Between Dentinal Defects and Root Canal Preparation: A Micro-CT Assessment. Braz Dent J $\underline{27}, 664-669$

De-Deus, Júlio César de Azevedo Carvalhal, Belladonna FG, Silva EJNL, Lopes RT, Moreira Filho RE, Souza EM, Provenzano JC, Versiani MA (2017a): Dentinal Microcrack Development after Canal Preparation: A Longitudinal in Situ Microcomputed Tomography Study Using a Cadaver Model. J Endod 43, 1553-1558

De-Deus G, Belladonna FG, Silva EJNL, Souza EM, Carvalhal JCA, Perez R, Lopes $\mathrm{RT}$, Versiani MA (2017b): Micro-CT assessment of dentinal micro-cracks after root canal filling procedures. Int Endod J $\underline{50}, 895-901$

De-Deus G, Belladonna FG, de Siqueira Zuolo A, Perez R, Carvalho MS, Souza EM, Lopes RT, Silva EJNL (2019): Micro-CT comparison of XP-endo Finisher and passive ultrasonic irrigation as final irrigation protocols on the removal of accumulated hard-tissue debris from oval shaped-canals. Clin Oral Investig $\underline{23}$, 3087-3093

Deller T (Hrsg): Histologie: Zytologie, Histologie und mikroskopische Anatomie: Das Lehrbuch. 5. Aufl.; Elsevier GmbH, Urban \& Fischer, München (2018)

DGZMK Stellungnahme zum Thema Wurzelkanalspülungen 2006

Dorow C, Krstin N, Sander F-G (2002): Experiments to Determine the Material Properties of the Periodontal Ligament. J Orofac Orthop $\underline{63}, 94-104$

Dorow C, Krstin N, Sander F-G (2003): Determination of the Mechanical Properties of the Periodontal Ligament in a Uniaxial Tensional Experiment. J Orofac Orthop $\underline{64}, 100-107$

Drukteinis S, Peciuliene V, Dummer PMH, Hupp J (2019): Shaping ability of BioRace, ProTaper NEXT and nickel-titanium instruments in curved canals of mandibular molars: a MicroCT study. Int Endod J $\underline{52}, 86-93$

Elliott JC, Dover SD (1982): X-ray microtomography. J Microsc 뜨, 211-213

Engelke K, Karolczak M, Lutz A, Seibert U, Schaller S, Kalender W (1999): MikroCT. Der Radiologe $\underline{39}$, 203-212 
Espir CG, Nascimento-Mendes CA, Guerreiro-Tanomaru JM, Freire LG, Gavini G, Tanomaru-Filho M (2018): Counterclockwise or clockwise reciprocating motion for oval root canal preparation: a micro-CT analysis. Int Endod J $\underline{51}, 541-548$

Esposito PT, Cunningham CJ (1995): A comparison of canal preparation with nickeltitanium and stainless steel instruments. J Endod 21, 173-176

European Society of Endodontology (2006): Quality guidelines for endodontic treatment: consensus report of the European Society of Endodontology. Int Endod J $\underline{39}, 921-930$

Feldkamp LA, Davis LC, Kress JW (1984): Practical cone-beam algorithm. J Opt Soc Am A 1,612

Feldkamp LA, Goldstein SA, Parfitt MA, Jesion G, Kleerekoper M (1989): The direct examination of three-dimensional bone architecture in vitro by computed tomography. J Bone Miner Res 4 , 3-11

Fuss Z, Lustig J, Tamse A (1999): Prevalence of vertical root fractures in extracted endodontically treated teeth. Int Endod J $\underline{32}, 283-286$

Gabor C, Tam E, Shen Y, Haapasalo M (2012): Prevalence of Internal Inflammatory Root Resorption. J Endod $\underline{38}, 24-27$

Gagliardi J, Versiani MA, de Sousa-Neto MD, Plazas-Garzon A, Basrani B (2015): Evaluation of the Shaping Characteristics of ProTaper Gold, ProTaper NEXT, and ProTaper Universal in Curved Canals. J Endod 41, 1718-1724

Gambarini G, Tucci E, Bedini R, Pecci R, Galli M, Milana V, Luca MD, Testarelli L (2010): The effect of brushing motion on the cyclic fatigue of rotary nickel titanium instruments. Ann Ist Super Sanita 4, 400-404

Gernhardt CR, Eppendorf K, Kozlowski A, Brandt M (2004): Toxicity of concentrated sodium hypochlorite used as an endodontic irrigant. Int Endod J 37, 272-280

Goerig AC, Michelich RJ, Schultz HH (1982): Instrumentation of root canals in molar using the step-down technique. J Endod $\underline{8}, 550-554$

Grande NM, Ahmed HMA, Cohen S, Bukiet F, Plotino G (2015): Current Assessment of Reciprocation in Endodontic Preparation: A Comprehensive 
Review-Part I: Historic Perspectives and Current Applications. J Endod 41, 17781783

Grass M, Koppe R, Klotz E, Proksa R, Kuhn MH, Aerts H, Op de Beek J, Kemkers $R$ (1999): Three-dimensional reconstruction of high contrast objects using C-arm image intensifier projection data. Comput Med Imaging Graph $\underline{23}$, 311-321

Haddad WS, McNulty I, Trebes JE, Anderson EH, Levesque RA, Yang L (1994): Ultrahigh-Resolution X-ray Tomography. Science 266, 1213-1215

Hellwig E, Klimek J, Attin T (Hrsg.): Einführung in die Zahnerhaltung. 3. Aufl.; Elsevier GmbH, Urban \& Fischer, München (2003)

Henderson E, Buis A (2011): Nitinol for Prosthetic and Orthotic Applications. J Mater Eng Perform 20, 663-665

Hiatt WH (1973): Incomplete Crown-Root Fracture in Pulpal-Periodontal Disease. J Periodontol $\underline{44}$, 369-379

Hin ES, Wu M-K, Wesselink PR, Shemesh H (2013): Effects of Self-Adjusting File, Mtwo, and ProTaper on the Root Canal Wall. J Endod $\underline{39}$, 262-264

Ingle JI (1961): A standardized endodontic technique utilizing newly designed instruments and filling materials. Oral Surg Oral Med Oral Pathol_14, 83-91

ISO (Internationale Organisation für Normung) (2019): ISO 3630-1:2019 DentistryEndodontic Instruments-Part 1: General requirements [URL: https://www.iso.org/standard/75260.html] Zugriff 15.05.20

Jaiswal N, Mantri S, Paul B, Dube K, Singh V, Bhatnagar N (2019): Comparative evaluation of the effectiveness and fracture rate of three pathfinding nickel-titanium rotary instruments, Mtwo, OneG, and ProGlider, in mechanically negotiating moderately curved molar canals to the full working length. J Conserv Dent $\underline{22}, 260$ Jamleh A, Komabayashi T, Ebihara A, Nassar M, Watanabe S, Yoshioka T, Miyara $\mathrm{K}$, Suda $\mathrm{H}$ (2015): Root surface strain during canal shaping and its influence on apical microcrack development: a preliminary investigation. Int Endod J $\underline{48}, 1103-$ 1111 
Jorgensen SM, Demirkaya O, Ritman EL (1998): Three-dimensional imaging of vasculature and parenchyma in intact rodent organs with $\mathrm{X}$-ray micro-CT. American Am J Physiol Heart Circ Physiol 275, H1103-H1114

Kakehashi S, Stanley HR, Fitzgerald RJ (1965): The effects of surgical exposures of dental pulps in germ-free and conventional laboratory rats. Oral Surg Oral Med Oral Pathol 20, 340-349

Kansal R, Rajput A, Talwar S, Roongta R, Verma M (2014): Assessment of Dentinal Damage during Canal Preparation Using Reciprocating and Rotary Files. J Endod $\underline{40}, 1443-1446$

Karataş E, Gündüz HA, Kırıcı DÖ, Arslan H, Topçu MÇ, Yeter KY (2015): Dentinal Crack Formation during Root Canal Preparations by the Twisted File Adaptive, ProTaper Next, ProTaper Universal, and WaveOne Instruments. J Endod 411, 261264

Kim H-C, Lee M-H, Yum J, Versluis A, Lee C-J, Kim B-M (2010): Potential Relationship between Design of Nickel-Titanium Rotary Instruments and Vertical Root Fracture. J Endod 36, 1195-1199

Kimura S, Ebihara A, Maki K, Nishijo M, Tokita D, Okiji T (2019): Effect of Optimum Torque Reverse Motion on Torque and Force Generation during Root Canal Instrumentation with Crown-down and Single-length Techniques. J Endod $\underline{46}, 232-$ 237

Landrigan MD, Flatley JC, Turnbull TL, Kruzic JJ, Ferracane JL, Hilton TJ, Roeder RK (2010): Detection of dentinal cracks using contrast-enhanced micro-computed tomography. J Mech Behav Biomed Mater $\underline{3}, 223-227$

Lee JK, Yoo YJ, Perinpanayagam H, Ha BH, Lim SM, Oh SR, Gu Y, Chang SW, Zhu Q, Kum KY (2015): Three-dimensional modelling and concurrent measurements of root anatomy in mandibular first molar mesial roots using microcomputed tomography. Int Endod J $\underline{48}, 380-389$

Li M, Liao W, Cai H (2017): A micro-computed tomographic evaluation of dentinal microcrack alterations during root canal preparation using single-file Ni-Ti systems. Exp Ther Med 
Li S, Lu Y, Song D, Zhou X, Zheng Q, Gao Y, Huang D (2015): Occurrence of Dentinal Microcracks in Severely Curved Root Canals with ProTaper Universal, WaveOne, and ProTaper Next File Systems. J Endod 41, 1875-1879

Liao C-W, Fuh L-J, Shen Y-W, Huang H-L, Kuo C-W, Tsai M-T, Hsu J-T (2018): Self-assembled micro-computed tomography for dental education. PLOS ONE $\underline{13}$, e0209698

Liu R, Hou BX, Wesselink PR, Wu M-K, Shemesh H (2013): The Incidence of Root Microcracks Caused by 3 Different Single-file Systems versus the ProTaper System. J Endod $\underline{39}$, 1054-1056

Llena-Puy MC, Forner-Navarro L, Barbero-Navarro I (2001): Vertical root fracture in endodontically treated teeth: A review of 25 cases. Oral Surg Oral Med Oral Pathol Oral Radiol Endod 92, 553-555

Lopes HP, Elias CN, Vieira MVB, Siqueira JF, Mangelli M, Lopes WSP, Vieira VTL, Alves FRF, Oliveira JCM, Soares TG (2013): Fatigue Life of Reciproc and Mtwo Instruments Subjected to Static and Dynamic Tests. J Endod 39, 693-696

Márton IJ, Kiss C (2014): Overlapping Protective and Destructive Regulatory Pathways in Apical Periodontitis. J Endod 느, 155-163

Mohd Jani J, Leary M, Subic A, Gibson MA (2014): A review of shape memory alloy research, applications and opportunities. Mater Des (1980-2015) $\underline{56}, 1078-1113$

Morgan LF, Montgomery S (1984): An evaluation of the crown-down pressureless technique. J Endod 10, 491-498

Mullaney TP (1979): Instrumentation of finely curved canals. Dent Clin North Am $\underline{23}$, 575-592

Nair PNR (2004): Pathogenesis of apical periodotitis and the causes of endodontic failures. Crit Rev Oral Biol Med 15, 348-381

Nair PNR (2006): On the causes of persistent apical periodontitis: a review. Int Endod J $\underline{39}$, 249-281

Natali AN, Pavan PG, Carniel EL, Dorow C (2004): Viscoelastic Response of the Periodontal Ligament: An Experimental-Numerical Analysis. Connect Tissue Res $\underline{45}, 222-230$ 
Ng Y-L, Mann V, Rahbaran S, Lewsey J, Gulabivala K (2007): Outcome of primary root canal treatment: systematic review of the literature - Part 2. Influence of clinical factors. Int Endod J $\underline{41,6-31}$

Nielsen RB, Alyassin AM, Peters DD, Carnes DL, Lancaster J (1995): Microcomputed tomography: An advanced system for detailed endodontic research. J Endod 21, $561-568$

Okitsu M, Takahashi H, Yoshioka T, Iwasaki N, Suda H (2005): Effective Factors Including Periodontal Ligament on Vertical Root Fractures. Dent Mater J ㄴ4, 66-69 Özyürek T, Uslu G, Yılmaz K, Gündoğar M (2018): Effect of Glide Path Creating on Cyclic Fatigue Resistance of Reciproc and Reciproc Blue Nickel-titanium Files: A Laboratory Study. J Endod 44, 1033-1037

Paqué F, Balmer M, Attin T, Peters OA (2010): Preparation of Oval-shaped Root Canals in Mandibular Molars Using Nickel-Titanium Rotary Instruments: A Microcomputed Tomography Study. J Endod $\underline{36}, 703-707$

Pedullà E, Plotino G, Grande NM, Avarotti G, Gambarini G, Rapisarda E, Mannocci F (2016): Shaping ability of two nickel-titanium instruments activated by continuous rotation or adaptive motion: a micro-computed tomography study. Clin Oral Investig $\underline{20}, 2227-2233$

Pedullà E, Genovesi F, Rapisarda S, La Rosa GRM, Grande NM, Plotino G, Adorno CG (2017): Effects of 6 Single-File Systems on Dentinal Crack Formation. J Endod $\underline{43}, 456-461$

Peters OA, Schonenberger K, Laib A (2001): Effects of four Ni-Ti preparation techniques on root canal geometry assessed by micro computed tomography. Int Endod J 34, 221-230

Peters OA, Barbakow F (2002): Dynamic torque and apical forces of ProFile .04 rotary instruments during preparation of curved canals. Int Endod J $\underline{35}$, 379-389

Peters OA (2004): Current Challenges and Concepts in the Preparation of Root Canal Systems: A Review. J Endod $\underline{30}, 559-567$ 
Pop I, Manoharan A, Zanini F, Tromba G, Patel S, Foschi F (2015): Synchrotron light-based $\mu \mathrm{CT}$ to analyse the presence of dentinal microcracks post-rotary and reciprocating NiTi instrumentation. Clin Oral Investig $\underline{19}, 11-16$

Pruett JP, Clement DJ, Carnes DL (1997): Cyclic fatigue testing of nickel-titanium endodontic instruments. J Endod $\underline{23}, 77-85$

Ramírez-Bommer C, Gulabivala K, Ng Y-L, Young A (2018): Estimated depth of apatite and collagen degradation in human dentine by sequential exposure to sodium hypochlorite and EDTA: a quantitative FTIR study. Int Endod J 51, 469-478 Ricucci D, Siqueira JF (2010): Biofilms and Apical Periodontitis: Study of Prevalence and Association with Clinical and Histopathologic Findings. J Endod $\underline{36}, 1277-1288$ Ricucci D, Loghin S, Niu L, Tay FR (2018a): Changes in the radicular pulp-dentine complex in healthy intact teeth and in response to deep caries or restorations: $A$ histological and histobacteriological study. J Dent $\underline{73}, 76-90$

Ricucci D, Loghin S, Gonçalves LS, Rôças IN, Siqueira JF (2018b): Histobacteriologic Conditions of the Apical Root Canal System and Periapical Tissues in Teeth Associated with Sinus Tracts. J Endod $\underline{44}, 405-413$

Ritman EL (2004): Micro-Computed Tomography—Current Status and Developments. Annu Rev Biomed Eng $\underline{6}, 185-208$

Rivera EM, Walton RE (2007): Longitudinal tooth fractures: findings that contribute to complex endodontic diagnoses. Endod Topics $\underline{16}, 82-111$

Rödig T, Kupis J, Konietschke F, Dullin C, Drebenstedt S, Hülsmann M (2014a): Comparison of hand and rotary instrumentation for removing gutta-percha from previously treated curved root canals: a microcomputed tomography study. Int Endod J $\underline{47}, 173-182$

Rödig T, Reicherts P, Konietschke F, Dullin C, Hahn W, Hülsmann M (2014b): Efficacy of reciprocating and rotary NiTi instruments for retreatment of curved root canals assessed by micro-CT. Int Endod J 4ㄱ, 942-948

Rödig T, Wagner J, Wiegand A, Rizk M (2018a): Efficacy of the ProTaper retreatment system in removing Thermafil, GuttaCore or vertically compacted guttapercha from curved root canals assessed by micro-CT. Int Endod J $\underline{51}, 808-815$ 
Rödig T, Müller C, Hoch M, Haupt F, Schulz X, Wiegand A, Rizk M (2018b): Moisture content of root canal dentine affects detection of microcracks using micro-computed tomography. Int Endod J 토, 357-363

Rodrigues CT, Duarte MAH, de Almeida MM, de Andrade FB, Bernardineli N (2016): Efficacy of CM-Wire, M-Wire, and Nickel-Titanium Instruments for Removing Filling Material from Curved Root Canals: A Micro-Computed Tomography Study. J Endod $\underline{42}, 1651-1655$

Salehrabi R, Rotstein I (2004): Endodontic Treatment Outcomes in a Large Patient Population in the USA: An Epidemiological Study. J Endod $\underline{30}, 5$

Schäfer E, Diez C, Hoppe W, Tepel J (2002): Roentgenographic Investigation of Frequency and Degree of Canal Curvatures in Human Permanent Teeth. J Endod $\underline{28}, 211-216$

Schneider SW (1971): A comparison of canal preparations in straight and curved root canals. Oral Surg Oral Med Oral Pathol 32, 271-275

Shen Y, Zhou H, Zheng Y, Peng B, Haapasalo M (2013): Current Challenges and Concepts of the Thermomechanical Treatment of Nickel-Titanium Instruments. J Endod $\underline{39}, 163-172$

Silva EJNL, Belladonna FG, Carapiá MF, Muniz BL, Rocha MS, Moreira EJL (2018): Micro-computed tomographic evaluation of canal retreatments performed by undergraduate students using different techniques. Restor Dent Endod 43, pISSN 2234-7658, elSSN 2234-7666

Sim TPC, Knowles JC, Ng Y-L, Shelton J, Gulabivala K (2001): Effect of sodium hypochlorite on mechanical properties of dentine and tooth surface strain. Int Endod J $\underline{34}, 120-132$

Siqueira JF, Rocas IN (2013a): Microbiology and Treatment of Acute Apical Abscesses. Clin Microbiol Rev 26, 255-273

Siqueira JF, Alves FRF, Versiani MA, Rôças IN, Almeida BM, Neves MAS, SousaNeto MD (2013b): Correlative Bacteriologic and Micro-Computed Tomographic Analysis of Mandibular Molar Mesial Canals Prepared by Self-Adjusting File, Reciproc, and Twisted File Systems. J Endod 39, 1044-1050 
Soros C, Zinelis S, Lambrianidis T, Palaghias G (2008): Spreader load required for vertical root fracture during lateral compaction ex vivo: evaluation of periodontal simulation and fracture load information. Oral Surg Oral Med Oral Pathol Oral Radiol Endod 106, e64-e70

Sousa-Neto MD de, Silva-Sousa YC, Mazzi-Chaves JF, Carvalho KKT, Barbosa AFS, Versiani MA, Jacobs R, Leoni GB (2018): Root canal preparation using microcomputed tomography analysis: a literature review. Braz Oral Res $\underline{32}$, 20-43

Souza EM, Calixto AM, Lima CN, Pappen FG, De-Deus G (2014): Similar Influence of Stabilized Alkaline and Neutral Sodium Hypochlorite Solutions on the Fracture Resistance of Root Canal-treated Bovine Teeth. J Endod 느, 1600-1603

Staquet M-J, Carrouel F, Keller J-F, Baudouin C, Msika P, Bleicher F, Kufer TA, Farges J-C (2011): Pattern-recognition Receptors in Pulp Defense. Adv Dent Res $\underline{23}, 296-301$

Stojicic S, Zivkovic S, Qian W, Zhang H, Haapasalo M (2010): Tissue Dissolution by Sodium Hypochlorite: Effect of Concentration, Temperature, Agitation, and Surfactant. J Endod 36, 1558-1562

Swain MV, Xue J (2009): State of the Art of Micro-CT Applications in Dental Research. Int J Oral Sci 1, 177-188

Takahama A, Rôças IN, Faustino ISP, Alves FRF, Azevedo RS, Gomes CC, AraújoFilho WR, Siqueira JF (2018): Association between bacteria occurring in the apical canal system and expression of bone-resorbing mediators and matrix metalloproteinases in apical periodontitis. Int Endod J $\underline{51}, 738-746$

Tamse A (1988): latrogenic vertical root fractures in endodontically treated teeth. Dent Traumatol $\underline{4}, 190-196$

Thompson SA (2000): An overview of nickel-titanium alloys used in dentistry. Int Endod J $\underline{33}, 297-310$

Toms SR, Dakin GJ, Lemons JE, Eberhardt AW (2002): Quasi-linear viscoelastic behavior of the human periodontal ligament. J Biomech $\underline{35}, 1411-1415$ 
Touré B, Faye B, Kane AW, Lo CM, Niang B, Boucher Y (2011): Analysis of Reasons for Extraction of Endodontically Treated Teeth: A Prospective Study. J Endod $\underline{37}, 1512-1515$

van der Vyver PJ, Paleker F, Vorster M, de Wet FA (2019): Root Canal Shaping Using Nickel Titanium, M-Wire, and Gold Wire: A Micro-computed Tomographic Comparative Study of One Shape, ProTaper Next, and WaveOne Gold Instruments in Maxillary First Molars. J Endod $\underline{45}, 62-67$

Varela-Patiño $P$, Ibañez-Párraga $A$, Rivas-Mundiña $B$, Cantatore $G$, Otero $X L$, Martin-Biedma B (2010): Alternating versus Continuous Rotation: A Comparative Study of the Effect on Instrument Life. J Endod $\underline{36}, 157-159$

Verma N, Sangwan P, Tewari S, Duhan J (2019): Effect of Different Concentrations of Sodium Hypochlorite on Outcome of Primary Root Canal Treatment: A Randomized Controlled Trial. J Endod $\underline{45}$, 357-363

Versiani MA, Leoni GB, Steier L, De-Deus G, Tassani S, Pécora JD, de Sousa-Neto MD (2013): Micro-computed Tomography Study of Oval-shaped Canals Prepared with the Self-adjusting File, Reciproc, WaveOne, and ProTaper Universal Systems. J Endod 39, 1060-1066

Versiani MA, Souza E, De-Deus G (2015): Critical appraisal of studies on dentinal radicular microcracks in endodontics: methodological issues, contemporary concepts, and future perspectives. Endod Topics $\underline{33}, 87-156$

Vieira MLO, Dantas HV, de Sousa FB, Salazar-Silva JR, Silva EJNL, Batista AUD, Lima TFR (2020): Morphologic Changes of Apical Foramen and Microcrack Formation after Foraminal Enlargement: A Scanning Electron Microscopic and Micro-computed Tomographic Analysis. J Endod 4ㅌ, 1726-1732

Weine FS, Kelly RF, Lio PJ (1975): The effect of preparation procedures on original canal shape and on apical foramen shape. J Endod 1, 255-262

Wilcox LR, Roskelley C, Sutton T (1997): The relationship of root canal enlargement to finger-spreader induced vertical root fracture. J Endod $\underline{23}, 533-534$

Yared G (2008): Canal preparation using only one $\mathrm{Ni}-\mathrm{Ti}$ rotary instrument: preliminary observations. Int Endod J 41, 339-344 
Ye J, Gao Y (2012): Metallurgical Characterization of M-Wire Nickel-Titanium Shape Memory Alloy Used for Endodontic Rotary Instruments during Low-cycle Fatigue. Endod $\underline{38}, 105-107$

Yoldas O, Yilmaz S, Atakan G, Kuden C, Kasan Z (2012): Dentinal Microcrack Formation during Root Canal Preparations by Different NiTi Rotary Instruments and the Self-Adjusting File. J Endod $\underline{38}$, 232-235

Zadik Y, Sandler V, Bechor R, Salehrabi R (2008): Analysis of factors related to extraction of endodontically treated teeth. Oral Surg Oral Med Oral Pathol Oral Radiol Endod 106, e31-e35

Zehnder M (2006): Root Canal Irrigants. J Endod 32, 389-398

Zuolo ML, De-Deus G, Belladonna FG, Silva EJNL da, Lopes RT, Souza EM, Versiani MA, Zaia AA (2017): Micro-computed Tomography Assessment of Dentinal Micro-cracks after Root Canal Preparation with TRUShape and Selfadjusting File Systems. J Endod 4ㄴ, 619-622 


\section{Danksagung}

Mein besonderer Dank gilt Frau Prof. Dr. med. dent. Tina Rödig, Oberärztin der Poliklinik für Präventive Zahnmedizin, Parodontologie und Kariologie, für die Möglichkeit der Promotion. Ihr außerordentlich sorgfältiges und stetes Engagement trugen wesentlich zum Gelingen dieser Arbeit bei.

Ein großer Dank gilt Frau Dr. med. dent. Franziska Haupt, ebenfalls aus der Poliklinik für Präventive Zahnmedizin, Parodontologie und Kariologie für die Unterstützung sowohl bei der Datenerhebung als auch bei der statistischen Auswertung.

Für die Einweisung und immerwährende Hilfsbereitschaft am Mikro-CT möchte ich Frau Dr. rer. nat. Marta Rizk-Lungova danken.

Bei Frau Dr. med. dent. Christine Müller möchte ich mich außerdem für das zur Verfügungstellen der unpräparierten Proben als Ausgangsmaterial für diese Arbeit bedanken. 